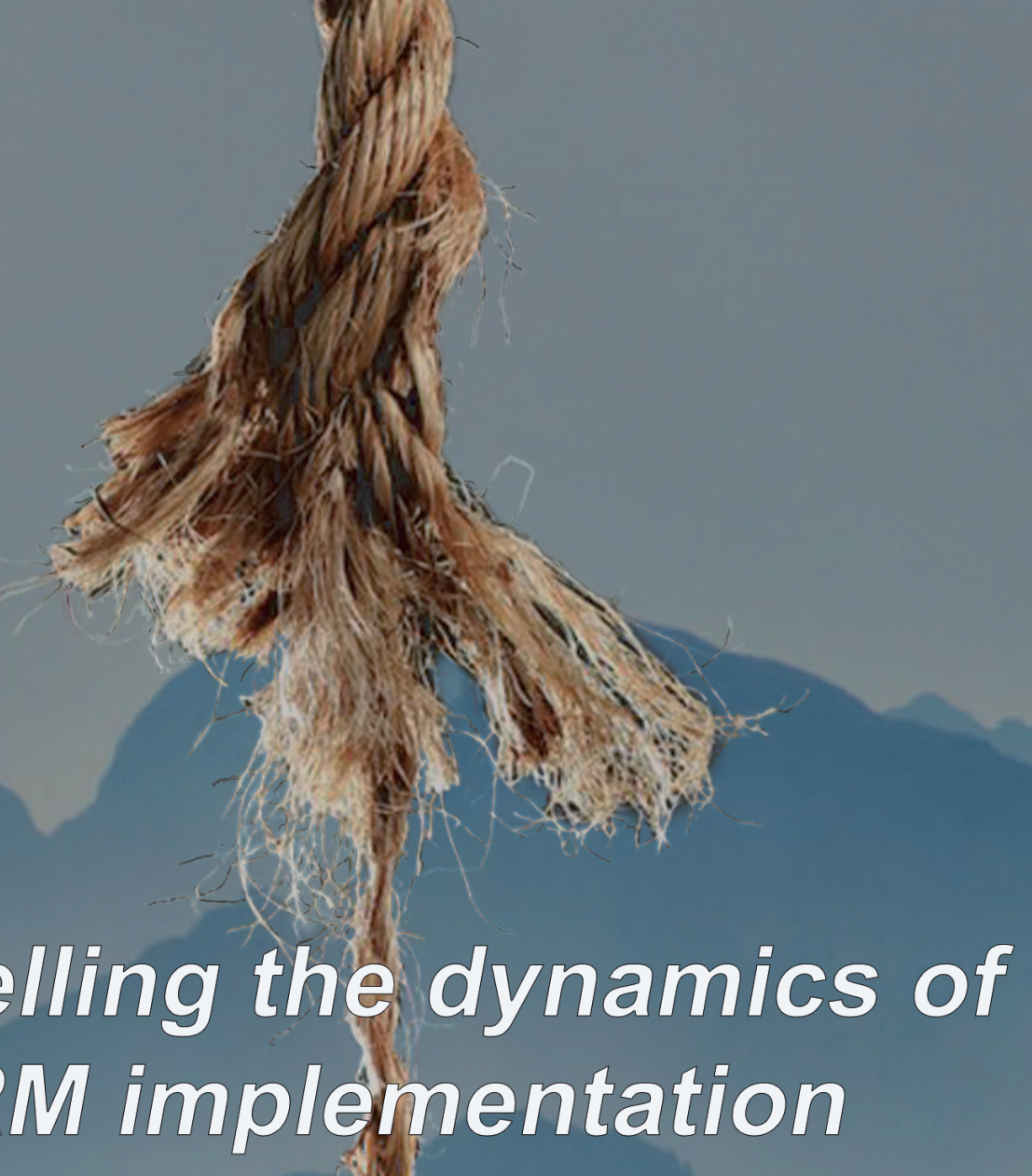

HRM implementation

\title{
A process perspective
}



UNRAVELLING THE DYNAMICS OF HRM IMPLEMENTATION A PROCESS PERSPECTIVE 


\section{Graduation committee:}

\begin{tabular}{|c|c|c|}
\hline Chairman: & Prof. dr. T.A.J. Toonen & University of Twente \\
\hline Secretary: & Prof. dr. T.A.J. Toonen & University of Twente \\
\hline Supervisor: & Prof. dr. T. Bondarouk & University of Twente \\
\hline Co-supervisor: & Dr. A.C. Bos-Nehles & University of Twente \\
\hline \multirow[t]{4}{*}{ Members: } & Prof. dr. A.E. Keegan & University College Dublin (Ireland) \\
\hline & Prof. dr. S.N. Khapova & Vrije Universiteit Amsterdam \\
\hline & Prof. dr. R. Torenvlied & University of Twente \\
\hline & Dr. H.A. van Vuuren & University of Twente \\
\hline
\end{tabular}

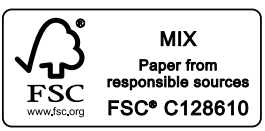

Printed by: Ipskamp Printing, Enschede

Cover design: Jorrit \& Samara van Mierlo

ISBN: 978-94-028-1209-1

(C) 2018 Jorrit van Mierlo

All rights reserved. No part of this publications may be reproduced, stored in a database or retrieval system, or published in any form or in any way, electronically, mechanically, by print, photo print, microfilm, or any other means without prior written permission from the author. 


\title{
UNRAVELLING THE DYNAMICS OF HRM IMPLEMENTATION A PROCESS PERSPECTIVE
}

\author{
DISSERTATION
}

to obtain

the degree of doctor at the University of Twente, on the authority of the rector magnificus, prof. dr. T.T.M. Palstra, on account of the decision of the graduation committee, to be publicly defended on Friday 19 October 2018 at 16.45 hours

by

Jorrit van Mierlo

born on the 09 June 1983

in Warnsveld, the Netherlands 
This dissertation has been approved by:

Supervisor Prof. dr. T. Bondarouk

Co-supervisor Dr. A.C. Bos Nehles 
This work is part of the research program Innovating Human Resource Management for Employee-Driven Innovation with project number 409-13-204, which is (partly) financed by The Netherlands Organization for Scientific Research (NWO). 



\section{Table of contents}

Table of contents .................................................................................................. vii

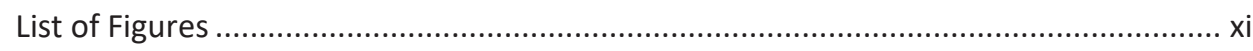

List of Tables .........................................................................................................

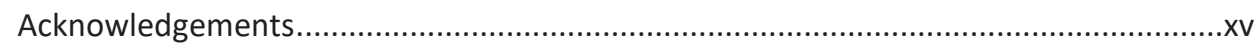

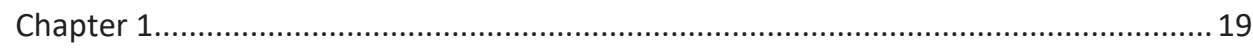

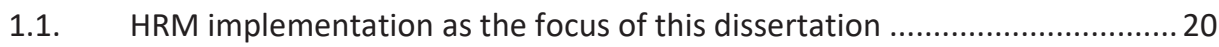

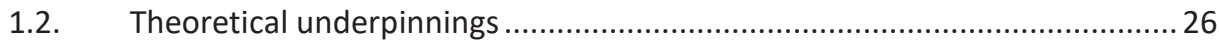

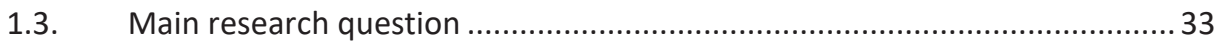

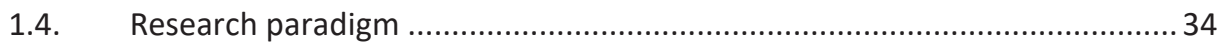

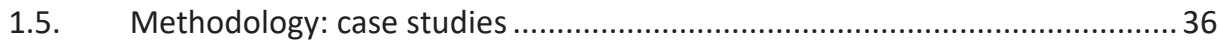

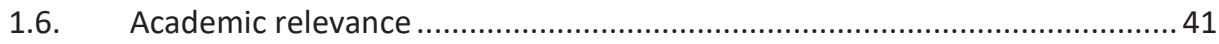

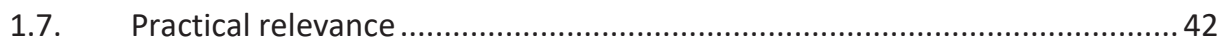

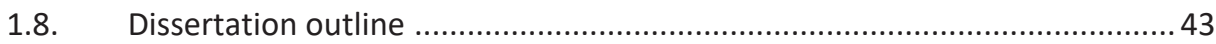

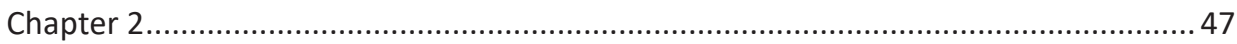

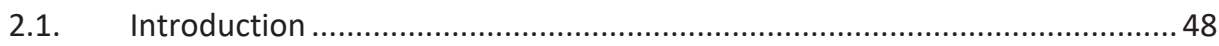

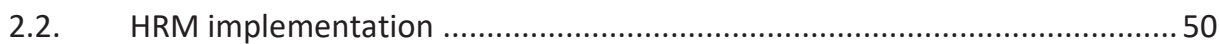

2.3. Structuration theory and its applications in HRM research ........................ 51

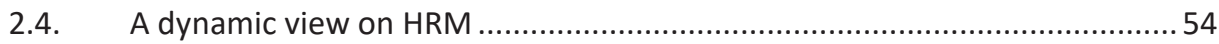

2.5. HRM implementation: a never-ending process? ...................................... 59

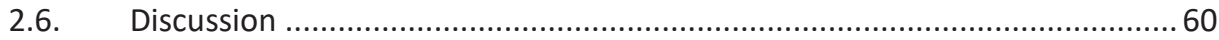

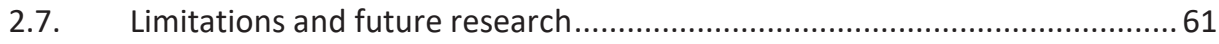

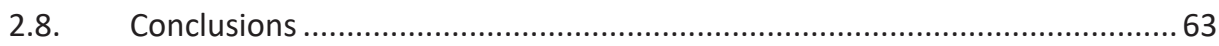

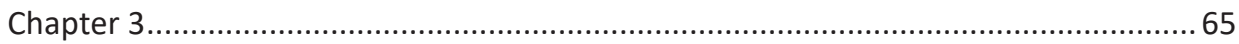




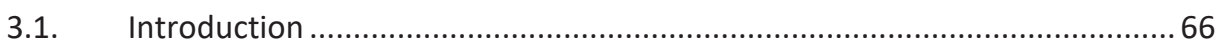

3.2. Theorising on the dynamic implementation of HRM practices ....................68

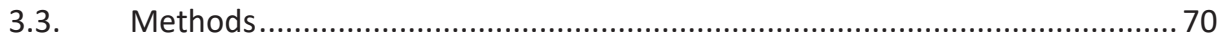

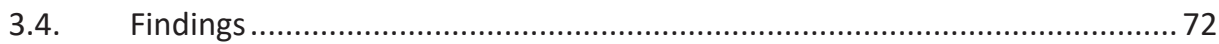

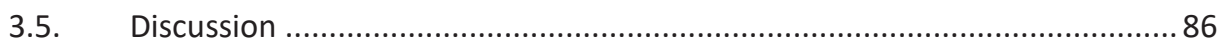

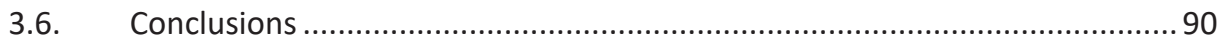

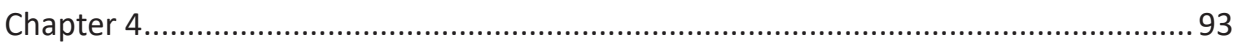

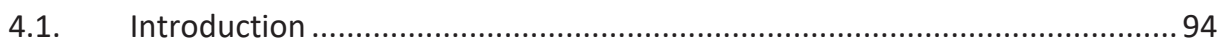

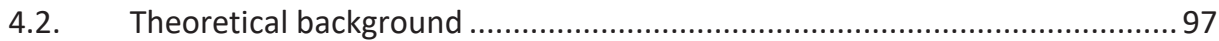

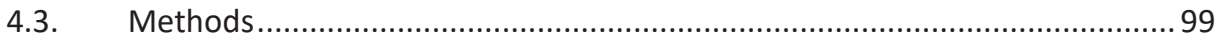

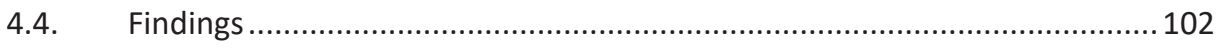

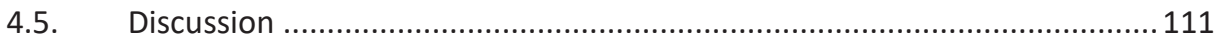

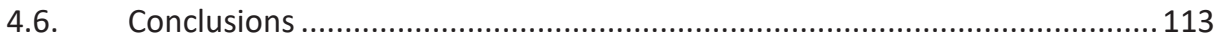

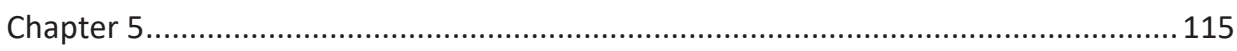

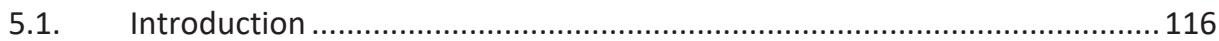

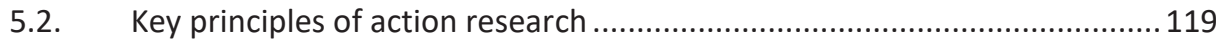

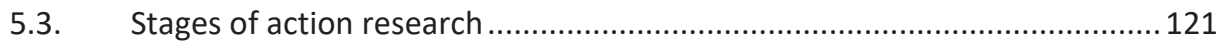

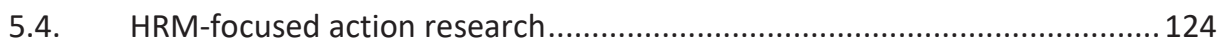

5.5. Guidelines for HRM-focused action research ...................................... 128

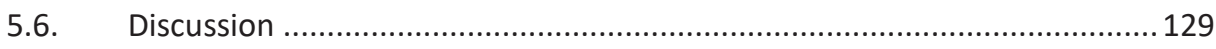

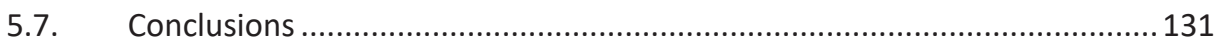

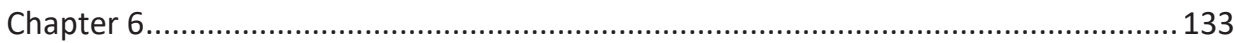

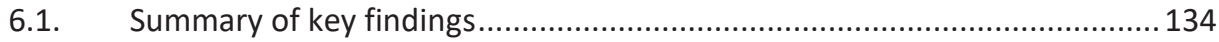

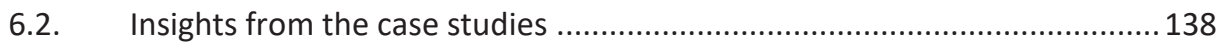

6.3. Answer to the overall research question ............................................... 143

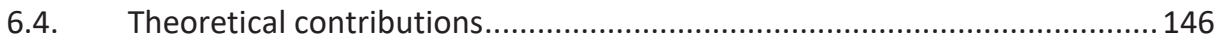

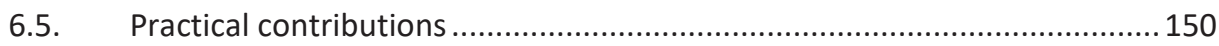

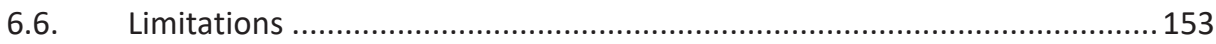




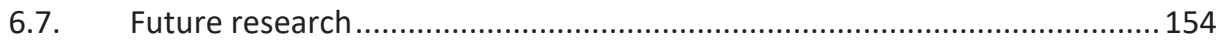

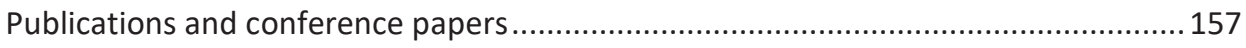

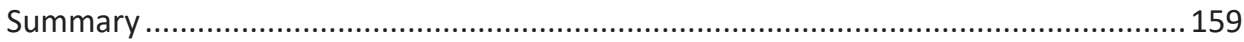

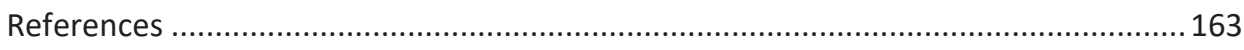

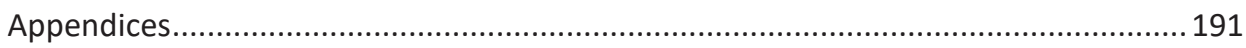

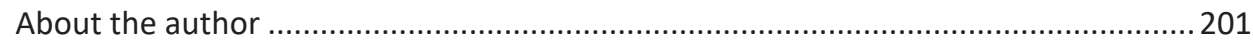





\section{List of Figures}

Figure 1: Structure and action, and their modalities 29

Figure 2: The reinforcing characteristics of structuration theory and routine dynamics .... 33

Figure 3: Dissertation outline .. 46

Figure 4: The dynamic nature of HRM implementation ...... .. 55

Figure 5: The continuous interaction between HRM practice and behaviour over time .... 57

Figure 6: The process of implementing the new HRM practice at the Ministry .................. 74

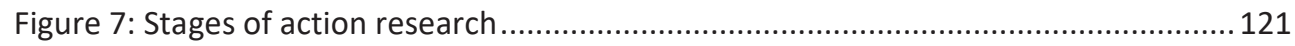





\section{List of Tables}

Table 1: Interpretive research approach adopted to study HRM implementation 35

Table 2: Characteristics of the target groups for the case studies 38

Table 3: Overview of respondents in the Ministry 39

Table 4: Overview of respondents in Dutch Cleaners. 41

Table 5: Overview of data sources the Ministry 70

Table 6: Overview of data sources Dutch Cleaners 101

Table 7: Overview of HRM-action research papers 127

Table 8: Cross-case differences 138 



\section{Acknowledgements}

When I started my big adventure as a PhD Candidate at the University of Twente four years back, I had no idea where it would lead me. I knew I loved doing research, to question 'common knowledge', and to study something nobody else had done before. But what I would be doing day by day, that I wasn't sure of. This adventure took me to places such as Los Angeles, Liverpool, Chicago, and Copenhagen. It also made me part of the University of Twente's awesome HRM department. And now it brings me to a stage on which I will be defending my dissertation. However, even though the book has got my name on the front, it doesn't mean that I did it without the invaluable help of many others. It is impossible to express how thankful I am to those people on a piece of paper.

But I am going to try.

To my promotor Tanya. Each time that I visited a doctoral consortium at whichever conference, there always was at least one session focused on the question 'How to survive your supervisor?' I must admit that I visited some of such sessions. However, I visited those sessions more or less as a tourist, or to be entertained by the stories of fellows PhDs. I have never felt the need for having to 'survive' neither you nor your supervision, because I feel that from the beginning we have had a great chemistry. Your passion for, let's say constructivist research, and above all, structuration theory, has been a massive inspiration for me from day one. I remember that during one of our first meetings, you told me 'if you start with structuration theory, then you're in it for life!' Your dedication to my research and your ability to continuously raise questions which I could not answer, has played an invaluable role in the development of this book - and for me as a person. My thanks to you could not be bigger.

I also would like to express my thankfulness to the members of my Promotion Committee: prof. dr. Anne Keegan, prof. dr. Svetlana Khapova, prof. dr. René Torenvlied and dr. Mark van Vuuren. I am honoured that you have accepted the invitation to be part of my committee. Some of you had to travel quite far, while for others this is a 'home game', but I am equally thankful for the time and effort that you have invested in my promotion.

A big word of thanks to my co-authors. Besides Tanya, these are: Karin Sanders, Inge Bleijenbergh and Raymond Loohuis. It has been an honour working with you on the actual 
content of this dissertation. Your expertise and experience have contributed a lot to the end result.

Anna and Jeroen, together with Tanya, you formed the interview committee in June 2014. As I was in Mexico at the time, this interview took place through Skype. And to be honest, I can only remember that we were laughing all the time. It was different from other job interviews that I have had over the years and it made me realise from the beginning that the atmosphere in the HRM department was one in which I would feel entirely at home. From the beginning you have occupied the role of mentor whenever Tanya was unavailable. Therefore, I feel that both of you have served as my co-promotors and I would like to express my thanks for this.

My fellow PhDs from the employee-driven innovation project Maarten and Milana. I still remember the day we met. I arrived first to Tanya's office, then Milana, and Maarten arrived latest. Probably, that was the last time I arrived at the office earlier than Maarten. I have had great fun with you guys and your support has been vital for me.

My colleagues of the HRM department: Jan, Milou, Jan Kees, Huub, Dustin, Dennis, Gregory, Luuk, Henk-Jan, Lew, André, Irene, Ida, Ewold, Sri, Sjoerd, Marie-Christine and Jeannette. Thank you so much for supporting me and for creating an awesome department. Our trips to Lattrop, Rome, L'Aquila, Monnickendam and Vilsteren were always filled with laughter and a great atmosphere. Also, your broad perspectives and critical questions have helped me in my PhD process.

I am also very thankful to the Netherlands Organisation for Scientific Research (NWO) and the consortium partners of the research program Innovating Human Resource Management for Employee-Driven Innovation for making this research possible. The consortium partners are: the Ministry of the Interior and Kingdom Relations (BZK), Medisch Spectrum Twente, WGV Zorg en Welzijn and TSN.

My fellow PhDs with whom I had great fun during lunch breaks, PhD dinners, pub quizzes, random meetings in the corridor, at PhD parties, etc. Anna, Raja, Igors, Frederik, Niels, Tamara, Ari, Haider, Arturo, Andrés, Imke, Kathy, Siraj, Silvia, Arjan, Martin, Timo, Koen, Lisa, Yasin, Tijs, and all of those who I have failed to mention: thank you!

Another group of people who have been important throughout these years are those of the UT futsal group. Being able to play football every week on Monday night was a pleasure and proves that people who wear t-shirts saying 'I hate Mondays' should consider looking for a hobby on Mondays. Especially thanks to my fellow board members Michel, Maarten, Sebastiaan and Anne. 
To be able to transcend from armchair research, it is vital for researchers to be able to obtain actual insights from the field. Therefore, I am very thankful to those at BZK and Asito who have opened their gates to me and allowed me to obtain extremely rich and insightful data. Particularly, I would like to thank Wendy, Arina, Netty and Emilie of BZK, and Hans and Leonore of Asito. I am also extremely grateful to everyone who was willing to be interviewed by me. Even though this was sometimes done after work hours and time is precious, I have never felt rushed during our (long) talks.

To my paranimfs Maarten and Jacco. You have become great friends over the last couple of years and I am honoured to have you guys on my side on this day.

Finally, the most important people in my life. First of all, I would like to thank my parents Ben and Caroline who have stood by my side from the beginning. I can still hear my mother's words 'these days, children tend to be educated higher than their parents'. She told me this somewhere in 2010. When my highest education was a bachelor's in tourism management, and both my parents had obtained their master's. Those words got stuck in my mind though, and I am sure they played a part in my decision to start a premaster and master in Rotterdam. Later, those same words echoed in my mind when I was thinking about doing a PhD. Thanks mom! My father has also been a great source of inspiration. When I was young he obtained his title in psychology and I remember the wooden sign my mother had placed in the garden: drs. B. van Mierlo, Psycholoog. Now that was cool! These days I know it is not so much about the title, but more about the road to get there. The entire journey towards a PhD is tough, but also incredibly rewarding. The academic background of my parents has definitely helped me getting through it. Thank you for everything, you are the best!

And now really finally: Samara. I still remember discussing about doing a PhD. It was May 2014 and we were in Zacatecas, Mexico, driving behind a pick-up truck filled with pineapples. While I was wondering how those pineapples stayed in place instead of flying through the air, we discussed our future. We had recently decided to get married and now, I needed to take some responsibility. At first, you weren't very enthusiastic about the idea of me doing a PhD. In Mexico, that means back to student life and living from a modest scholarship. However, after I explained it means being an employee and earning money, you were convinced. So we decided to live in the Netherlands. In a city where the both of us had never been in our lives and which for you turned out to be quite difficult to pronounce correctly. But you have managed to adapt to the country (except for the weather) and you are close to finishing you master's in industrial engineering. Sami, a thousand times thanks. I couldn't have done this without your support and love and today is also for you. Te amo! 

CHAPTER 1

Introduction

A good idea is about ten percent.

Implementation,

hard work, and luck is 90 percent

- Guy Kawasaki 


\subsection{HRM IMPLEMENTATION AS THE FOCUS OF THIS DISSERTATION}

HRM implementation concerns the process in which HRM practices are developed from an idea into a fully working organisational instrument. This includes taking the decision to adopt a best practice or create a new one, then designing it, assigning tasks and responsibilities for its delivery, and the moment of introducing it to employees ${ }^{1}$ on the work floor. Scholarly attention to HRM implementation has grown steadily over the past couple of decades, leading to over 1500 publications $^{2}$ in academic journals. Therefore, it is reasonable to claim that it has become an established and recognised tradition in HRM research.

Interestingly, a clear, widely-used definition of HRM implementation is lacking (Mirfakhar, Trullen, \& Valverde, 2018), which makes it hard for scholars to compare and build on each other's work. Instead of defining HRM implementation, authors of HRM implementation studies tend to describe it implicitly. For instance, in studying the implementation of HRM, Khilji and Wang (2006) focus on gaps between intended and implemented HRM practices. Makhecha, Srinivasan, Prabhu and Mukherji (2016) add employee perceptions to that, whereas Guest and Bos-Nehles (2013) chose to define a series of phases in which HR managers and line managers play certain roles. Recently, Mirfakhar et al. (2018, p. 3) pleaded for a unanimous definition of HRM implementation and proposed the following: "the transition period during which targeted organizational members ideally become increasingly skillful, consistent, and committed in their use of [a new HRM policy or practice]". However, as I will argue in this dissertation, I perceive the HRM implementation process to be more than a journey from a to $b$ or the role of line managers in adopting certain HRM practices. As such, the definition that comes closest to the one that I will use in this dissertation comes from Bondarouk, Trullen, and Valverde (2016, p. 906), who define HRM implementation as "a non-linear process that starts with the design of a new HRM policy and/or practice, and evolves toward its engaged use by employees, managers and HRM professionals". However, as the authors do not specify the nature of the 'non-linear process' and offer a rather broad description of the process from design to engaged use, without taking the role of organisational actors into account, I will use the following definition: HRM implementation is the transposition process in which HR practices are incorporated into daily organisational life by HR professionals, targeted

\footnotetext{
${ }^{1}$ Technically, all people who are employed within an organisation are employees. However, when I write about 'employees', I refer to people who work on the shop floor and have few if any managerial tasks. Usually, such employees are the main 'end users' of HRM practices. 2 Based on a search for "HR implementation" and "HRM implementation" on Google Scholar.
} 
managers and employees, through the design, introduction, application, enforcement, experience and perception, but also the subsequent evaluation, redesign and reintroduction of the HR practices (Van Mierlo \& Bondarouk, 2015, p. 7).

Even though insights and findings reported by HRM implementation scholars are valuable for both HRM scholars and practitioners, they provide, in my view, an incomplete picture of the HRM implementation process. Therefore, in aiming to lift HRM implementation to the next level, in such a way that it portrays an even more accurate and realistic perspective, I identify three main misconceptions regarding HRM implementation that need to be addressed:

1. The concept of HRM-as-a-process is incomplete;

2. HRM implementation is viewed as a one-directional process;

3. Roles are strictly separated in HRM implementation.

\section{Research problem 1: The concept of HRM-as-a-process is incomplete}

Scholarly interest in HRM implementation, as well as the way in which HRM implementation is today seen, is mainly built on the key ideas in the paper by Bowen and Ostroff (2004) about the process of HRM. Their highly influential study has already been cited 2400 times according to Google Scholar. With their seminal paper on HRM system strength, they created a new line of research for HRM scholars: HRM-as-a-process. Prior to their paper, HRM scholars used to focus mainly on the content of HRM, including conceptualising and testing which, and to what extent, HRM practices contributed to organisational performance. Bowen and Ostroff (2004) theorised that is not only important what is implemented, but also how this is done, as well as the way in which employees perceive this. They termed this the process of HRM. As such, by making a distinction between the content and process of HRM, Bowen and Ostroff shifted the scholarly focus from a search for best practices towards the creation of a shared collective understanding of HRM practices as the condition for HRM to successfully contribute to performance. Their main message was that, even though organisations put a lot of effort into adopting best HRM practices, if these practices are not implemented in the right way, they will not achieve their full potential. Bowen and Ostroff (2004) explained that HRM systems were seen by employees as messages that policymakers and managers sent to them. Therefore, the authors argued, it is of great importance that employees perceive these messages as 'strong': i.e., as distinctive (capture employees' attention), consistent (similar in different situations and for different employees) and that there is a consensus among policymakers as to their importance. 
In 2016, Ostroff and Bowen (2016) reflected on their seminal 2004 paper. They concluded that: "The concept of HRM strength has become a fundamental component in theories of strategic HRM, effective management of human capital and HRM architecture, employee-organizational exchanges in the form of psychological and normative contracts, and climate strength" (p. 200). Indeed, their 2004 paper had inspired many authors to test its key elements, and to build new models and frameworks based upon it (Den Hartog, Boon, Verburg, \& Croon, 2013; Li, Frenkel, \& Sanders, 2011; Nishii, Lepak, \& Schneider, 2008; Sanders, Dorenbosch, \& de Reuver, 2008; Wright \& Nishii, 2013). However, Ostroff and Bowen (2016) also identified several aspects which had been overlooked or needed further investigation. Examples are the almost sole attention to employee-level perceptions, an incorrect measurement of HRM system strength and the lack of reasons for why an HRM system can be found to be weak. Furthermore, Ostroff and Bowen (2016) made a case for exploring the nonlinearity of the HRM process, by which they referred to potential side-effects such as an overly high consensus. Although the concept of HRM system strength proved difficult to operationalise (for an overview, see Sanders, Shipton, \& Gomes, 2014), their original (2004) paper did create scholarly awareness of the importance of employees' perceptions and experiences of the HRM practices that play a role in their daily routines. Moreover, Bowen and Ostroff's insights inspired many scholars into conceptualising and investigating the effects of employees' perceptions on performance. For instance, Nishii et al. (2008) found that the attributions employees make regarding the HRM practices adopted by their organisation influence individual outcomes such as commitment and satisfaction. Their findings underlined the idea that employees are not mindless receivers of HRM practices, and that they need to be taken into account by decision-makers and line managers. Den Hartog, Boon, Verburg, and Croon (2013) primarily used the concept of HRM system strength in assessing the influence of high-quality manager communication on the differences in the quality of HRM as perceived through the eyes of the manager and by employees. They found support for the hypothesis that high-quality communication moderates this relationship, thereby confirming elements of the concept of HRM system strength (Bowen \& Ostroff, 2004).

Unfortunately, because authors have not paid much attention to what happens to HRM practices after their initial introduction, the entire HRM-as-a-process perspective ends rather abruptly. Most studies into HRM implementation end once HRM practices have been perceived by employees (Makhecha et al., 2016; Piening, Baluch, \& Ridder, 2014), or when individual-level or organisational-level results are visible (Nishii et al., 2008; Purcell \& Hutchinson, 2007; Woodrow \& Guest, 2014). Therefore, given that the HRM implementation process includes activities such as idea generation, design, introduction and perception of HRM practices, the question remains whether HRM practices have 
themselves finished developing at the moment they are introduced to shop-floor employees, or whether they will continue evolving from a preliminary idea towards a fully matured and integrated organisational tool. More specifically, the process element in HRMas-a-process seems incomplete as an evolutionary perspective is lacking, implicitly accepting that HRM practices do not change during the process of their implementation.

\section{Research problem 2: HRM implementation is viewed as a one-directional process}

Another influential framework, the intended-actual-perceived HRM framework, in the field of HRM implementation was developed by Wright and Nishii (2013). With this framework, the authors theorise a trajectory through which new HRM practices go from intended HRM to actual HRM and finally to perceived HRM. The authors understand intended HRM as a translation of decision-makers' ideas on increasing employees' contribution to the overall organisational performance, whereas they see actual HRM as they way in which HRM practices are subsequently implemented in practice by managers. Wright and Nishii (2013) explain that intended and actual HRM can differ because the implementation is usually done by different actors such as supervisors and trainers. In a subsequent step, building on the concept of HRM system strength (Bowen \& Ostroff, 2004), Wright and Nishii (2013) theorise that, on the individual level, HRM practices will be perceived idiosyncratically by each employee, after which they begin to influence employee behaviour and ultimately organisational performance. The difference between intended and actual HRM is labelled the implementation gap, and the difference between actual and perceived HRM the perception gap (Piening et al., 2014). Bos-Nehles and Bondarouk (2017, p. 512), state that: "slight' changes from the intended direction may cascade to huge gaps between designed, implemented and perceived HRM practices".

The intended-actual-perceived conceptualisation of HRM has been widely used by HRM implementation scholars in their empirical studies. Many examples of empirical evidence of gaps have been reported, as well as reasons for their existence. One of the first studies to investigate differences between intended and actual HRM was by Khilji and Wang (2006). They demonstrated that, in the Pakistani banking sector, a better aligned fit between intended and actual HRM led to higher employee satisfaction, which was positively related with organisational performance. In a study at an Indian supermarket chain, Makhecha et al. (2016) observed that intended HRM practices differed from actual HRM because managers implemented them only partially, added aspects, or even changed the HRM practices entirely. The authors also observed how the actual HRM practices were not experienced as such by the employees, even though their managers did apply them. In addressing the effectiveness of HRM implementation, Mirfakhar, Trullen and Valverde 
(2018) carried out a scoping review of 62 peer-reviewed papers related to HRM implementation. They investigated antecedents that were either found to be or conceptualised as influencing the successful implementation of HRM policies or practices. Distinguishing between content, context and process antecedents, the authors developed a framework that demonstrates the interdependency of organisational actors such as HRM professionals, senior managers, line managers and employees during the HRM implementation process. As such, they identified several factors that can influence the successfulness of HRM implementation positively or negatively. Examples of this are the user-friendliness of HRM, skills of line managers, and senior management support.

Reflecting on the current literature related to the intended-actual-perceived HRM discussion, I sense that the HRM implementation process is portrayed as a mechanistic, onedirectional process, flowing merely from HRM message senders to receivers (Bowen \& Ostroff, 2004; Nishii et al., 2008). This mechanistic perspective on HRM implementation suggests this process can be largely planned so as to avoid or overcome potential implementation and perception gaps (Wright \& Nishii, 2013). Moreover, HRM practices are often treated as though they also follow a one-way path, in which they are designed in the HRM department and applied by line managers to achieve organisational outcomes (Bowen \& Ostroff, 2004; Guest \& Conway, 2011; Khilji \& Wang, 2006; Purcell \& Hutchinson, 2007; Wright \& Nishii, 2013). However, based on a case study at a Dutch subsidiary of an American company, Bos-Nehles, Bondarouk and Labrenz (2017, p. 531) noted: "Our results show that HRM implementation is not necessarily only a downward flow of HRM practices from corporate HRM to subsidiary HRM managers and subsidiary line managers, but could also be a bottom-up transfer of HRM practices in which subsidiary line managers initiate HRM practices and deviate from the intended course". As such, it seems that there is more to HRM implementation than a straight line from policymakers to employees. If this is true, then the current perspective on HRM implementation fails to provide an accurate reflection of the dynamics that occur during the HRM implementation process and, more specifically, the possible interactions between top-down and bottom-up activities during the HRM implementation process.

\section{Research problem 3: Roles are strictly separated in HRM implementation}

In assessing the roles of organisational actors in the HRM implementation process, scholars have focused mainly on theorising about and investigating the contribution of line managers. Since the 1980s, the so-called 'devolution of HRM' has resulted in many HRM tasks, such as recruitment and selection, employee appraisal and employee motivation, increasingly becoming the tasks of line managers (Brewster, Gollan, \& Wright, 2013; Guest \& Bos-Nehles, 2013; Valverde, Ryan, \& Soler, 2006). Since line managers are nowadays seen 
as the main actor in administering HRM practices to employees, they are considered to be the most influential group of organisational actors in the HRM implementation process (A. C. Bos-Nehles, Van Riemsdijk, \& Looise, 2013; Purcell \& Hutchinson, 2007). They are, after all, tasked with translating intended HRM practices into that which is actually administered to their employees (Purcell \& Hutchinson, 2007). As a consequence, line managers are seen as the main cause of the previously discussed gaps between intended, actual and perceived HRM (A. C. Bos-Nehles et al., 2013; Makhecha et al., 2016). For instance, in their study into four Dutch companies, Nehles, Van Riemsdijk, Kok and Looise (2006) conclude that factors such as limited ability and time hinder line managers in implementing HRM practices as intended. In a multilevel study in a Dutch municipality, Vermeeren (2014) found that the way in which line managers implement HRM practices depends on their leadership approach. More specifically, managers with a more transformational approach tended to implement more commitment-oriented HRM practices than managers with a less transformational approach.

In the HRM implementation literature, the roles of organisational actors during the HRM implementation process are often strictly segregated (Bondarouk et al., 2016): HRM professionals design (Bowen \& Ostroff, 2004), line managers implement (Marchington, 2015) and employees perceive (Khilji \& Wang, 2006; Makhecha et al., 2016; Piening et al., 2014; Wright \& Nishii, 2013). As such, most studies concerned with HRM perceptions, merely focus on the perceptions of employees (A. C. Bos-Nehles et al., 2013; Nishii et al., 2008; Piening et al., 2014; Sanders \& Yang, 2016; Wright \& Nishii, 2013). Guest and Conway (2011, p. 1687) noted the same trend: "Recent research has increasingly sought information from employees about HRM practices and their reactions to them...but the views of senior managers, other than HR managers, have been largely neglected". Recently, Bos-Nehles and Meijerink (2018) expanded the scope of organisational actors' roles in the HRM implementation process by taking the relationships between line managers, employees and HRM professionals into account. They found that the relationship between line managers and employees influences both employees' perceptions of HRM and their commitment to the organisation. Moreover, the authors found that line managers' motivation to implement HRM was boosted by perceived support from HRM professionals. In a similar vein, Budjanovcanin (2018) investigated the role that employees play in shaping HRM implementation. Budjanovcanin, studying the implementation of agile working practices in law firms in the United Kingdom, found that, even though employees lack legitimate power, they make use of different forms of power, such as coercive power and expert power, to influence HRM. 
Papers such as those by Bos-Nehles and Meijerink (2018) and Budjanovcanin (2018) suggest that the contributions organisational actors make to HRM implementation are more complex than they are portrayed in the current HRM implementation research literature. Overall, it seems that introducing new HRM practices is not a monopoly of line managers, nor that designing HRM practices is a task only for HRM professionals. Strictly separating the roles of organisational actors in HRM implementation in this way gives only a partial perspective of their actual contributions to the HRM implementation process. In order to fully grasp 'who does what' in HRM implementation, it is necessary to extend the scholarly knowledge on this topic.

\subsection{THEORETICAL UNDERPINNINGS}

To obtain insights into both the dynamics of HRM implementation and the roles that organisational actors play in it, two theoretical frameworks play a central role in this dissertation. First, structuration theory (Giddens, 1984) serves as a lens to study the HRM implementation process. Second, insights from the research stream of routine dynamics (Feldman \& Orlikowski, 2011; Pentland \& Feldman, 2005) enable studying the efforts and contributions of organisational actors in implementing novel HRM practices in a very concise and detailed manner. A strength of these two theoretical frameworks is that their central ideas are related and reinforcing. Both theoretical approaches are introduced in this section.

\section{Structuration theory}

With structuration theory, Giddens (1984) aimed to bridge the gap between macro- and micro-focussed research, and also to combine objectivist (institutional) and subjectivist (human action) elements. Structuration theory focuses on the reciprocal interaction between human actors and structural elements of the organisation. Through their actions, structural elements, such as regulations, constrain people in their behaviour while also enabling them to behave with a certain amount of freedom within the boundaries of the structure. As such, structure both constrains and enables the behaviour of people.

Giddens (1984) developed structuration theory as a response to disagreements between, on the one hand, functionalists and structuralists (who favour objectified, quantitative data) and, on the other, interpretivists (who prefer subjective, qualitative data). He explained that he did not agree with the functionalist idea that the only correct methodology is a deductive one, aiming to generalise and predict, and that he preferred "operating with an interpretation of agency more sophisticated than is normally held by those inclined towards functionalist premises" (Giddens, 1984, p. xxxi). Further, Giddens also believed that subjective data alone could not provide a complete overview. He argued 
that scholars who follow the hermeneutics tradition are unable to study phenomena that are more objective: "for hermeneutics, it is the world of nature which is opaque - which, unlike human activity, can be grasped only from the outside. In interpretative sociologies, action and meaning are accorded primacy in the explication of human conduct; structural concepts are not notably prominent" (p. 2). Giddens expressed his ambition as to "put an end to each of these empire-building endeavours" (p. 2) and claimed that structuration theory could help with this by combining objective and subjective data.

Through structuration theory, Giddens aims to explain the production and reproduction of social systems across time and space. Hence, he asks why our behaviour is similar, not only at different moments in time and in different situations, but also among different people. Giddens sees the concept of structure as having a vital role in linking social systems with time and space, through providing behavioural rules as well as resources with which to act. Resources are the mechanisms that provide the facilities that make the production and reproduction of social practices possible, while rules constitute meaning and are connected with sanctioning. The rules of social life are "techniques or generalizable procedures applied in the enactment/reproduction of social practices" (Giddens, 1984, p. 21). As such, rules can be seen as formulas that provide general guidelines that determine what behaviour is appropriate in different contexts. The most enduring elements of structure are those rules and resources that are institutionalised, and it is these elements that give solidity in time and space. In this way, structure (rules and resources) guides people in their everyday behaviour. By defining behavioural boundaries, structure has a limiting or steering effect on people's behaviour. As such, structure constrains behaviour. However, within the behavioural boundaries set, people can exert their agency and use resources to act. Consequently, structure not only constrains, it also enables.

The core of structuration theory is the interaction between structure and action. This interaction is recursive and continuous and, in it, Giddens sees the answer to how social systems are produced and reproduced over time and space. While structure has a constraining and enabling influence over human action, structure only exists because people act within its boundaries. As such, there is a continuous interaction between structure and action through which they mutually influence each other. Action produces, reproduces and modifies structure and, in its turn, structure enables and constrains action. This is what Giddens refers to as the duality of structure: structure as both the medium and the outcome of action. It means that structure and action are not independent of each other, but go hand in hand. Feldman notes: "We cannot take action without operation within structures and without producing and reproducing them" $(2015$, p. 322). 
The notion that structure is not some untouchable 'out there' force that exerts an unmodifiable power over our actions, but rather is something created by our own actions has implications for its ontology. This clearly contrasts with the view of functionalists who see structure as something external that merely constrains human action. Giddens (1984, p. 2) explains that in structuralists' view: "structure...has primacy over action, and the constraining qualities of structures are strongly accentuated". Giddens' view on structure also means that structures do not exist if people do not act according to them because, as Giddens explains "Structure exists only as memory traces, the organic basis of human knowledgeability, and as instantiated in action" (Giddens, 1984, p. 377). This means that if people do not behave according to a certain structure, it is in effect 'non-existent'. It also means that people can actively influence the structures that enable and constrain them in their behaviour. Giddens explains that, by acting within the behavioural boundaries of a structure, people reinforce it. The structural properties which are most profoundly embedded in social systems are referred to as structural principles, and the practices which are most consistent across time and space are labelled institutions. Further, if people routinely cross the behavioural boundaries of a structure, over time they can modify its shape. Therefore, action does not only confirm or reinforce structure, it can also modify it.

Giddens identifies three domains within structure: signification, domination and legitimation. The actions that these structural domains respectively enable and constrain are communication, power and sanction. Hence, the signification structure provides rules and resources that enable communication. An example of this is a language's grammar rules that allow people to construct comprehensible sentences. As outlined above, by sticking to the structure, people reinforce it, but, by using new grammatical constructions, they can, over time, modify the formal grammar. With power, Giddens refers to the capacity to influence the behaviour of other actors, which is enabled by the structure of domination. The legitimation structure allows people to sanction others.

Giddens explains that, in acting within these three structures, people draw upon so-called modalities, which "serve to clarify the main dimensions of the duality of structure in interaction, relating the knowledgeable capacities of agents to structural features" (Giddens, 1984, p. 28). Interpretive schemes form the modality that people draw on in communicating. These are 'stocks of knowledge' that enable actors to explain their actions and interpret situations. In exerting power, actors draw on facilities. These can be either allocative (materials, resources) or authoritative (over other actors). An example of this is managers using their more senior position in an organisation to influence the behaviour of their employees. Lastly, actors make use of norms, or "tacitly understood moral imperatives" (Jarzabkowski, 2008, p. 623), in sanctioning other actors. These norms can be formal (laws, regulations, guidelines) or informal. The modalities and their position between 
structure and action are shown in Figure 1. Giddens stresses that although they have been separated for analytical purposes, they are intertwined in daily life. For instance, to sanction, it is necessary to know the norms which allow people to do so. However, to know those norms also means that the interpretive schemes of actors are necessarily involved.

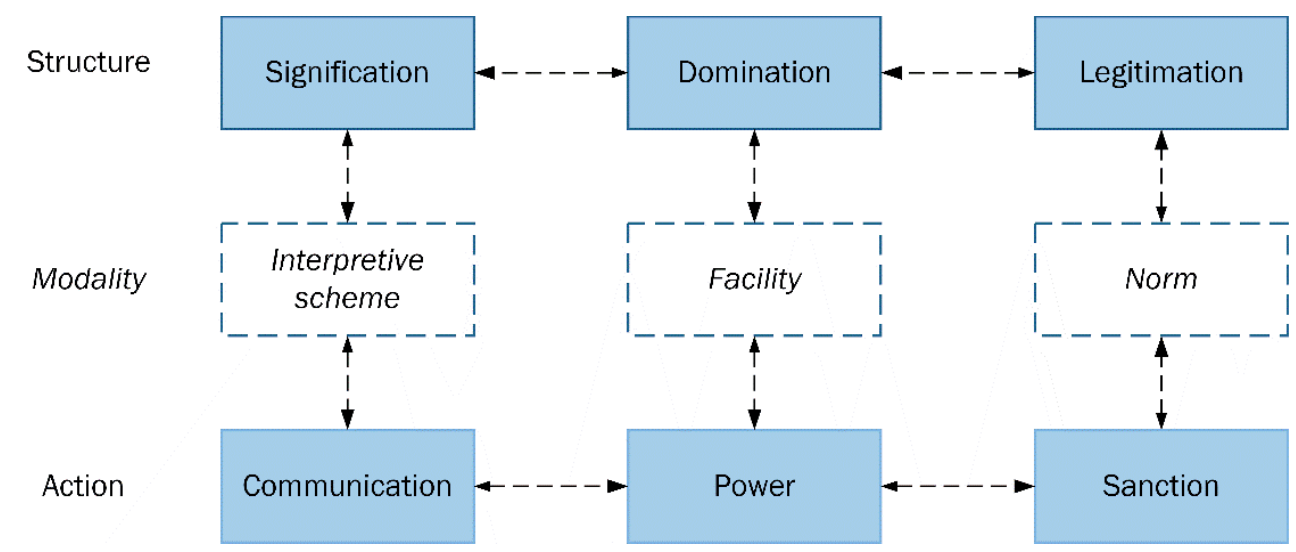

Figure 1: Structure and action, and their modalities (adapted from Giddens, 1984, p. 29)

\section{Organisational routine dynamics}

The organisational routine dynamics stream uses the same lens as structuration theory (Giddens, 1984) and habitus/field theory (Bourdieu, 1977). As such, many of the key elements overlap. An initial overlap is that practice theorists consider everyday actions to be central in the production of social life. So, by acting, people produce and reproduce social life. In another overlap, practice theorists reject dualisms in favour of dualities. Hence, instead of perceiving structure and action as two distinct phenomena, they see them as related: "The constitution of agents and structures are not two independently given sets of phenomena, a dualism, but represent a duality" (Giddens, 1984, p. 25). In organisational routine dynamics, a similar duality is seen between ostensive and performative aspects of routines (Feldman \& Pentland, 2003). A third overlap is the shared concept of mutual constitution, which claims that phenomena are created and recreated in relation with other phenomena (Feldman \& Orlikowski, 2011). Hence, as Giddens explains, action creates and recreates action, and structure influences action. Similarly, organisational routine dynamics scholars consider performative aspects of routines to create and recreate ostensive aspects, and vice versa (Feldman \& Pentland, 2003).

In applying organisational routine dynamics, extremely detailed attention is given to the way in which daily organisational routines are created by everyday actions, and in particular the way in which routines can be modified over time and produce the capacity 
for change: "stability and change in routines are generated through the acting and reenacting of routines" (Feldman, 2015, p. 323).

Organisational routines can be defined as repetitive, recognisable patterns of interdependent actions, carried out by multiple actors (Feldman \& Pentland, 2003). Researchers in organisational routine dynamics particularly consider the capacity, and even the source of change and innovation, that an organisation's routines have. Feldman and Pentland (2003) argue that a static view of organisational routines overemphasises their inertia, and that they should be perceived as sources of change and innovation. Here, they see a sharp contrast with scholars who see routines as merely a source of stability and structure (Feldman, 2000). Feldman and Pentland explain that routines can lead to changes in behaviour, and subsequently to changes in routines, because they are: "...produced by many people with different information, preferences, and interpretation, they are enacted over time and space, and they interact with other streams of action in such a way that it is not always clear where one organizational routine ends and another begins. For these reasons, organizational routines always have the potential for change" (Feldman \& Pentland, 2003, p. 115). Feldman (2000, p. 613) had earlier noted that outcomes of routinised behaviour (unexpected consequences, coincidental modifications) can lead to a modified or even new routine. She gives the example of actions that lead to disastrous outcomes, which "encourages one to try something different next time". Over time, the 'something different' can lead to modified routinised behaviour. In her paper on the dynamics in routines of a large housing organisation of an American university, Feldman (2000) showed how unintended or undesirable outcomes, or the failure to achieve intended outcomes, over time led to modifications in moving-in and hiring routines. Building on this, Feldman and Pentland (2003) argue that the dynamic capabilities of routines mean that any organisational routine, through its continuous performance, is capable of generating change.

\section{The relevance of using both theories in this dissertation}

As HRM implementation is the topic of this dissertation, and structuration theory (Giddens, 1984 ) is to play a guiding role, it is necessary to 'translate' the concepts and terms of structuration theory to HRM. Structure consists of the rules and resources that constrain and enable organisational actors in their daily work routines. Therefore, I see HRM practices as structure since they are designed to influence organisational actors in such a way that they are more productive, engaged, committed and motivated, or possess more adequate skills for completing their tasks. Giddens (1984) theorises a continuous interaction between structure and action, and a similar interaction takes place between HRM practices and organisational actors. That is, the actions of organisational actors recursively influence the 
HRM practices that enable and constrain them in their daily job. This dynamic process passes through the modalities of interpretive schemes, facilities and norms, and will eventually lead to a more stable version of the HRM practice, as well as to modified work routines of organisational actors. As such, HRM practices are structured the moment that facilities are in place, organisational actors perceive the practice as legitimate, and they are aware of the HRM practice and understand it (Taylor, Groleau, Heaton, \& Van Every, 2001; Van Mierlo, Bondarouk, \& Sanders, 2018).

Routines in this dissertation are seen as stable, but always open to modification by organisational actors. In this, I consider organisational 'routines in principal' - the way in which actors describe them. Similar to structure in Giddens' sense, routines in principal consist of rules and resources that enable those routines to be enacted. Conversely, a 'routine in practice', is what actors routinely do.

A difference between structuration theory and organisational routine dynamics is that while Giddens considers structure to consist of formalised rules, this is not the case for routines. Rather, the formalised aspects of routines, such as protocols and standard operating procedures, are labelled as artefacts since organisational routines exist in the minds of organisational actors (Feldman \& Pentland, 2003). This seems to be contradictory: Giddens sees structure as formal, whereas scholars in the organisational routine dynamics tradition do not consider routines - which they compare to structure (Feldman \& Pentland, 2003) - as formal. However, this ontological difference is easily explained by the following. Even though structure, according to Giddens, consists of formal rules, the way in which people understand those rules and enact the structure makes the structure less solid: "Structure exists only as memory traces, the organic basis of human knowledgeability, and as instantiated in action" (p. 377). Hence, Giddens explains that even though structures consist of formal aspects, the way in which people interpret and make use of those formal aspects influences whether structures actually 'structure'. In other words, as structures only exist in the memory traces of people, they merely have the capacity to influence their behaviour. As such, although the formal aspects related to structures are indeed different from the notion of routines, the effect of those formal aspects is equal to that of routines.

The question remains as to in what way structuration theory can contribute to the field of HRM implementation, and why it makes sense to apply this now over thirty years old theory to a relatively young field of research. The strength of structuration theory is that it provides researchers with a lens through which they can obtain a full perspective of the HRM implementation process: from the birth of an HRM practice, through its development - including all sorts of 'growing pains', towards a more stable, mature version of the same HRM practice. By not focussing on either the structural aspects or the actions of actors, but 
on the continuous interaction between the two, structuration theory provides mechanisms to study the dynamics in the HRM implementation process, including the process through which behaviour becomes embedded in organisational routines. I would argue that to study HRM implementation - acknowledging that it is a process in which various organisational actors are involved in different stages of development - involves a dynamic and evolutionary process.

To strengthen the focus on the role of organisational actors in that process, it is necessary to adopt a micro-level theory that focuses particularly on the way in which organisational actors, through their actions, create and recreate their own routines, and therewith, organisational routines. Feldman and Pentland's (2003) explanation of routine dynamics, as well as empirical findings, have contributed considerably to this. Insights from routine dynamics (Feldman \& Orlikowski, 2011; Feldman \& Pentland, 2003) provide a very detailed overview of the actions of actors during the HRM implementation process. This approach enables one to study the creation and modification of routines during the HRM implementation process, and hence provides a means to study the contributions that actors make during the HRM implementation process. The fact that researchers following the routine dynamics tradition are largely building on the outlines of structuration theory demonstrates its synergistic value. The two perspectives are not contradictory but rather strengthen each other. Furthermore, routine dynamics is a relatively young and growing field. Having been founded in a structuration tradition (Feldman \& Orlikowski, 2011), this supports my argument that structuration theory (Giddens, 1984) is still relevant when it comes to studying organisational processes. After all, even though structuration theory is often seen as complex and difficult to operationalise, this has not stopped many scholars using it to study dynamic processes in organisations (for an overview, see Jones and Karsten (2008)).

I have portrayed my interpretation of the reinforcing characteristics brought about by combining structuration theory and organisational routines dynamics in Figure 2 . The upper half of the figure demonstrates the main points of structuration theory: structure (HRM practices) influences the actions of actors who, through their routinised actions, recursively influence that very structure. Over time, those routinised actions have the capacity to change the overarching structure. However, as insights from the organisational routine dynamics literature explain, these routinised actions can be changed through the actions of actors themselves. As noted by Feldman and Orlikowski, social regularities, such as routines, can change "in every instance of action" (2011, p. 1242). Hence, even though actors have their routines, these can be changed in any instance. Each instance might be in line with the routine, but it could also differ. Organisational routine dynamics shows that each of these instances can then lead to a new or modified routine. This is portrayed in the 
lower half of the figure. Again, referring back to structuration theory, these modified routines can, over time, lead to modified structures.

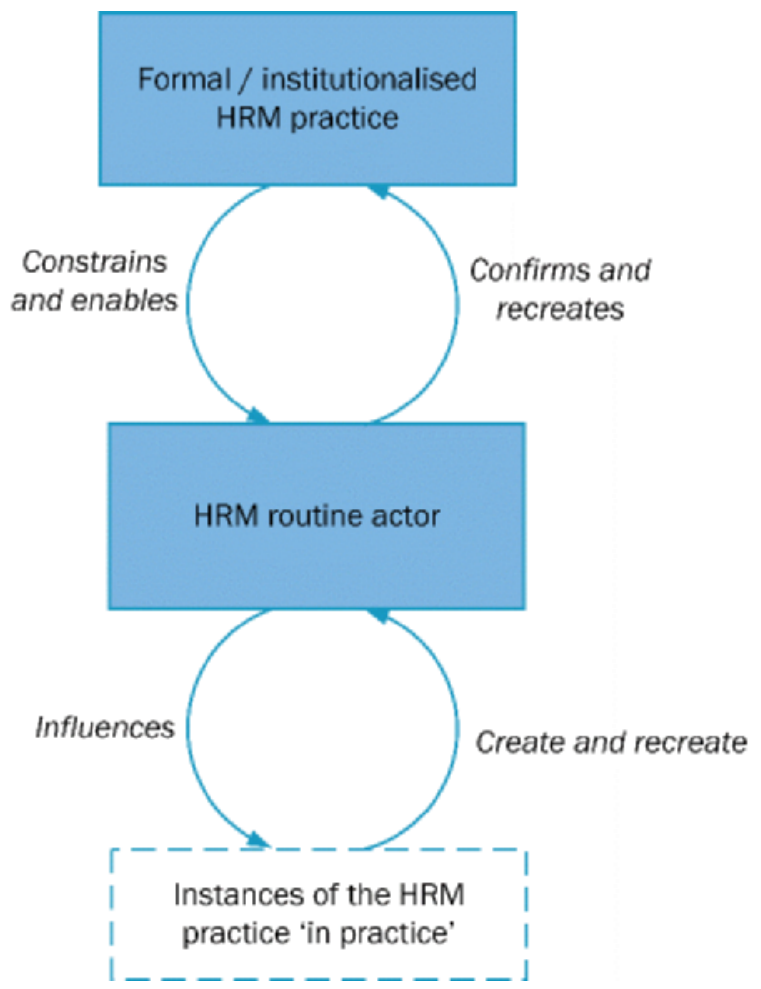

Figure 2: The reinforcing characteristics of structuration theory and routine dynamics

\subsection{MAIN RESEARCH QUESTION}

Inspired by the key assumptions and insights that structuration theory (Giddens, 1984) and organisational routine dynamics (Feldman \& Orlikowski, 2011; Pentland \& Feldman, 2005) offer, and building on insights in the field of HRM implementation, I argue that we need to acknowledge that the HRM implementation process and HRM practices are far more dynamic and evolutionary than they are often viewed in contemporary HRM literature (Bowen \& Ostroff, 2004; Wright \& Nishii, 2013). This leads up to the question as to what happens after the "moment" of deciding to adopt a new HRM practice. The constant interaction between HRM and the behaviour of organisational actors is at the heart of these dynamics. Furthermore, given that line managers are seen as the key players in implementing new practices (Brewster et al., 2013; Guest \& Bos-Nehles, 2013; Valverde et al., 2006), the role of other actors, has to date been underexposed (notable exceptions are 
the papers by Budjanovcanin (2018), and Bos-Nehles and Meijerink (2018)). Insights from routine dynamics indicate that the bottom-up role and dedication of users, such as workfloor employees, in this process is key for the successful adaptation and routinisation of new practices (Bertels, Howard-Grenville, \& Pek, 2016; Howard-Grenville, 2005; van der Steen, 2011).

On this basis, the research question leading this dissertation is formulated as:

What do the dynamics of the HRM implementation process look like, and which roles do organisational actors play in it?

\subsection{RESEARCH PARADIGM}

In this dissertation I adopt an interpretivist paradigm (also see Table 1) in which ideas, meanings and feelings have central roles in the scientific endeavour (Burrell \& Morgan, 1979). Therefore, ontologically, this study builds on the assumption that the social world is constructed by the actions and interactions of human actors, implying that reality does not exist independently of them, and thus differs from person to person (Scotland, 2012). In the context of HRM, this means that the organisation in which people work consists of their actions, interactions, relations, thoughts and meanings. The same is true for the process of implementing HRM practices since this is an organisational process: one in which organisational actors interact, cooperate, negotiate and, hence, enact the creation, adoption and perception of new HRM practices. Since an etic approach entails studying a phenomenon from the perspective of the researcher (Berry, 1989), adopting an etic approach would not be sufficient for obtaining knowledge about the HRM implementation process. Rather, an emic approach, studying the HRM implementation process from the perspective of the organisational actors involved in the process themselves, will provide much richer insights into their ideas, meanings and values. Therefore, epistemologically, this study builds on interpretivism traditions, and aims at understanding the way in which social reality is constructed by its actors (Morgan \& Smircich, 1980). 


\begin{tabular}{|l|l|}
\hline Ontology & $\begin{array}{l}\text { HRM implementation is constructed and reconstructed by the behaviour } \\
\text { of organisational actors, in which meanings and beliefs take a central } \\
\text { place (Goldkuhl, 2012). Hence, HRM implementation does not exist } \\
\text { independently of the interpretations of organisational actors of it } \\
\text { (Walsham, 1995) but is created by them. }\end{array}$ \\
\hline Epistemology & $\begin{array}{l}\text { The goal is to understand the way in which HRM implementation is } \\
\text { created through the eyes of the subjects of investigation (Morgan \& } \\
\text { Smircich, 1980). }\end{array}$ \\
\hline Methodology & $\begin{array}{l}\text { Qualitative methods, making use of case studies and } \\
\text { ethnomethodology, in which data are collected by means of interviews, } \\
\text { document analysis and observations. }\end{array}$ \\
\hline
\end{tabular}

Table 1: Interpretive research approach adopted to study HRM implementation

Given the leading role given to the theoretical underpinnings of structuration theory (Giddens, 1984) and organisational routine dynamics (Feldman \& Pentland, 2003), gaining insights into the social world of organisational actors stands central in this research. Their ideas, values, experiences, thoughts and frustrations are only partially captured by taking a positivist or critical realist viewpoint. The same is true for their behaviour; even though it would be possible to observe their actions, an emic approach will provide further insights into what they do and why they do it, beyond merely seeing them act. For these reasons, in-depth conversational interviews play a major role in the data collection for this dissertation. Obtaining insights into the HRM implementation process from the perspective of the subjects is vital for answering the second part of the research question regarding the roles of organisational actors in the HRM implementation process.

Adopting an interpretivist paradigm in a study that is so heavily embedded in structuration theory and organisational routine dynamics inevitably raises questions. Indeed, Giddens aimed to bridge the divide between functionalism and interpretivism through structuration theory. However, this is not to suggest that he rejected both paradigms. Rather, even though his preference for the more interpretivist paradigm is fairly obvious in his writings, he leaves this to the researcher's discretion. The same is true for methodological approaches, where Giddens (1989, p. 296) stresses "Structuration theory is not intended as a method of research, or even as a methodological approach...I have an eclectic approach to method, which again rests upon the premise that research enquires are contextually oriented. For some purposes, detailed ethnographic work is appropriate, while for others archival research, or the sophisticated statistical analysis of secondary materials, might be more suitable". 


\subsection{METHODOLOGY: CASE STUDIES}

In my doctoral work, I have used a case study approach to obtain empirical insights into the HRM implementation process of two organisations. As Stake (2005, p. 443) observed: " $a$ case study is not a methodological choice but a choice of what is to be studied". A case study approach particularly fits the research question because of its potential to observe HRM implementation throughout the process in which it is being implemented. Moreover, case studies, by being close to the research subjects, allow one to study the development of a new HRM practice over time in the work setting. As such, a case study approach provides the opportunity to study the subjects' experiences and learn about their thoughts, ideas, frustrations and efforts regarding the HRM implementation process.

Probably the most influential work on case studies was written by Yin $\left(2018,6^{\text {th }}\right.$ edition), who defines case studies as "an empirical inquiry that investigates a contemporary phenomenon within its real life context, especially when the boundaries between phenomenon and context are not clearly evident" (2018, p. 16). While this definition is essentially true, it ignores the possibility that case studies should also be open to a retrospective view. It is logical that it is generally easier to study a phenomenon in situ, but several exemplary cases studies have used retrospective methods (Danner-Schröder \& Geiger, 2016; Jarzabkowski, 2008). Therefore, I adopt the definition of Flyvbjerg (2011), and view a case study as a study that (i) demarcates the boundaries, identifying the unit of investigation, (ii) is intensive, producing rich, detailed information, (iii) evolves over time and (iv) is focused on the context of the case.

To answer my main research question, I conducted two case studies. An important selection criterion in both cases was that they should allow new HRM practices to be studied during their implementation process. In this, by new HRM practices I meant practices that need not be a novelty in the field of HRM, but were new for the organisation itself. Furthermore, the practices had to already be in their adaptation phase, rather than a project that might be launched in the near future. As such, it would be possible to study the entire HRM implementation process through adopting longitudinal studies.

Both case studies took place in a similar context: recruitment and selection practices related to the recent adoption of a policy to hire a large number of impaired workers (case 1) and disadvantaged workers (case 2). In both cases, the targeted people were at a distance from the labour market. In the case of impaired workers, this was directly related to their mental or physical handicap. Disadvantaged workers, a broader term, also includes workers whose distance to the labour market is due to other factors such as their educational background or immigration history. In the remainder of this section, I will describe both case studies and the contexts in which they were situated. 


\section{Overarching context: the Participation Act}

In early 2013, the Dutch federal government and its social partners ${ }^{3}$ came to an agreement to create 125,000 additional jobs for impaired people. Of these, 100,000 would be realised by private-sector employers by 2026 , and the other 25,000 jobs by the public sector by 2024. This agreement was christened the 'job agreement', and the impaired and disadvantaged candidates simply referred to as the 'target group'. The details of this agreement were formalised in the new Dutch Participation Act.

The impaired category consists of people who, due to their physical or mental disabilities, are unable to earn the minimum wage - for example because they cannot work more than a certain number of hours per week or are unable to perform certain tasks. For organisations, it is important to be aware that only employees who are registered by the Dutch employee insurance agency (UWV) as 'impaired' count towards the abovementioned 125,000 jobs. As such, impaired workers who do not want to be so labelled do not contribute to their employer's assigned quota. To safeguard the objectives of the job agreement, its details were incorporated in the Participation Act, which was accepted by the Dutch Senate in 2014 and became effective as of January 2015. Articles in the Participation Act address the type and cause of workers' disabilities, the number of hours that constitutes a job and the remuneration of employees.

The other group of people, which we label 'disadvantaged', are those who for various reasons, such as poor skills or long-term unemployment, seem to be at a disadvantage when it comes to (re-)entering the labour market. These employees do not contribute to the employer's quota as they are not (registered as) impaired. An overview of both target groups is provided in Table 2 .

\footnotetext{
${ }^{3}$ The social partners are all private-sector Dutch employers that are affiliated to a labour union.
} 
Case study $1 \quad$ Case study 2

\begin{tabular}{l|l|l}
\hline Organisation & Dutch ministry & Dutch cleaning company \\
\hline Target group & Impaired workers & Disadvantaged workers \\
\hline $\begin{array}{l}\text { Reason for distance to the } \\
\text { labour market }\end{array}$ & $\begin{array}{l}\text { Mental or physical } \\
\text { disability }\end{array}$ & $\begin{array}{l}\text { Low educational } \\
\text { background, immigration } \\
\text { status, long-term } \\
\text { unemployment }\end{array}$ \\
\hline $\begin{array}{l}\text { Contribute to quota under } \\
\text { the Participation Act? }\end{array}$ & Yes (if registered) & Not necessarily \\
\hline
\end{tabular}

Table 2: Characteristics of the target groups for case studies 1 and 2

Studying the implementation of a policy related to seeking to engage impaired and disadvantaged workers is particularly relevant for this dissertation given its inherently dynamic nature. Not only are many organisational actors involved in its implementation (designing, administering, checking progress, evaluating), it will also affect their organisational routines. For instance, whereas managers were used to filling their vacancies by uploading a job description to the government's or their employer's website and inviting candidates, the process is less straightforward in seeking impaired or disadvantaged workers. Further, giving preference to a certain group of candidates, merely because of their disability, will provoke a lot of mixed responses from actors throughout the entire organisation. As a result, I chose to study these HRM practices because of their dynamic nature and multi-actor influence throughout both cases.

As they are dynamic, involving multiple actors on multiple organisational levels, and recognisable by their repetitive nature (Feldman \& Pentland, 2003), recruitment and selection practices should be particularly revealing for a study on dynamic HRM implementation processes. Moreover, they often entail the first interaction that employees have with an organisation and, as such, involve first impressions and preconceptions. Especially when hiring employees at a distance from the labour market, whether this is due to a disability or another reason, these first impressions and preconceptions are assumed to play a major role.

Interestingly, in mid-2017, the Minister of State responsible for safeguarding the job agreement, reported large differences in the progress of hiring impaired workers between the public and private sectors during 2016. Whereas the private sector had hired almost 35\% more than their yearly quota of impaired workers, the public sector was almost $45 \%$ behind their target. It is perhaps significant that the responsible Ministry was, itself, doing much better than its counterparts, and had achieved its personal target. 


\section{Case 1: Dutch ministry}

The first case study concerned a Dutch federal-level governmental department. In this dissertation, it will be termed 'the Ministry'. This ministry employs around 7,500 people, who are primarily based in the government seat of The Hague. Under the Participation Act, the Ministry has a double role: first, it has a pivotal role in the process of translating the Participation Act into HRM policies and practices. As a ministry, it was given the task of creating awareness among governmental members, explaining the Participation Act and creating tools and instruments to facilitate members to fulfil their responsibilities. The second role of the Ministry is to meet its own target for impaired workers. As such, the Ministry serves as both the deliverer and a receiver of HRM policies concerning the Participation Act.

The Ministry was a particularly interesting and valuable case for observing dynamics during the implementation process of HRM for several reasons. First, it allowed insights into the dynamic ministerial context given the large number of actors, organisational levels and interested parties involved, as well as the politically sensitive context and the complex environment in which it operates. The double role of the Ministry also makes it a 'critical' case "cases that are rich in information because they are unusual, special or make a point quite dramatically" (Fletcher \& Plakoyiannaki, 2011, p. 179). In this instance, this is because the way in which actors in the Ministry design instruments and tools can steer other ministries and governmental departments in undertaking similar tasks.

To obtain insights into ministerial processes, dynamics and terminology, I was granted full access to the Ministry's facilities. Furthermore, I was present at least one day a week and participated in departmental activities such as meetings and social events. Further, at several points during the research, preliminary findings were fed back to departmental members for their reflection. Data collection involved document analysis (over 250 documents including policy descriptions, reports, notes and emails), 33 in-depth interviews (for an overview of participants, see Table 3), as well as walking-the-floor observations.

\begin{tabular}{|l|l|}
\hline Policymakers & 5 \\
\hline HRM professionals & 10 \\
\hline Coordinators & 9 \\
\hline Managers & 8 \\
\hline Impaired workers & 1 \\
\hline \hline Total & 33 \\
\hline
\end{tabular}

Table 3: Overview of respondents in the Ministry 


\section{Case 2: Dutch company}

Dutch Cleaners provides cleaning services to organisations in the public and private sectors. Its client base covers schools, hospitals, large companies and small offices. Each client is referred to as a 'location'. The company currently has around 10,000 employees. Dutch Cleaners is active throughout the entire country and has subdivided its operations into six regions. Therefore, apart from central staff in the company's headquarters, each region consists of a region manager, four to six middle level managers and 25 to 30 line managers. Further, each region employs an HRM professional who is responsible for all employeerelated issues in that region.

The line managers are each assigned a certain number of locations, for which they are responsible for supervising all the day-to-day tasks. This includes the hiring and firing of employees, training and integrating them, managing them, and the associated administrative tasks. Line managers seeking to hire employees can access the company's database, onto which candidates can upload their CVs. Whenever a vacancy occurs, line managers can make a selection from those CVs and invite candidates to apply, or directly schedule an interview. Since the workforce demand can fluctuate rapidly in the cleaning business, line managers will often aim to fill vacancies within a week or even days. Middlelevel managers and HRM professionals do not have a major role in this process since line managers are able to execute most of the tasks themselves.

Dutch Cleaners has gained a reputation as one of the most inclusive organisations in the Netherlands. Furthermore, their decentralised approach to implementing new HRM practices clearly differs from the regular implementation models reported in the current HRM literature which adopt a more top-down approach (e.g. Guest \& Bos-Nehles, 2013; Wright \& Nishii, 2013). Notably, and contrary to the approach taken by the Ministry, Dutch Cleaners started without a clear description of responsibilities and tools. Instead, it set itself the goal of 'becoming inclusive' by hiring a large number of disadvantaged workers, and gave the HRM professionals the task of developing policy to achieve this.

As such, Dutch Cleaners can be seen as an exemplary or extreme case because of its unusual implementation approach. Given its decentralised implementation approach, it makes a perfect case for studying the contributions that organisational actors make during the HRM implementation process. Adopting a routine dynamics approach (Feldman \& Pentland, 2003) made it possible to study in detail the actions of organisational actors in modifying existing organisation hiring routines, and in adopting new ones.

Data collection at Dutch Cleaners, which lasted six months, consisted mainly of interviews. In total, 28 of the company's employees were interviewed. Further, some documents were analysed. An overview of respondents' functions is given in Table 4. 


\begin{tabular}{|l|l|}
\hline Policymakers & 1 \\
\hline HRM professionals & 4 \\
\hline Senior managers & 1 \\
\hline Middle managers & 8 \\
\hline Line managers & 10 \\
\hline Supervisors & 1 \\
\hline Disadvantaged employees & 3 \\
\hline \hline Total & 28 \\
\hline
\end{tabular}

Table 4: Overview of respondents in Dutch Cleaners

\subsection{ACADEMIC RELEVANCE}

Obtaining a more detailed overview of the dynamics that occur during the HRM implementation process will add greatly to the HRM implementation research stream. In the current HRM implementation literature, the level of sophistication in terms of the roles of actors in HRM implementation, as well as the dynamics that occur during this process, is low. As discussed earlier, when identifying the three research problems to be addressed in this dissertation, most of the focus to date on organisational roles in HRM implementation has been limited to line managers, thereby neglecting the contributions of employees among others (notable exceptions include the work by Bos-Nehles and Meijerink (2018) and Budjanovcanin (2018)). Further, the unidirectional perspective and the lack of attention to the evolutionary nature of HRM practices provide only a partial picture of the HRM implementation process.

Obtaining insights into the dynamics of the HRM implementation process and the roles that various organisational actors play in it will deepen current insights in the field and provide opportunities on which researchers could build further. First, demonstrating that HRM implementation is neither unidirectional nor static, will add to the concept of HRM system strength (Bowen \& Ostroff, 2004; Nishii et al., 2008; Ostroff \& Bowen, 2016; Sanders \& Yang, 2016) and to the research on intended-actual-perceived gaps (Chow, 2012; Khilji \& Wang, 2006; Makhecha et al., 2016; Wright \& Nishii, 2013). Taking the dynamic nature of HRM practices into account will bring us closer to understanding the HRM implementation process and, hence, towards a smoother introduction of HRM practices into daily work routines. Second, by conceptualising and demonstrating the role of organisational actors such as senior managers, HRM professionals, line managers and employees, this dissertation adds to research into the HRM function (Beer, 1997; Valverde et al., 2006).

Finally, I argue that a distinctive conceptualisation of HRM implementation requires particular research methods. During the conceptualisation of the dynamics of the 
HRM implementation process, as well as the fieldwork related to it, it became clear that the process is too complex to focus merely on organisational - hence, internal - actors. For instance, external actors such as consultants, municipalities and recruitment agencies turned out to be involved in the implementation process as well. For that reason, in the penultimate chapter of this dissertation, I demonstrate the (potential) contribution that action research can make to the HRM scholarly discipline in aiming to understand the HRM implementation process. Action research (Lewin, 1946) is a research approach that aims to bridge the gap between academia and practice by endeavouring to solve practical problems through academic research. It goes beyond the practice of purely deductive or inductive research, and is based on the principle that research that is done without informing practice is wasted effort (Lewin, 1946). Rather than researchers going to organisations seeking permission to collect data to answer their research question, researchers in this tradition take on the role of academic consultants with the aim of solving an actual organisational problem or challenge through the use of academic literature and methods. Having contributed to solving the problem, this should lead to informing practice and academia. As such, HRM scholars could adopt the key premises of action research by doing research that is relevant for HRM practitioners but still contributes to the HRM literature. By making a plea for action-research-inspired HRM research, this dissertation aims to contribute to HRM theory development and bring it closer to practice (Beer, 2015, 2017; Kaufman, 2012). Thereby, I attempt to introduce HRM scholars to a different perspective for their research endeavours.

\subsection{PRACTICAL RELEVANCE}

Obtaining thorough insights into what happens during the process of implementing new HRM practices should prove valuable for HRM practitioners. The assumption that HRM practices evolve during the implementation process is of great importance when adopting new practices. If true, it would imply that better monitoring of top-down designed HRM implementation is necessary. It could be that HRM practices that do not lead to the expected results might simply need more time to become embedded in the daily routines of their users.

Also the question as to which roles various organisational actors play during this process is important for practitioners. For instance, the idea that employees play an active role in implementing HRM practices that have been adopted by their organisation to influence employee behaviour has implications for the organisation's decision-makers. This includes the need to involve employees to a greater extent when designing and adopting new HRM practices and monitoring their experience throughout the process. 
Another aspect that is relevant for practitioners is that a gap has long existed between the efforts and outputs of HRM scholars on the one hand, and the activities and interests of HRM practitioners on the other. As a result, neither party has been able to reap the full benefits of each other's efforts. Creating an environment in which action research is seen as a valid and powerful strategy for solving practical HRM-related issues, and providing guidelines for doing so, could prove valuable for HRM practitioners.

Finally, the empirical findings on which Chapters 3 and 4 are based are related to the policy to hire additional impaired workers and disadvantaged workers respectively. In Chapter 3, I assess episodes of a top-down implemented HRM practice, and this could help practitioners streamline and identify the progress of HRM implementations in their organisations. The decentralised implementation approach described in Chapter 4 has the potential to inform organisational decision-makers and HRM practitioners on ways to adopt new HRM policies without having to describe tasks and protocols in a detailed manner.

\subsection{DISSERTATION OUTLINE}

In working towards an answer to the overarching research question of this dissertation, I have presented four papers, reproduced here as four chapters. All of these papers, which were written with co-authors, contribute to answering the overall research question. In drawing the dissertation to a close, I pull the findings in these four chapters together, discuss their implications and offer conclusions. A schematic overview is given in Figure 3.

Chapter 2 reflects on the way that HRM practices evolve after their introduction and the roles that organisational actors play in this process. This conceptual study makes use of structuration theory (Giddens, 1984) to look at HRM implementation. It is theorised that an ongoing interaction between HRM practices and organisational actors is the basis of an anything but straightforward HRM implementation process. In this, HRM practices are influenced by organisational actors such as HRM professionals, managers and employees during a process in which the HRM practice needs to become legitimised by its users, become inscribed in their interpretive schemes, and appropriate resources distributed. The chapter provides a conceptual framework which portrays this dynamic HRM implementation process. As such, it provides a conceptual view of the three research problems addressed in this dissertation: the incomplete notion of HRM-as-a-process, the inaccurate unidirectional view of HRM implementation and the overly strict separation of the roles of organisational actors during this process. Furthermore, the chapter serves as a theoretical foundation on which the later chapters build.

Chapters 3 and 4 are based on empirical insights obtained during two periods of fieldwork in two Dutch organisations. The development of a new HRM practice stands 
central in Chapter 3. By following it from its earliest, most premature form, until the moment it was fully adopted in the organisation, this chapter demonstrates the mechanisms that contribute to the evolution of the HRM practice during its implementation process. By focusing on the evolution of HRM during its implementation process, this chapter addresses the first two research problems posed in this dissertation. The data used, which were obtained from a Dutch ministry, show that HRM practices are not finished when the decision is taken to adopt them, or when a manager initiates them. Rather, a non-linear process of adaptation and negotiation starts, involving a dynamic back-and-forth between policymakers, HRM professionals and managers. For my dissertation, it answers the question as to what the dynamics of the HRM implementation process look like in practice.

In Chapter 4, the focus shifts to the roles that organisational actors play in creating, developing and modifying recruitment and selection routines. This chapter, based on fieldwork at a Dutch cleaning company, looks at the way in which old routines are maintained or modified, and new routines created and incorporated. As such, this chapter provides insights into the roles that organisational actors fill during the HRM implementation process. The findings demonstrate that a decentralised bottom-up approach to implementing a new hiring process can lead to an interesting dynamic between HR managers, middle managers and first-line managers. In our study, this interaction led to a well-fitting and legitimised HRM practice that provided satisfactory outcomes for the company. For my overall dissertation, this chapter provides answers to the question as to what roles organisational actors play in the HRM implementation process.

In Chapter 5, I present and argue for action research as an intensive and legitimate strategy for research in the field of HRM implementation. As HRM implementation is a complex process, which involves several different internal and external actors, I argue in this chapter that a broader research approach could contribute to our understanding of the process. In action research, cooperation between researchers and practitioners is central to solving a real-life organisational challenge. This cooperative approach demonstrates the importance of recognising that are key phases of problem identification, designing possible solutions and then implementing them. In terms of my dissertation, this, in a sense, extends the dynamic framework presented in Chapter 2 by also creating a key role for researchers in the HRM implementation process. This chapter demonstrates that HRM implementation is not achieved by the organisation alone, or by external actors such as consultants, but that it is a process involving both internal and external actors. As such, it adds another layer to the spectrum of actors' contributions to HRM implementation. By adopting an action research approach, HRM researchers will be able to focus on novel and relevant problems, thereby advancing the field to a higher level by crossing the borders that have constrained HRM research in recent decades. 
Finally, in Chapter 6, I will draw this dissertation to a close by answering the overall research question and discussing the theoretical and practical contributions made. As part of this, I will assess this dissertation's limitations and offer suggestions for future research endeavours. 


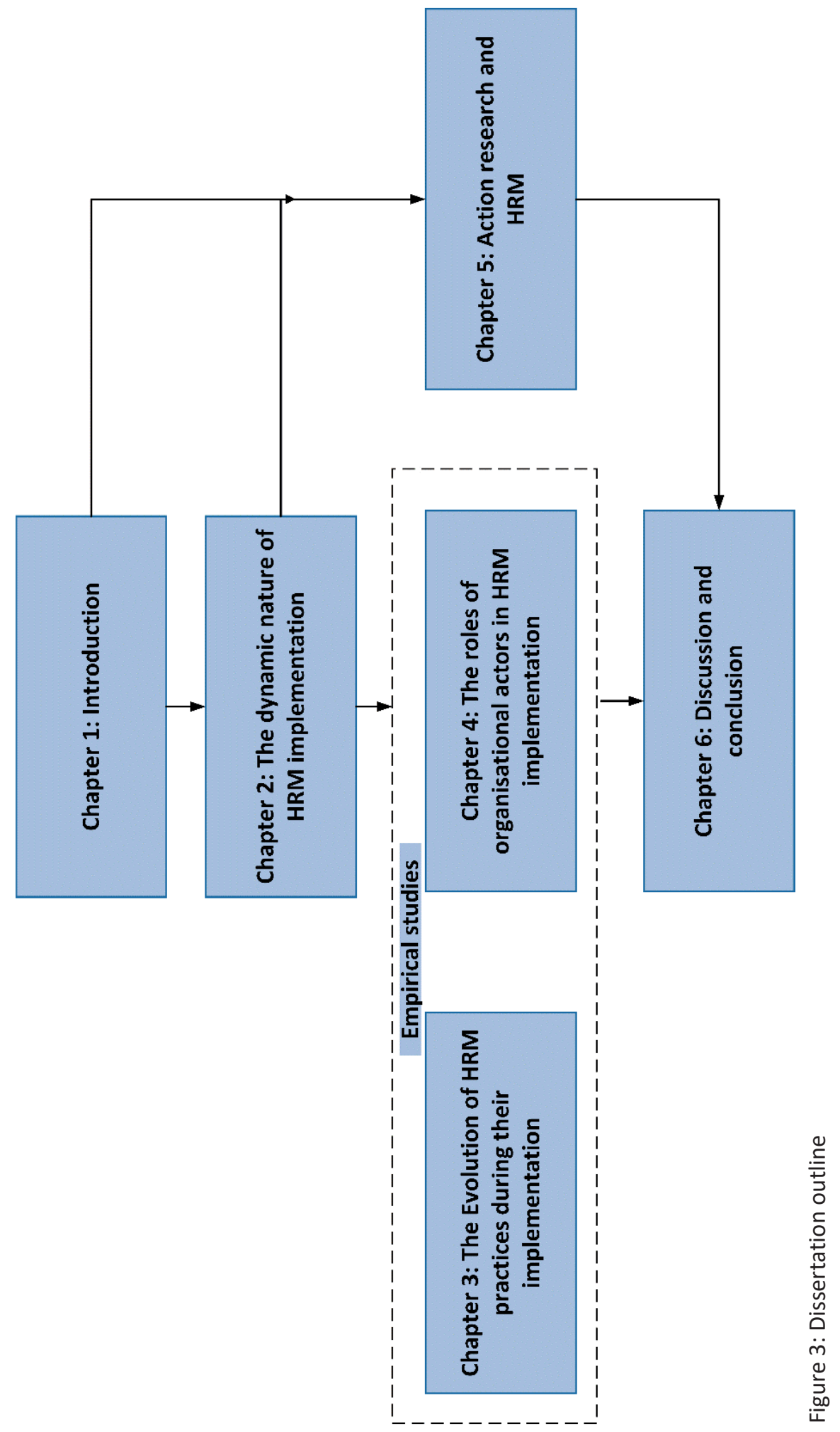




\section{CHAPTER 2}

\section{The dynamic nature of HRM implementation}

This chapter is focused on developing a conceptual framework that theorises the dynamics that take place during the HRM implementation process. Therefore, it provides insights into the current state of HRM implementation research and assesses areas that provide opportunities for further investigation. As such, this chapter serves as a basis for the rest of this dissertation and relates to the entire overall research question: 'What do the dynamics of the HRM implementation process look like, and which roles do organisational actors play in it?'

This chapter is based on Van Mierlo, J., Bondarouk, T., \& Sanders, K. (2018). The dynamic nature of HRM implementation: a structuration perspective. The International Journal of Human Resource Management, to appear in Vol. 29 no. 22, 2018. DOI: 10.1080/09585192.2018.1443957. 


\begin{abstract}
Over the past decades, scholars have dedicated substantial attention to HRM implementation. Most progress has been made with debates on HRM system strength, roles of organisational actors in HRM implementation, and intended, actual and perceived HRM. In this paper, we challenge the current view on HRM implementation as being too static and one-directional. By building on structuration theory (Giddens, 1984), we show that the process of HRM implementation is less straightforward than has been previously assumed. After their initial introduction, HRM practices evolve through turbulent developments. Furthermore, instead of neatly distributed roles following meticulously scheduled planning, HRM practices are influenced by various organisational actors. For successful implementation, HRM practices need to become inscribed into the interpretive schemes of organisational actors, resources have to be distributed, the HRM practice has to gain legitimacy. We develop a comprehensive framework that assists in understanding the process of HRM implementation.
\end{abstract}

Keywords: HRM implementation; HRM practices; HRM actors; structuration theory; HRM roles

\title{
2.1. INTRODUCTION
}

Since the turn of the century, a number of influential papers have laid the groundwork into Human Resource Management (HRM) as a process. Lately, this has embodied research into the implementation of HRM (Bowen \& Ostroff, 2004; Nishii et al., 2008; Ostroff \& Bowen, 2016; Purcell \& Hutchinson, 2007; Wright \& Nishii, 2013), which entails broadly the transition process during which HRM policies and practices develop from an idea or goal, into an institutionalised, functioning organisational instrument. We have observed three main foci in the academic study of HRM implementation; even though these are not always termed as such: (i) HRM system strength (Bowen \& Ostroff, 2004; Farndale \& Kelliher, 2013; Sanders \& Yang, 2016), (ii) intended, actual and perceived HRM (Bondarouk, Bos-Nehles, \& Hesselink, 2016; A. C. Bos-Nehles, Bondarouk, \& Labrenz, 2017; Khilji \& Wang, 2006; Makhecha et al., 2016; Nishii et al., 2008; Piening et al., 2014; Wright \& Nishii, 2013), (iii) roles of line managers in implementing HRM (A. C. Bos-Nehles, Bondarouk, \& Nijenhuis, 2017; Gilbert, De Winne, \& Sels, 2011; Op de Beeck, Wynen, \& Hondeghem, 2016; Purcell \& Hutchinson, 2007; Trullen, Stirpe, Bonache, \& Valverde, 2016; Vermeeren, 2014).

Researchers in these focus areas have different ideas about how to achieve 'successful' implementation of HRM. For instance, Bowen and Ostroff (2004) postulate that HRM implementation would be successful if employees perceived HRM to be distinctive, consistent, and had perceived a consensus among policy makers. Bondarouk, Looise and 
Lempsink (2009), in their turn, advocated for an alignment in understanding of HRM between line managers and HRM professionals, while Wright and Nishii (2013) suggested that, in order to implement HRM successfully, the gap between intended, actual and perceived HRM should be kept to a minimum. Meanwhile, Bos-Nehles et al. (2013) stated that it was necessary to get line managers committed to the HRM practice.

Thus far, HRM practices are seen as to travel along a one-way street that is designed in the HRM department and aligned with the strategy, and applied top-down to achieve outcomes, such as commitment or organisational performance (Delery \& Doty, 1996; Huselid, 1995; Jiang, Lepak, Hu, \& Baer, 2012; Lepak \& Snell, 2002). Also, HRM implementation is considered to be a rational process with predictable and analysable complications. The assumption here is that these complications can even be overcome or avoided if HRM is designed and managed correctly. An example of this is Wright and Nishii's (2013) suggestion that making the gap between actual and perceived HRM as small as possible, by providing 'social information' from the start of introducing a new HRM practice, would enhance its implementation process.

We recognise the importance and convenience of many of the explanations and solutions offered by HRM researchers so far, which have led to many valuable insights into HRM implementation. However, the view on HRM implementation remains one-sided and static. Moreover, it does not follow the dynamics of HRM implementation, nor interactions between organisational actors and HRM. Therefore, we know only little about what happens during the process of HRM implementation, making it hard to understand and explain why implementation gaps occur. Moreover, the question remains in what way perceptions of different groups of organisational actors like HRM professionals, top managers and line managers, but also employees on the shop floor influence each other and how such a ravel of idiosyncratic perceptions, in the end, impacts the HRM implementation process. To summarise, scholars have failed to provide an accurate overview of the dynamics of HRM implementation.

Therefore, in this paper, we aim to conceptualise the HRM implementation process by considering the interaction between HRM systems, employees and organisational context. We theorise a continuous interplay between organisational actors' behaviour and their interpretation of HRM, an evolution of characteristics of HRM systems, and the dynamics of contextual factors and resources in HRM implementation. By a continuous interplay we mean a recursive process, where HRM practices, organisational actors like line managers, employees and HRM professionals, and the organisational context mutually influence each other, and gradually reach a stable phase characterised by a success of HRM implementation. Hence, after sending an HRM message, a recursive process starts, which 
emerges bottom-up from message receivers, feeding back towards the HRM message senders and, thereby, influences the HRM practice. We argue that HRM practices could be considered as though they are live entities that have their own dynamics and keep developing after their introduction. By taking the dynamic nature of HRM practices into account, this provides us with insights into understanding the HRM implementation process and, hence, facilitates a smoother introduction of HRM practices into daily work routines.

To conceptualise HRM implementation in this way, we build on structuration theory (Giddens, 1984) which serves as a lens through which we analyse the process of HRM implementation. The main premise of structuration theory is that a continuous interplay exists between structure and action. In this paper, we present a novel model on the HRM implementation process by assessing the nonlinear reciprocal and recursive nature of the HRM implementation process, and the interplay between HRM systems, all groups of employees, and organisational context and resources. This approach differs from extant research and insights into HRM implementation.

Therewith, we contribute to the knowledge about the HRM implementation process in three ways. Firstly, by uncovering the dynamics of the HRM implementation process we add to the HRM-as-a-process debate (Bowen \& Ostroff, 2004; Ostroff \& Bowen, 2016). Secondly, by revealing organisational actors' roles we extend the literature on the role of not only line managers (Gilbert et al., 2011; Guest \& Bos-Nehles, 2013; Nehles et al., 2006; Trullen et al., 2016), but also of the broader HRM function (Beer, 1997; Valverde et al., 2006). Finally, by demonstrating the process through which new behaviour becomes incorporated within organisations we contribute to insights in the intended-actualperceived HRM debate (Khilji \& Wang, 2006; Makhecha et al., 2016; Piening et al., 2014; Wright \& Nishii, 2013).

In the remainder of this article we first look back at scholarly insights into HRM implementation thus far and then we summarise the main ideas of structuration theory (Giddens, 1984). Subsequently, we present and explain our dynamic view on HRM implementation along with our framework.

\subsection{HRM IMPLEMENTATION}

Scholars in the field of HRM implementation broadly focus on three topics. First, the stream of HRM system strength (Bowen \& Ostroff, 2004; Ostroff \& Bowen, 2016) is characterised by studies in which HRM practices or HRM systems are distinctive and consistent, and where consensus between policy makers exists (Sanders et al., 2014). Influential studies in this stream are those of Delmotte, De Winne and Sels (2012), Sanders, Dorenbosch and De Reuver (2008) Li, Frenkel and Sanders (2011), Nishii, Lepak and Schneider (2008), and Bednall, Sanders and Runhaar (2014). A second stream of HRM implementation researchers 
study the difference between HRM (practices or systems) as intended and the way it is actually applied, along with the way organisational members (most often employees) perceive it. Leading studies in this stream are those of Wright and Nishii (2013), Khilji and Wang (2006), and Woodrow and Guest (2014). A third group of HRM implementation researchers focus more on the roles of organisational actors in implementing HRM; particularly on the contribution of line managers. Examples of such studies include Purcell and Hutchinson (2007) and Bos-Nehles, Van Riemsdijk and Looise (2013).

Even though HRM scholars generally coincide in their view that HRM implementation does involve a process, they have not settled yet on what this process exactly comprises of. For instance, HRM implementation is seen as actual and perceived HRM practices (Nishii et al., 2008), the translation of intended into actual practices (Khilji \& Wang, 2006), or intended, implemented and perceived HRM practices (Makhecha et al., 2016; Piening et al., 2014; Purcell \& Hutchinson, 2007; Wright \& Nishii, 2013). Other scholars view it more broadly and mention the design of HRM practices and policies as an essential part of HRM implementation (Guest \& Bos-Nehles, 2013; Woodrow \& Guest, 2014). Furthermore, perspectives differ on what HRM implementation comprises and which tasks are to be included in the concept. When HRM implementation refers to the translation of intended to actual HRM practices, line managers are seen as the key actors (Boselie, Dietz, \& Boon, 2005; Brewster et al., 2013; Geare, Edgar, \& Deng, 2006; Wright \& Nishii, 2013). However, when it is viewed as a multi-staged process, senior executives and HR managers are included in the framework (Guest \& Bos-Nehles, 2013).

Even though we acknowledge the effort done by scholars in the field of HRM implementation research, we consider the above-mentioned conceptualisations of HRM implementation to be insufficient. Furthermore, a literature review has shown that HRM scholars often write about HRM implementation, but rarely define it (e.g. Boselie et al., 2005; Guest \& Bos-Nehles, 2013; Runhaar \& Sanders, 2013; Woodrow \& Guest, 2014; Wright \& Nishii, 2013). Therefore, at the outset of building our model, we provide a definition of HRM implementation. We borrow ideas from the study into innovation implementation by Klein and Sorra (1996), and define HRM implementation as: the process of gaining targeted employees' appropriate, committed, and skilful use of an HRM practice, aligned with the corporate strategy.

\subsection{STRUCTURATION THEORY AND ITS APPLICATIONS IN HRM RESEARCH}

The key principles of structuration theory (Giddens, 1984) inspired us to develop a dynamic view of the process of HRM implementation. The main objective of structuration theory is to explain the way in which social systems are produced and reproduced over time and 
space. Giddens (1984) theorised that a duality of structure exists: a continuous interaction between structure and action, which lies at the basis of the production and reproduction of any social organisation. This means that social systems do not exist merely because of structure or action, but because of the interaction between them: 'structure is both medium and outcome of the reproduction of practices' (Giddens, 1979, p. 5). Therefore, structure and action are not independent of each other: "We cannot take action without operation within structures and without producing and reproducing them" (Feldman, 2015, p. 322).

Given that structure does not exist without action, and the other way around, structure influences the behaviour of actors, who, in their turn, recursively produce and reproduce that very structure (Jones \& Karsten, 2008). Giddens also states that structure is not something physical, but merely exists "as memory traces orienting the conduct of knowledgeable human agents" (Giddens, 1984, p. 17). As a consequence, actors are constantly influencing the structure that enables and constrains their actions. If actors behave according to the rules of the structure, they reinforce it, but if they routinely (Jarzabkowski, 2008) move outside of those rules, they modify the structure. If actors do not make use of a structure at all, Giddens (1984) explains, the structure is virtually nonexistent, because it does not influence their behaviour.

According to Giddens (1984), structure consists of rules and resources. Rules define the boundaries of behaviour, and resources can be either allocative (materials) or authoritative (over people). Structure limits behaviour, even though, at the same time, actors can move freely within those boundaries. Therefore, rules and resources both constrain and enable action. Giddens (1984) identifies three dimensions of structure: signification, domination and legitimation. These are transformed into action by three socalled 'modalities': interpretive schemes, facilities and norms.

Interpretive schemes are 'the modes of typification incorporated within actors' stocks of knowledge, applied reflexively in the sustaining of communication' (Giddens, 1984 , p. 29). Actors utilise their interpretive schemes to make sense of both their own actions and those of others (Walsham \& Han, 1990). Interpretive schemes consist of information that they have learned beforehand. Examples in a work setting are: specific organisational terms and names of colleagues. Facilities are authoritative (to have the capacity to give commands to other actors, (Giddens, 1984)), or allocative (over objects and materials, (Jones \& Karsten, 2008)). Norms are "tacitly understood moral imperatives" (Jarzabkowski, 2008, p. 623). Therefore, norms give a sense of direction in daily life. They inform us what is acceptable and what is not. In interaction, actors draw upon these modalities and transform them into communication, power and sanctions (J. H. Turner, 1986). Even though the modalities were presented here separately, and will be applied in separate steps later in the paper, they have only been separated for analytical purposes. In 
real life, the modalities are interconnected and function at the same instance (Giddens, 1984).

Despite the fact that structuration theory was not specifically designed for the field of management studies, it has helped numerous scholars in their empirical studies to provide more insight in complex situation. For instance, Jones and Karsten (2008) found that structuration theory had until 2004 inspired scholars in more than 330 studies in the field of information systems. Furthermore, exemplary empirical studies using Giddens' thoughts have been published in top-tier journals: Barley (1986), Orlikowski (2000), Jarzabkowski (2008).

HRM scholars have made use of structuration theory to a lesser extent, and their attempts - although very insightful - stay fragmented. Kroon and Paauwe (2014) used structuration theory as a lens to analyse why some agricultural companies make use of what they term 'precarious employment conditions', while others have more socially responsible policies. The authors used elements of structuration theory to explain why certain employment aspects remain over time, while others did not. By using structuration theory, they were able to identify structural properties of the agricultural sector, such as collective work permits, or seasonal labour conditions, which support organisations in adopting and maintaining precarious employment conditions, or hampers them from adopting socially responsible employment conditions. They also identified structural properties, such as good employer projects, and collective initiatives to improve working conditions, which can serve as a mediator towards more socially responsible employment relations. In another study, Meijerink (2014) used elements of structuration theory to theorise how employees enact the employee-organisation relationship. Since structuration theory explains that structure only exists in the behaviour of individuals, according to Meijerink (2014), employeeorganisation relationships only structure employees' day-to-day activities if they emerge from the recurrent actions of employees and managers. Festing and Maletzky (2011) used structuration theory to analyse how change in interaction between leaders and subordinates comes about, and to design a multilevel framework depicting the leadership adjustment process. Elements of structuration theory (Giddens, 1984), such as its modalities, and the interaction between them, allowed the authors to theorise the process of adjustment and add to the HRM stream of cross-cultural adjustment. In another paper, Björkman, Ehrnrooth, Mäkelä, Smale and Sumelius (2014) adopted a practice-based perspective - the stream of sociological thought to which structuration theory belongs - to conceptualise how HRM literature could benefit from adopting a practice-based perspective. The authors demonstrated that, by focusing on intersections between practitioners, HRM practices and praxis (behaviour), researchers could advance knowledge 
about both the HRM-performance stream and the HRM function. Earlier, (Bondarouk \& Ruël, 2009) applied structuration theory to the HRM field. Their study helped us to understand that the transformation into information technology-enabled HRM services is not merely a process of designing and applying, but " $a$ dynamic process in which stakeholders frame and reframe their perceptions and, thus, actually construct the transformation of the HRM function" (2009b, p. 273). Finally, Ostroff and Bowen (2016) suggested that (adaptive) structuration theory (DeSanctis \& Poole, 1994) could shed light on the concept of climate strength by demonstrating how groups of employees differ in their perceptions on the climate.

The examples above clearly show that structuration theory has already informed HRM scholars to some extent. Previous HRM-structuration theory studies have mainly focused on individual HRM practices and HRM policies (Festing \& Maletzky, 2011; Kroon \& Paauwe, 2014; Meijerink, 2014). However, the main strength of structuration theory is to explain the dynamic interplay between structure and action, and how they maintain and modify recursively. Therefore, by theorising a dynamic interplay between HRM systems, context, and organisational actors, we move this tradition further, and enrich the literature on HRM implementation.

\subsection{A DYNAMIC VIEW ON HRM}

In this section, we analyse what we see when we look at the HRM implementation process through the lens of structuration theory. The framework (Figure 4) we present in this paper focuses not merely on either HRM professionals (Rynes, Colbert, \& Brown, 2002), managers (Nehles et al., 2006; Op de Beeck et al., 2016), or employees (Bowen \& Ostroff, 2004; Nishii et al., 2008), but on the role of all organisational actors (managers at several organisational levels, HRM professionals, employees) at different hierarchical and functional levels. A manager can be the communicator of the HRM practice, as well as the receiver of the HRM messages. Similarly, an HRM professional can be a receiver of an HRM message sent by top managers, as well as the communicator to line managers. 


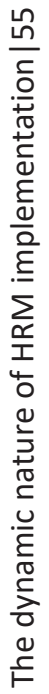

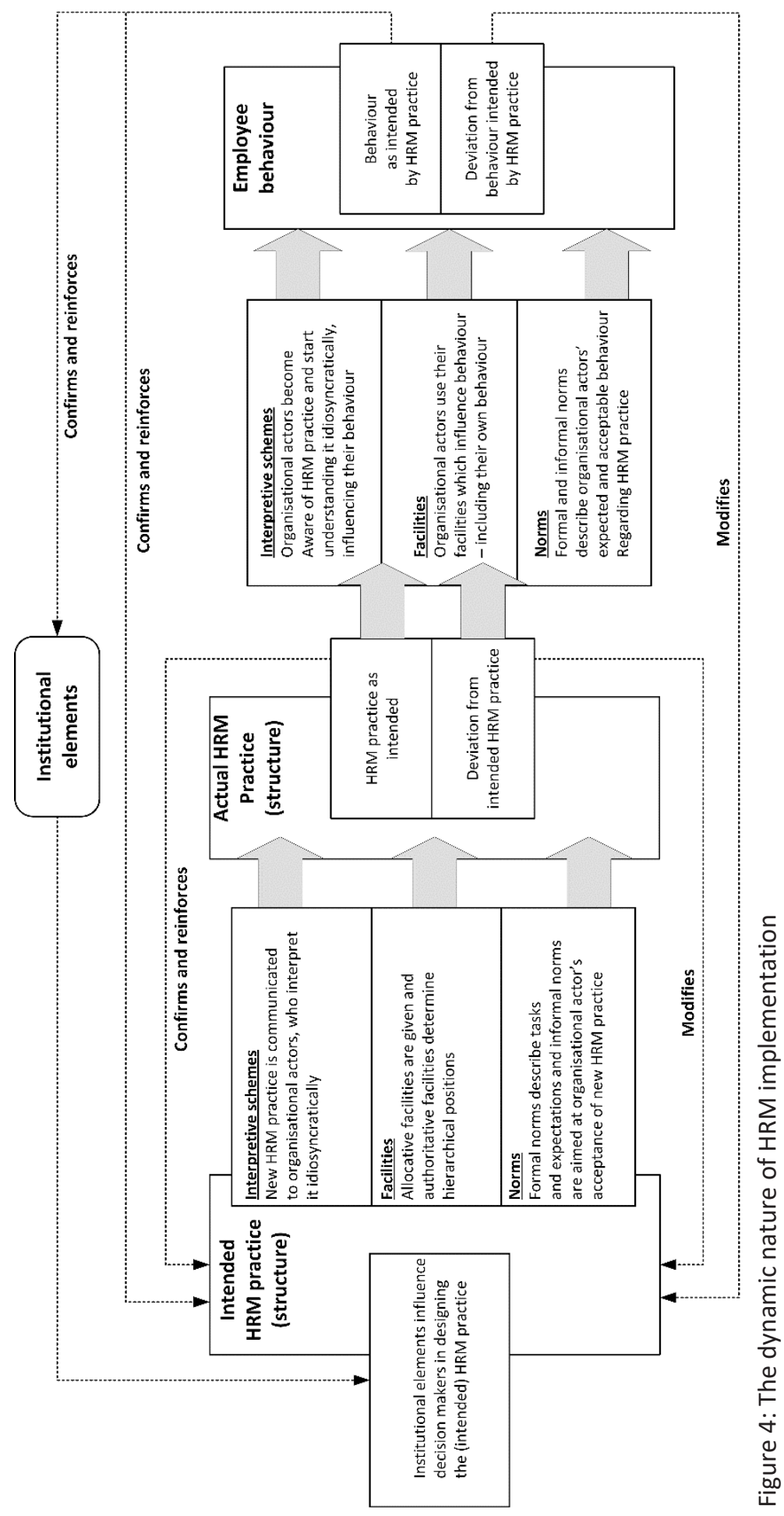


Starting from the premise that HRM practices consist of rules aimed at influencing employee behaviour, we consider HRM practices as a structure in Giddens' sense. Therefore, by looking through the lens of structuration theory (Giddens, 1984), we consider a continuous process in which HRM practices and behaviour recursively and continuously influence each other. During that process, HRM practices influence the behaviour of organisational actors in two ways: by constraining and by enabling. The rules of HRM practices, demarcating behavioural boundaries, inherently constrain behaviour. However, within those rules, a certain degree of freedom exists, allowing the actor to fill in his or her role with some discretion. Therefore, the behavioural guidelines of HRM practices do not only constrain, but also enable organisational actors during their work routines. Recursively, organisational actors influence the HRM practices to which they are exposed during their work routine by behaving within or outside of the behavioural boundaries of those HRM practices.

We have visualised this process in Figure 5. It demonstrates a continuous interaction between structural aspects of the HRM practice (rules and resources) and behaviour of organisational actors. Broadly, each cycle can be seen as one 'round' of the process depicted in Figure 4. Consequently, in Figure 5, we show that the HRM practice influences the behaviour of organisational actors, but also that it is influenced vice versa. Over time, both the HRM practice and the behaviour become more and more a mixed outcome of each other.

As stated earlier, more organisational actors are involved in the HRM implementation process than is assumed in existing HRM literature. Hence, not only HRM professionals design and line managers implement novel HRM practices, but HRM professionals or top managers do this as well. In designing new HRM practices, decisionmakers are bounded by internal and external institutional elements. Examples of these are labour regulations. Depending on the organisation, the design of HRM practices can be the task of HRM professionals or top managers, but also line managers and end users. Examples of the latter are national government institutions in which new HRM practices are first discussed extensively through many organisational layers before introducing them (Van Mierlo \& Bondarouk, 2017). Top managers and HRM professionals are also often the organisational actors who take the decision to implement a new HRM practice or not (Guest \& Bos-Nehles, 2013; Valverde et al., 2006). Therefore, their contributions in the first two stages of HRM implementation (the idea of a new HRM practice and its design) are significant. After a decision has been taken to create a new HRM practice and it has been designed, people responsible for administering it to the end users will be informed about this. In most organisations, this task is given to line managers (Guest, 1987; Guest \& BosNehles, 2013; Valverde et al., 2006). 


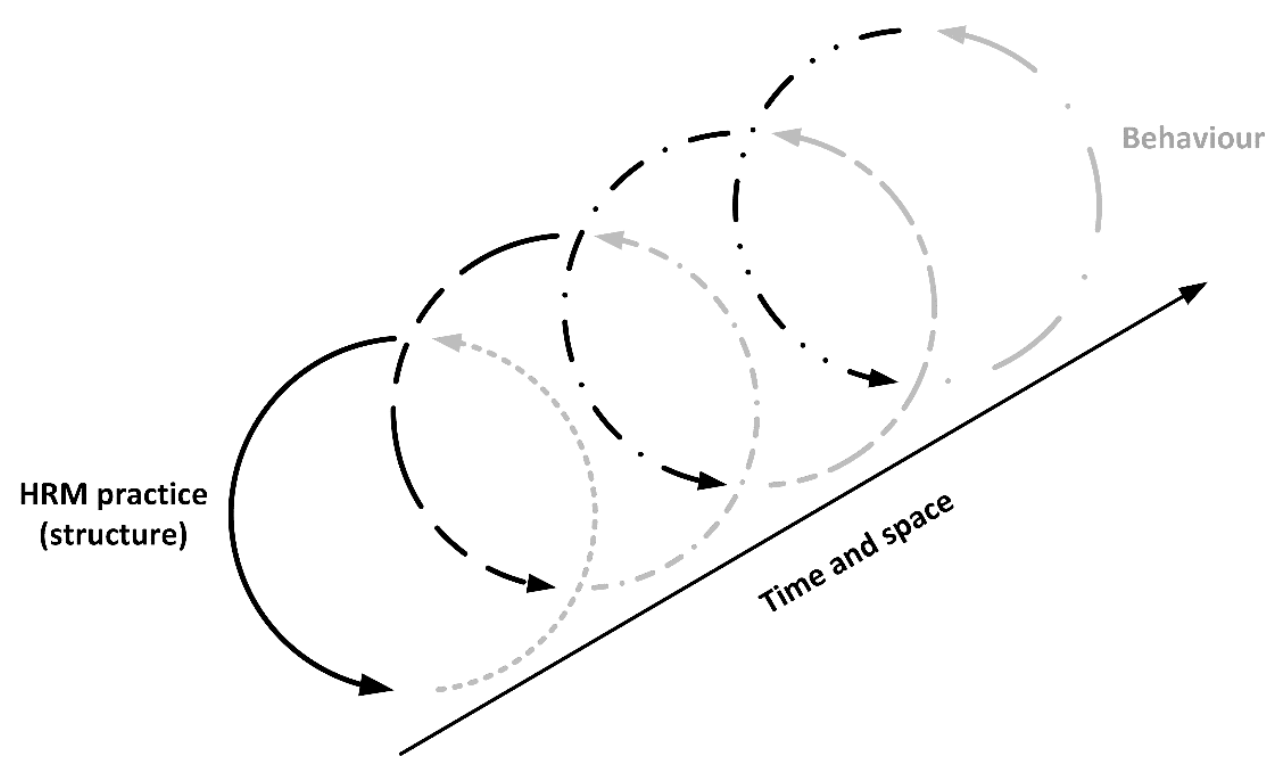

Figure 5: The continuous interaction between HRM practice and behaviour over time

Managers function as the sender of HRM practices (Bowen \& Ostroff, 2004; Wright \& Nishii, 2013), but also as the receiver, since they have to understand it and become familiar with it. HRM professionals will inform the managers about the newly designed HRM practice, which managers will filter through their interpretive schemes. Their understanding of the HRM practice will further influence the way in which they will shape and deliver the practice to their employees. As theorised by Guest and Bos-Nehles (2013), the quality provided by managers while delivering HRM practices plays an important role in the final success of their implementation. Also, allocative facilities - money and other means to finance the new HRM practice - are provided to managers, while authoritative facilities explain the hierarchy for the HRM practice and who reports to whom. Formal norms explain tasks, responsibilities and expected behaviour, while informal norms inform managers about that behaviour which is seen as acceptable within the organisation and among colleagues. HRM professionals are tasked with informing the managers about the importance of the new HRM practice and solve or counter their objections. As mentioned earlier, even though these modalities were discussed separately, they were only separated for analytical purposes, as they are entwined in real-life.

Applying the HRM practice to employees - its actual introduction - is also portrayed in the framework by means of Giddens' (1984) three modalities. Firstly, the manager introduces the HRM practice by communicating the new set of rules to employees, 
which the employees filter through their interpretive schemes, making sense of the message (Bowen \& Ostroff, 2004). Also, the way employees understand and perceive the HRM practice will affect its implementation. For instance, employees can accept a new HRM practice as some bureaucratic ritual and 'tick the box' after performing it (Guest \& BosNehles, 2013), or actively contribute to its development (Meijerink, Bondarouk, \& Lepak, 2016). Secondly, authoritative facilities, in the shape of the manager's higher hierarchical organisational position, give a certain degree of power over the employees. For example, the manager can give a negative evaluation during the appraisal talk and, therefore, decide not to give a bonus, or to reject a leave of absence request. Allocative facilities can be the means to finance, for example, employee training. Thirdly, norms inform the employees that orders from their superiors should (informal norms) and must (formal norms) be followed to provide a moral order within the organisation (Orlikowski, 1992). Through these three steps, the behaviour of employees is influenced.

Following the structuration framework, we identify two possible courses of action that follow from the process described in the previous section. One possibility is that employees behave according to guidelines of the new HRM practice. Thereby, employees are reinforcing the HRM practice. More specifically, we consider this to recursively influence the actual HRM practice. This is because managers see that their - possibly deviant approach is working. As a result, managers will stick to their approach. Over time, the manager's approach can become a best-practice within the organisation. Conversely, if the manager's approach deviates from the originally intended HRM practice, this might eventually modify the design of the HRM practice.

In reality, this process is often less straightforward. For instance, communication difficulties could distort the message sent from manager to employee (Bowen \& Ostroff, 2004; Den Hartog et al., 2013). Another possibility is that, even though the manager occupies a higher hierarchical position (hence possesses authoritative facilities), in practice, he or she is not able to convert these facilities into actual power or leverage. Therefore, the employees may overrule or ignore their manager. After all, not only superiors, such as managers and HRM professionals have facilities, but employees too, because of their ability to act according to the rules of the HRM practice, or to deviate from them. Hence, if employees ignore the HRM practice, it does not exert any influence over their work routine and, thus, can be considered non-existent. Therefore, employees will always possess a certain level of freedom, which they can use to undermine and even modify the existing structure of domination (Orlikowski, 1992). Even so, managers will adopt their approach to find out what works. In this stage, newly implemented HRM practices are in the stage of trial-and-error, instead of execution according to a detailed step-by-step plan. 
At this phase, HRM professionals have the task to monitor the progress of implementation of the new HRM practice. In case the implementation of the intended HRM practice does not work as scheduled, decision-makers, such as top managers and HRM professionals, might respond by modifying the intended HRM practice to provoke a desired behavioural reaction from managers and employees. Therefore, through their work routines, employees recursively influence the intended HRM practices they are exposed to during their daily jobs. Also, the behaviour of line managers influences the shape of the HRM practice. It enhances their role from merely being the executor of HRM, towards a more active participant in the HRM implementation process.

If behaviour becomes routine, this eventually becomes institutionalised; meaning that people within the organisation behave in that way unconsciously (Giddens, 1984). The institutional elements of organisations contain organisational structures that are taken for granted by most organisational actors and they are consciously aware of. Since institutionalised structures are used unconsciously, they can be considered to be concrete, although still modifiable (Battilana, Leca, \& Boxenbaum, 2009) and observable (Lammers \& Barbour, 2006). Consequently, the behaviour of organisational actors, such as managers and employees, might eventually become institutionalised.

\subsection{HRM IMPLEMENTATION: A NEVER-ENDING PROCESS?}

The process described thus far has theorised the way in which HRM practices evolve after their initial design. During that process, HRM practices can influence the behaviour of organisational actors, who can recursively contribute to the evolution of those HRM practices. Subsequently, we theorised how policy makers might adapt the rules of HRM practices to the behaviour of organisational actors. However, this raises the question: at what point does an HRM practice become stable?

We argue that HRM practices never completely finish evolving. As we discussed above, even institutionalised elements of organisations can be modified (Battilana et al., 2009). Furthermore, from routine dynamics literature, we know that even the most internalised and stable routines can change from one instance to the next (Feldman, 2015). However, after a period of turbulence and modifications, structures do become more stable. This is what we term the structuration process: an epoch during which structures are being undermined by actors whose behaviour influences the shape - or rather shaping - of the structure. New structures will provoke unanticipated behaviour because of misunderstandings, contradictions in its design, incorrectly distributed facilities, or different opinions regarding its usefulness. 
Therefore, we claim that an HRM practice becomes stable once it has become inscribed into the interpretive schemes of its users, facilities have been appropriately distributed, and it is perceived as legitimate by all organisational actors (Taylor et al., 2001). In other words, organisational actors have to become aware of the rules of the HRM practice and understand them, acknowledge and obey the roles of the HRM function ('who does what?'), and perceive the HRM practice as legitimate. Hence, an HRM practice becomes stable when it is accepted, legitimised and inscribed in the mental frames of all organisational actors. This process portrays the complexities of the HRM implementation process.

\subsection{DISCUSSION}

Throughout this paper, we have claimed that the HRM literature can profit from a more dynamic perspective on the HRM implementation process. As the term implies, it is a process. Therefore, it inherently involves a variety of people, planning, evaluation, and inevitably setbacks. Yet, HRM scholars have not paid attention to this, thereby limiting the conciseness of the existing view on the HRM implementation process. Gratton and Truss (2003) have demonstrated that it is not only necessary that coherence exists between business goals, the HRM strategy, and HRM policies, but also that those policies - in the shape of HRM practices - actually have to be put into action.

This paper contributes to scholarly knowledge about the HRM implementation process in three ways. Our first contribution is that we, by adopting a structuration theory (Giddens, 1984) perspective, have added to the HRM-as-a-process (Bowen \& Ostroff, 2004) and intended-actual-perceived HRM (Wright \& Nishii, 2013) debates by focusing, not only on the design, implementation and perception of HRM practices, but also by theorising what happens to HRM practices after those preliminary steps. We argue that by taking HRM implementation further than looking for gaps between intended, actual, and perceived HRM, we have been able to create a more realistic view on HRM implementation. Practitioners can use these insights when implementing novel HRM practices by continuing to monitor the state of the implemented HRM practice, also after it has been administered and transferred to their employees. Structuration theory has played a key role in these insights, and - to our knowledge - no other theories consider this dynamic interplay. Some other concepts come close to examine certain aspects of HRM implementation, but they fall short to integrate the total complexity and dynamism of all aspects of HRM implementation. For instance, using a practice lens (e.g. Cetina, Schatzki, \& Von Savigny, 2005) would have been useful to analyse the role actors play in the implementation process, but it would fail to show the way in which structure influences actors' behaviour in the process. On the other hand, a functionalist approach, like institutional theory (Scott, 2005) 
would have underplayed the role of organisational actors, leading to the one-sighted view on HRM implementation that was common in HRM research before Bowen and Ostroff's (2004) influential paper. Structuration theory on the other hand, incorporates both structural forces and actions and, hence, has been able to demonstrate the dynamic process of HRM implementation.

The second contribution that this paper makes is by theorising the roles organisational actors play in the implementation process of HRM, we have provided more accurate insights into the HRM function (Beer, 1997; Guest, 1987; Valverde et al., 2006). Analytically, structuration theory looks at all actors equally, and does not distinguish between top manager, HRM professional, higher-, middle-, or first-line manager, or employee. Rather, structuration theory looks at what actors do, instead of their duties in the HRM implementation process. We acknowledge that organisational actors have certain tasks and responsibilities while implementing new HRM practices but, as we have attempted to demonstrate with this paper, those tasks and responsibilities are less demarcated, and more diffuse and dynamic than merely the actor's task description. We state that especially is this period, in which a lot of attention exists for topics like co-creation (Meijerink et al., 2016), job crafting (Wrzesniewski \& Dutton, 2001), and I-deals (Rousseau, 2005), it is important to look at contribution of all organisational actors in the HRM implementation process. Practitioners can use these insights to take into consideration when implementing HRM practices through a bottom-up approach, in which most policy concerning HRM practices is created in situ.

Finally, the notion that all managers interpret and understand new HRM practices idiosyncratically, truly adds to explaining the implementation gap (Piening et al., 2014). However, not only do managers have different objectives and goals (Nehles et al., 2006), they also understand the HRM practice differently from the way it was intended and designed by the HRM department (and possibly higher management). This adds to the line of research of Bowen and Ostroff $(2004 ; 2016)$ in the sense that not only employees perceive and interpret HRM, but managers and other organisational actors as well.

\subsection{LIMITATIONS AND FUTURE RESEARCH}

Although this paper has provided new perspectives on the nature of HRM practices and HRM implementation, it also has its limitations. These limitations can serve as a basis for future research. We are aware that structuration theory has, throughout its existence, been criticised for being difficult to operationalise to obtain empirical results. Even so, many authors have been able to publish empirical papers based on structuration theory (for an overview, see Jones and Karsten (2008)). 
For operationalisation's sake, it is not necessary to apply structuration theory in full. As Giddens (1984, pp. 326-327) argues, structuration theory is rather meant to guide researchers in their endeavour: "The concepts of structuration theory, as with any competing theoretical perspective, should, for many research purposes, be regarded as sensitizing devices, nothing more. That is to say, they may be useful for thinking about research problems and the interpretation of research results". Moreover, Giddens states "I like least those works in which authors have attempted to import structuration theory in toto into their given area of study" and that he rather sees studies "in which concepts, either from the logical framework of structuration theory, or other aspects of my writings, are used in a sparing and critical fashion" (1991, p. 213). As a consequence, in numerous studies, elements of structuration theory have been applied. Examples include Barley (1986) who focused on the recursive interaction between structure and (inter)action in radiology departments, while Orlikowski (2000) focused more on Giddens' modalities in studying the usage of technology in organisations. Therefore, the elements that are most useful depend on the focal point of the study at hand. If the goal is to study dynamics - like is the case in this paper - then structure and action (and its modalities which demonstrate it) are the most useful. On the other hand, a researcher who wants to study processes in which actors make sense of their world might opt to incorporate Giddens' thoughts on knowledgeability and consciousness. Therefore, we issue a call for further exploration of operationalisation possibilities of the structuration-based constructs for HRM implementation. A second limitation is that the danger exists that we have turned a relatively young field - HRM implementation - into an overly complex concept. Indeed, it is always possible to study HRM implementation in more detail, including more different organisational actors, and actors external to the organisation (e.g. consultants and clients) as well. We did not intent to overcomplicate HRM implementation. However, in order to grasp the full complexity of the HRM implementation process, we feel that we needed to take a step further than HRM scholars have done thus far.

The above-mentioned limitations provide many opportunities for future research. Firstly, empirical papers could be valuable in obtaining knowledge on the evolution of HRM practices and HRM implementation. Woodrow and Guest (2014) demonstrated that a case study approach can provide great insights into the HRM implementation process and reveal events that would remain unknown with a more quantitative approach. Hence, following their recommendations, we suggest scholars interested in HRM implementation consider a case study approach when designing empirical studies. As Feldman and Orlikowski (Feldman \& Orlikowski, 2011, p. 1248) put so fittingly: "In the box-and-arrow figures so prevalent in organization theory, the boxes are always labeled, whereas the arrows are often unadorned by any text, as if they speak for themselves". More than quantitative studies, case studies 
are able to open these arrows leading from one variable to another, instead of merely showing correlations between them. The outcomes of such research could possibly be used for a qualitative comparative analysis (QCA). Moreover, uncovering possible mechanisms leading from one phase of our framework (Figure 1) to another would provide great insights into what triggers the dynamic nature of HRM implementation. Studies applying techniques, such as process tracing, could test the hypothesised mechanisms subsequently.

Researchers might also be inspired to empirically study the dynamics of the roles of organisational actors during HRM implementation. We feel providing results to our claims, can both strengthen our claims and support practitioners while implementing novel HRM practices.

\subsection{CONCLUSIONS}

To conclude, an HRM practice is finished, neither when the HRM department gives the 'green light' decision, nor when a manager introduces it. Instead, HRM practices need to go through the entire HRM implementation process as described in this paper in order to become inscribed in the mental framework of all the relevant organisational actors. Furthermore, facilities have to be distributed properly, and the HRM practice has to become perceived as legitimate. Precisely because of the large number of organisational actors involved in this process, the risk of communication difficulties, conflicting interests, the (un)willingness to co-operate, and unforeseen setbacks, can lead to unexpected consequences that can prevent the HRM practice from achieving its desired effects. Even if these setbacks turn out to be very small or absent, newly introduced HRM practices still have to become internalised. Often, this process will involve much frustration and negotiation.

We finalise by stating that, even though the HRM department most often designs HRM practices, they come alive at employee-level. To make the HRM implementation process successful, it is necessary to pay attention to the understandings and desires of employees, and then see how the implementation process gradually works its way up into the organisation. 



\section{CHAPTER 3}

\section{The evolution of HRM practices during their implementation}

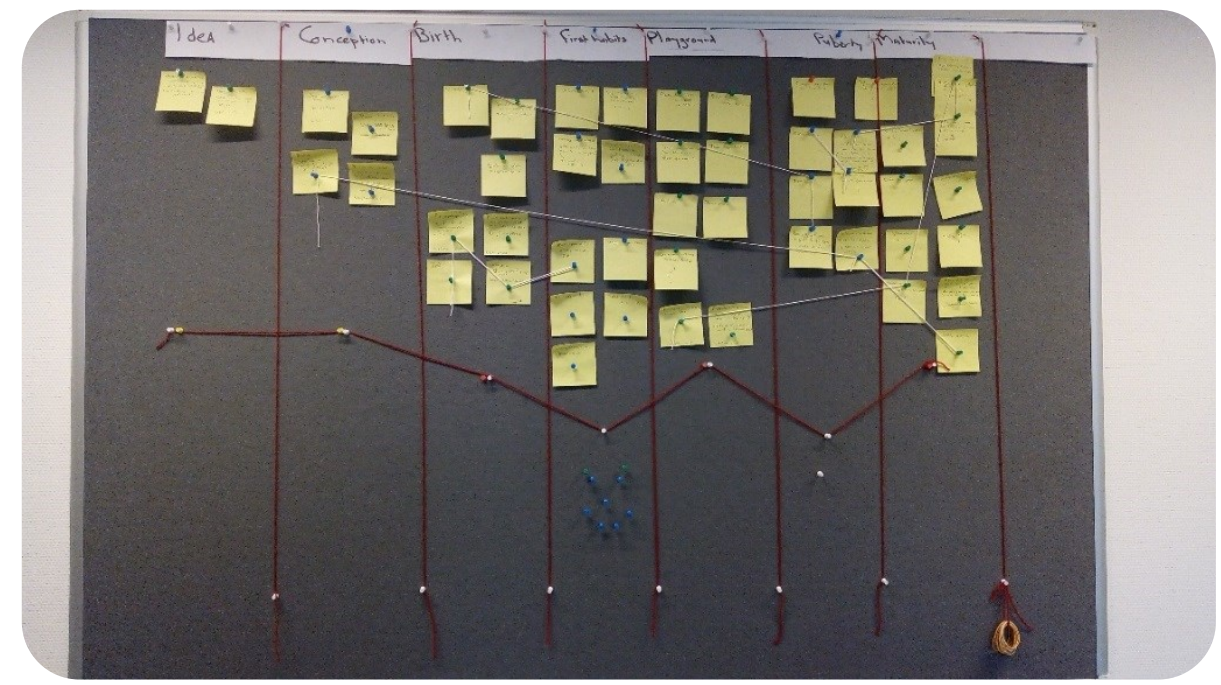

The objective in this chapter is to study the HRM implementation process from a practice perspective. Hence, the focus is on the way in which HRM practices themselves develop during the implementation process. This chapter builds on key insights from the previous chapter by taking the dynamic nature of HRM implementation into account. During the implementation process, several 'episodes' are visible and, rather than merely focusing on the characteristics of those episodes, a large part of the focus is on the mechanisms that connect one episode to another. Therefore, it contributes to the first part of my research question: 'What do the dynamics of the HRM implementation process look like?' 


\begin{abstract}
The goal of this chapter is to uncover the mechanisms of HRM implementation in a real-life context. We do this by studying the process during which HRM practices develop over time. Results were obtained through a longitudinal ethnographic case study at a Dutch ministry. During this case study, which lasted more than one year, we investigated the implementation of HRM practices designed to increase the inflow of impaired workers to the Dutch labour market.

Building on structuration theory (Giddens, 1984), we were able to identify several episodes in HRM practice development during the implementation process. Our findings show that HRM practices evolve from anticipated HRM practices, which consist of misaligned norms and facilities, to well-aligned, orchestrated HRM practices. During this process of mutual adaptation and negotiation, policymakers, HRM professionals and managers engage in actions that, over time, contribute to a well-fitting and well-supported HRM practice. Their interpretations, opinions and actions evolve, thereby changing the HRM practice. As a result, in the process of moving towards maturity, HRM practices undergo continuous and recursive reshaping. The findings reported in this chapter demonstrate that HRM implementation does not involve clearly demarcated stages but, rather, overlapping episodes. Furthermore, we show that gaps between intended, actual and perceived HRM are not undesirable, but actually necessary for successful HRM implementation.
\end{abstract}

Keywords: HRM implementation; HRM process; HRM practices; structuration theory; inclusive HRM

\title{
3.1. INTRODUCTION
}

Over recent decades, scholars have demonstrated the importance of HRM implementation (Bondarouk, Trullen, et al., 2016; A. C. Bos-Nehles \& Meijerink, 2018; Mirfakhar et al., 2018), which broadly covers the process during which HRM practices are designed, introduced, perceived and eventually incorporated in daily organisational life (Van Mierlo \& Bondarouk, 2015). This has led to HRM being conceptualised as a process, thereby moving away from the notion that HRM is all about the content. In other words, it is not only important which HRM practices are adopted by organisations, but also how these are delivered to their endusers such as employees (Bowen \& Ostroff, 2004; Ostroff \& Bowen, 2016). Such a perspective emphasises that organisational actors are not mindless robots who will work as expected with HRM, and that the way in which they do so is key in delivering HRM practices' full potential (Li et al., 2011; Nishii et al., 2008; Sanders et al., 2008). 
The organisational actor most often considered to be responsible for the delivery of HRM practices is the line manager, as he or she is the person closest to the work-floor employees (Guest, 1987; Valverde et al., 2006). Personal factors of line managers, such as their capacity to implement HRM practices as intended, competences to do so, and support provided by their organisation throughout the implementation process (Nehles et al., 2006), often create disparities between HRM practices as intended by policymakers, and the way in which they are actually delivered to the end users (Khilji \& Wang, 2006; Makhecha et al., 2016; Piening et al., 2014; Woodrow \& Guest, 2014). Further, scholars in the field of HRM implementation have developed insights into the importance of effective implementation. For instance, Woodrow and Guest (2014) adopted the framework developed by Guest and Bos-Nehles (2013) to assess the quality of the implementation of an HRM practice aimed at reducing bullying at a UK hospital. They found that even though the adopted practices were considered to be of high quality, they did not lead to the desired effects. The cause of this was found in the reluctance of the implementers - in this case the hospital's line managers - to adhere to the anti-bullying practices. Therefore, the well-designed HRM practices did not achieve the desired results because of unsuccessful or ineffective implementation. The findings of Woodrow and Guest clearly demonstrate the importance of effective HRM implementation in achieving satisfactory outcomes.

The conceptualisations and empirical insights from the field of HRM implementation have clearly demonstrated that appropriate implementation is vital if HRM practices are to achieve their full potential. However, a striking feature of HRM practices is that, in the literature, they are taken as technical artefacts that do not change over time (Bowen \& Ostroff, 2004; Ostroff \& Bowen, 2016; Wright \& Nishii, 2013). Both in conceptualisations of the HRM implementation process and empirical studies focused on it, the models, frameworks and data collection seem only to cover the factors and processes until the point when HRM practices have been delivered by line managers (Khilji \& Wang, 2006; Woodrow \& Guest, 2014), or employees have perceived them (Makhecha et al., 2016; Piening et al., 2014) or when they have influenced organisational performance (Bowen \& Ostroff, 2004; Nishii et al., 2008; Wright \& Nishii, 2013). However, theoretical insights from practice theorists such as Bourdieu $(1977,1990)$ and Giddens $(1979,1984)$ suggest that practices - in our case HRM practices - continue to change over time. In arguing this, they make use of the concept of mutual constitution, referring to the recursive relationship between two phenomena, such as structure and agency (Giddens, 1984) or field and habitus (Bourdieu, 1977). Feldman and Orlikowski (2011, p. 1242), inspired by the concept of 'mutual constitution', explain that "social regularities are always "in the making"; that is, they are ongoing accomplishments (re)produced and possibly transformed in every instance 
of action". Gherardi adds to this that structures are "constantly recreated by the same means whereby they express themselves" (2009, p. 31). As such, these researchers suggest that rather than being rigid and static, practices are dynamic and malleable. These dynamic and non-rigid characteristics of practices are to be found in the actions of actors who constantly create and recreate them while, at the same time, these practices influence the behaviour of those actors (Van Mierlo et al., 2018). While other scholarly fields of inquiry such as Management of Information Systems, Public Management, Strategy Implementation and Management Accounting have long worked within the tradition of social construction of implementation processes (Barley, 1986; Barrett, 2004; Jarzabkowski, 2008; Macintosh \& Scapens, 1990; Walsham \& Han, 1990), HRM scholars, for several reasons, have only recently started to acknowledge the importance of social construction processes and the contributions of a range of organisational actors in HRM implementation (Björkman et al., 2014; Van Mierlo et al., 2018).

Bringing these ideas to the field of HRM implementation could enable the HRM field to gain valuable insights into what actually happens during the HRM implementation process. Therefore, in this chapter, we aim to gain insights into the dynamics of new HRM practices during their implementation process. Particularly, we intend to study the evolutionary nature of HRM practices, as well as identify episodes in the development of HRM practices. As such, the research question of this paper is: in what ways do HRM practices evolve during their implementation process and which mechanisms contribute to this evolution?

To answer this question we have conducted a longitudinal case study at a Dutch ministry and focussed on the implementation of an HRM practice aimed at hiring impaired workers. We adopt a process perspective to study the ways in which this newly adopted HRM practice evolves during its implementation process. Guided by structuration theory (Giddens, 1984), we identify several implementation episodes during which different mechanisms and actors play roles in the evolution of the HRM practice.

In the remainder of this chapter, we start by summarising the key points of structuration theory. After discussing the methods as well as the case study, we present our findings, which we then analyse in the discussion section. We end the paper with our conclusions, thereby answering the above research question.

\subsection{THEORISING ON THE DYNAMIC IMPLEMENTATION OF HRM PRACTICES}

In this study, the outlines of structuration theory (Giddens, 1984) serve as a lens through which we study the evolution of HRM practices. According to structuration theory, social systems are produced and reproduced over time and space through an interplay between structure and action. Structure consists of rules and resources, and constrains our day-to- 
day behaviour by demarcating behavioural boundaries. However, within those boundaries a certain behavioural freedom exists, allowing actors to act beyond the structure's behavioural boundaries. As such, all actors have a degree of agency: the ability to determine their own actions. Consequently, structure both constrains and enables action.

The key element of structuration theory is the recursive interaction between structure and action: "the structural properties of social systems are both medium and outcome of the practices they recursively organize" (Giddens, 1984, p. 25). In other words, structure influences (constrains and enables) human actions, but is also the result of those actions. Therefore, structure only exists because we act according to it. As a consequence, by acting, people recursively influence the structure that influences their own actions. By acting within the behavioural boundaries of a structure, actors confirm and reinforce it. However, if actors routinely act outside a structure's behavioural boundaries, they have the ability to modify the structure. Feldman (2000) illustrated how only a few instances of deviation from routine behaviour could modify their structure. Looking at practices in this way implies that we "understand organizational phenomena as dynamic and accomplished in ongoing, everyday actions" (Feldman \& Orlikowski, 2011, p. 1250). However, this does not imply that social structures are forever changing because, over time, they can become institutionalised. This becomes the situation when they are inscribed in the interpretive schemes of actors, perceived as legitimate, and facilities are in place (Taylor et al., 2001).

As HRM practices consist of behavioural rules and resources, such as means and the information to execute them, as well as task descriptions of who does what, we consider HRM practices to be structures (Van Mierlo et al., 2018). Structuration theory provides a particularly valuable lens for studying the evolution of HRM practices because the theory is "inherently dynamic and grounded in human action" (Halperin \& Backhouse, 2007, p. 6). Furthermore, Barley and Tolbert (1997, p. 94) identify the ability to study how "...institutions are formed, reproduced, and modified through an interplay of action and structure" as one of structuration theory's strengths. As such, it enables us to observe in detail the dynamic process through which HRM practices pass. That is, we consider HRM practices to be structure in the sense of structuration theory, and organisational actors to be constrained and enabled in their daily organisational life by those HRM practices. However, as structure only exists in the minds of actors (Giddens, 1984), it only exists through the actions of actors, through their behaviour, and thus organisational actors have the capacity to reinforce and modify HRM practices (Van Mierlo et al., 2018). 


\subsection{METHODS}

Data were obtained during an ethnographic case study at a Dutch ministry ('the Ministry'). Data collection, which lasted more than one year, included 33 interviews, analysis of over 400 policy documents, as well as walking-the-floor observations (see Table 5). We opted to study the implementation of an HRM practice within a national federal governmental body as we expected it to offer a context of continuous change and a large number of events during the HRM implementation process. The reasons for this expectation are to be found in factors such as the size of the organisation and the large number of stakeholders and interested parties, the interconnectedness of governmental departments and the multiple layers of governmental actors, as well as political sensitivity and the public attention given to the government's activities.

\section{Data sources}

\begin{tabular}{l|l}
\hline Key informants & $\begin{array}{l}\text { Policymakers, coordinators, line managers, advisors, } \\
\text { HRM professionals }\end{array}$ \\
\hline Document analysis & $\begin{array}{l}\text { Over } 400 \text { documents: policy documents, emails, } \\
\text { meeting notes, promotional leaflets }\end{array}$ \\
\hline Number of people interviewed & 33 (28 hours in total) \\
\hline Observations & Walking-the-floor notes
\end{tabular}

Table 5: Overview of data sources the Ministry

To become acquainted with the context and governmental events, I was present within the Ministry for a period of one year. During this period, I had full access to the Ministry's facilities, as well as to its intranet. Furthermore, I participated in several departmental meetings, workshops and social gatherings that provided additional insights into departmental and ministerial routines and process. This also provided the opportunity to get to know potential interviewees and/or be introduced to them, and approach them (D’Adderio, 2008).

To start our data collection, we first analysed documents to become familiar with the new HRM practice and to map relevant organisational actors and departments. Our main contact person at the Ministry brought us into contact with several other actors whom we interviewed. Following this, we applied a snowballing technique (Flick, 2009) to get in touch with other organisational actors. Our interviews were semi-structured, making use of a topic list (see Appendix A) which served to ensure that most relevant topics were discussed. The interviews took place over a period of seven months, and we stopped seeking new informants when additional interviews were no longer providing new 
information. All interviews were recorded and transcribed using the transcription software 'Transcribe', after which the transcripts were coded using MaxQDA software.

To analyse our data, we created codes based on the modalities of structuration theory (Giddens, 1984). In this, the purpose of our study was not to 'test' structuration theory, nor to illustrate it; rather, the key insights of structuration theory informed us both by providing direction to our study and by helping us collect and analyse data from the case study. In total, we created five codes that are explained below (for a more detailed explanation of the codes, see Appendix B):

- Code 1: Institutional elements (organisational structures taken for granted by most organisational actors)

- Code 2: Norms (formal (i.e. written down) behavioural rules and informal (tacitly understood) moral imperatives)

- Code 3: Facilities (authoritative resources that are able to influence behaviour, and allocative resources that provide the ability to command objects and materials)

- Code 4: Interpretive schemes (stocks of knowledge (beliefs, assumptions, opinions, and perceptions) used in communication)

- Code 5: Actions (the actions of actors, within or beyond the behavioural boundaries of the structure)

To identify HRM implementation episodes, we used a temporal bracketing strategy (Langley, 1999) which entails dividing the data into phases that allow "the explicit examination of how actions of one period lead to changes in the context... With this strategy, a shapeless mass of process data is transformed into a series of more discrete but connected blocks" (Langley, 1999, p. 703). This strategy helps "moving from a shapeless data spaghetti toward some kind of theoretical understanding" (ibid., p. 694). Given the large amount of raw data that we had obtained from the interviews, documents and observations, this temporal bracketing strategy was necessary to make sense of it. Further, the abovedescribed codes were used to analyse the mechanisms that allowed one episode to flow into the next. This approach is often used by researchers who use structuration theory (Giddens, 1984) to study some sort of process. For example, Jarzabkowski (2008) followed a temporal bracketing strategy to study the process of shaping strategy in UK universities, and it allowed Barley (1986) to study the adoption of CT scanners in two American hospitals. 


\section{The case: Recruitment of impaired workers}

During our fieldwork, we investigated the implementation of HRM practices specifically developed for increasing the number of 'impaired' workers within the Ministry. The policy was aimed at recruiting people who were unable to achieve the minimum wage due to mental or physical disabilities. In 2015, the Dutch Participation Act became effective making it obligatory for all employers in the Netherlands to hire a certain number of impaired employees. The goal is that, between 2015 and 2026, Dutch employers hire 125,000 such impaired workers in addition to those who were already working for them before the Participation Act came into force. The Participation Act also describes who does, and who does not, qualify as an impaired worker. Broadly speaking, people who are unable to achieve the minimum wage due to their physical or mental disability, and who are also registered with the Dutch employee insurance agency, qualify as impaired under the Participation Act. As such, employees who are impaired but earn more than the minimum wage, or those who are not registered, do not count towards the total.

HRM practices related to the recruitment and selection of impaired workers are particularly interesting for our study because of the large number of actors involved whose daily tasks are influenced by the policy. Not only are many organisational actors such as top managers, policymakers, HRM professionals, coordinators, line managers and employees involved in implementing (designing, administering, checking its progress) the policy, but the new HRM practice also affects many of their organisational routines. For instance, whereas managers were used to filling vacancies by uploading the job description to the government's website and inviting applications, this process is less straightforward when seeking to attract impaired workers. Furthermore, giving preference to a certain group of candidates because of their disability also provokes mixed responses from actors across the entire organisation. Certain employees might feel threatened by this approach, or perceive it as unfair.

\subsection{FINDINGS}

We were able to identify six HRM implementation episodes during which the HRM practice evolved. This evolution was caused by the actions of organisational actors (policymakers coordinators and HRM professionals- line managers), who, in some way, contributed to the evolution from the anticipated HRM practice towards the orchestrated HRM practice. In this context, coordinators were assigned at each ministry to support line managers in their efforts to hire impaired workers. We have merged coordinators and HRM professionals because, at least in this case, their efforts were of a similar nature and largely overlapping.

This HRM implementation process is visualised in Figure 6. The figure also demonstrates the mechanisms (in italics) that played a major role in moving from one 
episode to the next. These mechanisms (institutional elements, interpretive schemes, facilities, norms, behaviour) are based on the codes discussed in the methods section. It is important to note that these mechanisms were only split for analytical purposes: in reality all the elements interacted with each other. Here, we have emphasised those mechanisms that were most prevalent in connecting the episodes. Another important finding is that these episodes do not necessarily mark completed stages, but rather interconnected events. Hence, in some cases, events take place in parallel to each other while, in other instances, they collide.

In the figure, we have also drawn two wavy lines from the HRM practice towards the 'shaping HRM practice' cloud. These are to illustrate that the actions of all actors, and particularly those of line managers, constantly influenced the shaping process of the HRM practice (Van Mierlo et al., 2018). Examples of such actions include the rather impassioned discussions regarding whether certain impaired workers actually counted as 'impaired' under the Job Agreement, and the level of potential fines. As the policymakers acknowledged, these discussions were constantly monitored and evaluated at the highest policymaking level. The modifications that are discussed in the last of our six episodes were clearly inspired by these discussions and actions of line managers.

In the remainder of this section we will discuss the episodes, with most attention given to the way in which the HRM practice developed and the mechanisms that connected the episodes together. This evolution of HRM is illustrated by events that occurred, such as decisions that were taken, as well as actions by actors that contributed to its development. 


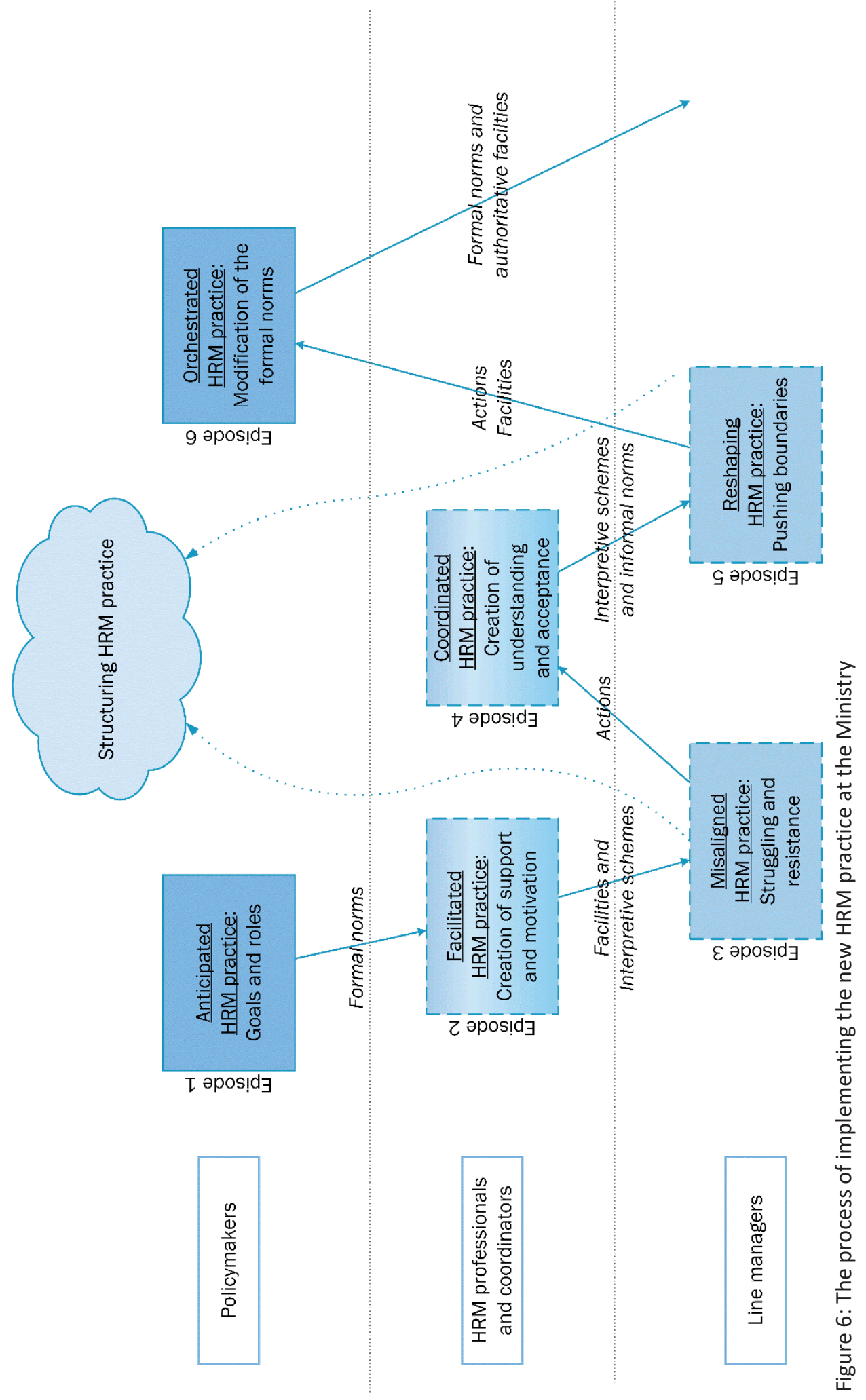




\section{Implementation episode 1: Anticipated HRM practice}

In the first HRM implementation episode, policymakers at the highest governmental level of the Netherlands took the decision to adopt an HRM practice in which the recruitment and selection procedures were heavily focused on bringing in impaired workers. This episode was mainly about getting formal norms in place to start influencing the routinized recruitment and selection approaches of organisational actors.

Policymakers intended to modify existing ministerial institutions related to the recruitment and selection processes within the Ministry. In the existing hiring structure (i.e., before adopting the policy to hire more impaired workers), there was little space for impaired workers. The marginal position of impaired workers within the Dutch government had even been reinforced by the approach taken by the previous government (2007-2010), in which all ministries were given the explicit task of focussing on their core tasks. As a result, tasks like cleaning, landscaping, reproduction and security - ones indicated by our respondents as suitable for the target group - were outsourced. This resulted in even fewer opportunities for impaired workers. To combat this, in the first episode, we observed that policymakers, through the government's coalition agreement, created new formal norms to start modifying the existing institutional recruitment and selection elements.

We take this coalition agreement that led to the formation of a new Dutch federal government (October 2012) as our starting point. During this episode, awareness of the need for an HRM policy change arose, leading to the decision to adopt novel HRM practices aimed at hiring impaired workers. This necessity had been recognised some years earlier and was inspired by a previous policy that the workforce of all government employers should have at least $1 \%$ impaired workers:

"I have decided to initiate... a regulation which entails the federal government structurally reserving $1 \%$ of (job-experience) vacancies for groups at a (long) distance from the labour market" (Ter Horst, 2009, p. 2).

When the new Dutch government was elected, policymakers decided to build on this decision by their predecessor and formalise the sustainable inflow of impaired workers. However, they did not specify whom should be regarded as 'impaired', nor how to approach it: 
"The Work to Ability bill will be replaced with a new Participation Act... The government will design a proportional regulation for hiring impaired workers by large employers. We will take care that nobody falls between two stools. While the number of sheltered-jobs decreases, the number of regular jobs for impaired workers increases"

(Dutch Federal Government, 2012, p. 34).

The modified Participation Act describes the obligation for Dutch employers to hire impaired workers and was the result of extensive discussions between the newly formed government and its social partners, which are broadly all private-sector Dutch employers who are represented by a labour union. The few details that were already outlined amounted to organisations with more than 25 employees having to have at least 5 per cent of impaired workers. Hence, in effect, only the final goal (more impaired employees in organisations in the Netherlands) was described. Therefore, the next step was to work out the details of who and how. These details were described in the newly adopted Job Agreement Act (Ministerie van Sociale Zaken en Werkgelegenheid, 2016). This Job Agreement Act includes details such as the number of extra jobs for impaired workers, who qualifies as 'impaired' and who does not, and also the number of hours that constitute a single job:

\footnotetext{
"125,000 additional jobs for people with a labour disability in 2026 compared to the baseline measurement on 1 January 2013, of which 100,000 will be in the private sector and 25,000 in the public sector. A job is equivalent to 25.5 paid hours per week" (Team Inclusief, 2015, p. 3).
}

The 25,000 additional jobs envisioned in the public sector were subsequently divided proportionately over the ten Dutch ministries and the High Councils of State. Furthermore, tasks were divided. In this, one ministry was made responsible for administering the Participation Act, and another for creating HRM practices for all ministries to use in hiring impaired workers. The latter of these, given responsibility for creating HRM policies and practices which could be used by all organisations in the public sector, is the focus of our case study. The reason that this ministry in particular was chosen, is that this ministry is also responsible for creating all other HRM policies and practices. For example, recently the Ministry developed a government-wide appraisal cycle.

Already in the first episode, roles were created for several key actors. First, in each ministry, a specialised coordinator was assigned the task of being the central actor in 
facilitating line managers in the process of recruiting and selecting impaired workers. Second, a platform organisation was created aimed at creating awareness, understanding and support in hiring impaired workers:

"The primary assignment is to support and facilitate the ministries as much as possible so they can achieve their proportion. Given my involvement in prior programmes, I knew that we needed a toolbox even though I did not know about its contents. Also, we needed to create a newsletter, so I started asking for input in sessions and workshops with representatives of all ministries and services"

(Policymaker 1).

As such, in this first episode of HRM implementation, the anticipated HRM practice consisted of two elements. First, overarching goals were pronounced, with policymakers determined to achieve these goals through the adoption of a new HRM practice. Second, roles were described and key actors assigned to facilitate line managers in finding and employing impaired workers.

\section{Implementation episode 2: Facilitated HRM practice}

During the second episode, the HRM professionals and coordinators made use of their allocative facilities (mainly instruments and support) to influence the interpretive schemes of managers. In more concrete terms, the activities by HRM professionals and several coordinators we observed during this episode were aimed at creating awareness and understanding of the new HRM practice. They did so by getting allocative facilities in place so that organisational actors were able to locate and hire impaired workers. Examples of these facilities include the allocation of a temporary budget specifically aimed at hiring impaired workers, the creation of platforms aimed at providing information to organisational actors about details of the new HRM practice, as well as reasons why it had been adopted. However, some frustrations regarding the designs of the Participation Act and the Job Agreement Act arose:

"Landscaping, catering tasks, where you would say there are opportunities for impaired workers, we outsource them. But outsourcing does not count, so this illustrates a major issue. It also raised questions from us to policymakers: 'Why do you make it so complicated?', 'Why doesn't a job of 10 hours count as a job?'”' (Coordinator 6). 
Also in this episode, the 'toolbox' described by Policymaker 1 in the previous episode began to take shape: (i) instruments to hire impaired workers were created, and (ii) newsletters were sent out on a monthly basis to give information on the why and the how, and to give examples of best-practices in successfully hiring impaired workers. Another facility that was created in this episode was a job-carving/job-creation tool that could be used by managers to identify potential tasks for which their existing employees were overqualified. Together, such small tasks, such as printing and archiving, could be merged into a job for an impaired worker. Nevertheless, this facility was again not received very favourably by all the actors involved:

"They offer this job-carving/job-creation method, but through the governmental platform it costs $€ 7000$, while the city council offers it for free. They do the same complete trajectory, and that costs us nothing. So we had them do it. Nowadays, the government also does it for free, but when we needed it, they didn't" (Coordinator 1).

Following this stage of its evolution, the HRM practice, which already consisted of goals and roles from the previous episode, now also included allocative facilities to inform and support line managers. However, even though facilities were created, in practice these often failed to fit the needs or approaches of the Ministry and its departments. Therefore, the evolution of the HRM practice at this stage of its development was still quite generic and included certain design flaws that influenced the actual process of recruiting and selecting impaired workers described in the next episode.

\section{Implementation episode 3: Misaligned HRM practice}

The interpretive schemes that were triggered during the second HRM implementation episode played a particularly large role in determining the actions of organisational actors during the third. This resulted in either actively looking for opportunities to accommodate and hire impaired workers, or reasons not to.

Coordinators and HRM professionals had hoped to see a positive response from line managers regarding their efforts to actively seek out impaired workers and start hiring them. Indeed, some actors started looking for impaired workers enthusiastically, but we would characterise this as an episode in which managers mainly responded impulsively to the new HRM policy, either adopting an ad-hoc approach or, in most cases, not taking any action at all.

A coordinator indicated at this point that her approach was the following: "Oh I found a nice CV here. Does this person fit somewhere?". A manager further explained: "We 
started without a plan. We just selected some people, created some functions, no plan, nothing written down. Based on those experiences, we have continued". An HRM professional has a similar experience: "We simply picked up some CVs which we got through a contact person at the municipality, and then we just invited a couple of candidates". It is notable that these instances show that several types of actors at the Ministry were actively looking for impaired workers.

As these illustrations show, not only line managers but also coordinators and HRM professionals were involved in the hiring process. They explained that these extra-curricular activities were sometimes because other actors, such as line managers, had asked them to assist in recruiting a group of candidates with which they were unfamiliar. Others stated that they themselves wanted to obtain experience with recruiting and selecting the target group. Nevertheless, even though these examples show that some organisational actors started hiring impaired workers, these were the exceptions. We often heard responses along the lines that people agreed with the need for more labour opportunities for impaired workers, but that they did not think the ministerial environment would be an appropriate place for them:

"I say: leave those people in their protected environment, they shouldn't be placed here. Also because it asks a lot of effort from our side. You want to do your civic duty, but it asks so much of their supervisors. So does this really benefit [the impaired workers]?" (Manager 2).

A coordinator explained some typical struggles with organisational actors who were less enthusiastic about the policy:

"There are also a lot of people who look at impaired workers with a lot of scepticism. They think the law is bad, they think impaired workers do not fit in our open-plan office, they think it costs a lot of money, and they think - and I agree with them - that having people to bring our coffee and tea conflicts with the self-service policy that we have had for the last couple of years, which states that you have to get your own cup of coffee, print your own documents, and receive your own visitors" (Coordinator 4).

Hence, even though goals, roles, awareness and facilities had by now been created, actors were still struggling with questions such as whom to hire and where to find them, and showed mixed feelings regarding the desirability of actually hiring employees who might be 
less productive and need more guidance than others. This misalignment in goals, roles and facilities led to a range of responses from organisational actors within the Ministry concerning the implementation of the policy to hire impaired workers. Even though some organisational actors were indeed actively looking for and hiring impaired workers, this was no more than a small portion of the Ministry.

\title{
Implementation episode 4: Coordinated HRM practice
}

The struggles and issues that became apparent during the previous episode were largely related to line managers' understanding and perceptions regarding impaired workers and their place in the Ministry. Given this situation, organisational actors such as coordinators and HRM professionals tried to influence the interpretive schemes (understanding and views of the HRM practice) and informal norms (values, perceptions of formal norms) of managers and other organisational actors. The goal here of coordinators and HRM professionals was to get other organisational actors to adopt a consistent approach in future recruitment and selection processes for impaired workers, and also to get organisational actors to interact more with impaired workers, thereby making them familiar with supervising and working alongside impaired workers:

\begin{abstract}
"Forty years ago, there were no sheltered workshops, impaired workers simply participated in the employment process. Then, at some point, people decided they should be together, so the sheltered workshops were introduced. We more or less took them away from society, so nowadays people don't know how to work with impaired workers, they don't know how to interact with them. Now we have some ministries in which it has become a reality, support is growing, and people are becoming enthusiastic to participate" (Policymaker1).
\end{abstract}

Also in this episode of HRM implementation, we saw initiatives acquiring a more centralised and standardised character. However, most initiatives were try-outs to see 'what works'. Coordinators took on bigger roles, partially shifting the hiring process from line managers towards themselves. This took place in the form of pilots involving groups of impaired workers: 
"I am now busy setting up three pilots for people cleaning up personnel files. We have to balance what they will be doing, so we will start really simply, the most basic tasks, the minimum. Then we look at the level, who can do more, who can do less. But, we also just leave them to it, so no pressure in the first couple of months, just let them get into the rhythm of working again. So, in the first months, they cannot do anything wrong, everything is allowed to go awry. For us, it is also new, so we also have to get used to and be able to supervise them correctly. Also the supervisors have to learn" (HRM professional 3).

Another HRM professional added:

"Those floor assistants are just a pilot to see if they want to expand this to other floors and ministries. However, the people cleaning up personnel files, that is really meaningful work, work that needs to be done. So then it is beneficial to everyone, and those people feel useful as well" (HRM professional 2).

Therefore, instead of individual impaired workers being hired by individual managers going through a process of creating or identifying a vacancy, looking for potential candidates and finally selecting one, groups of impaired workers were placed by coordinators and HRM professionals inside the Ministry's departments. Examples included the pilots of impaired employees serving coffee and tea, cleaning up personnel archives and receiving outside visitors and taking them to their destination within the Ministry's facilities. Another example was an annual initiative during which impaired people were invited to work for a day in the Ministry, as a security guard, a steward for the minister or in digitalising documents, with the goal of becoming acquainted with working in a ministerial setting, and for organisational actors to get used to impaired workers.

The activities and views described in this episode reflect that the HRM practice could be characterised by coordinated recruitment and selection approaches. Hence, rather than decentralised recruitment and selection aimed at hiring impaired workers for individual departments and teams, impaired workers were being hired for larger entities such as floors of the Ministry's facilities and the personnel records of several ministries.

\section{Implementation episode 5: Reshaping HRM practice}

The fifth HRM implementation episode included many events. To a large extent, organisational actors such as line managers were limited by formal norms (regulations) in 
their ability and willingness to hire impaired workers, which influenced their actions. By making use of their authoritative facilities and allocative facilities such as funding, they found ways to cope with this. However, in so doing, they moved outside the structure's behavioural boundaries.

The overall goal of the policy is to establish a continuous inflow of impaired workers into the Ministry. However, several regulations created frustrations for those organisational actors who had to do the actual hiring. First, only impaired workers registered with the employee insurance centre (the central governmental labour institution in the Netherlands, the UWV) count towards the target 25,000 impaired workers. Second, only people whose disability stops them earning at least the monthly minimum wage are registered as 'impaired'. Hence, employees who are registered as 'impaired' will cease to contribute to the total should their earnings increase to above the monthly minimum wage. As a consequence, managers within the Ministry feared that, after going through an extensive process of looking for a suitable impaired worker, their new impaired worker would stop being labelled as 'impaired' after a couple of years due to salary increases. This issue was also acknowledged by the following coordinator:

"We have hired people in a permanent form, they have a fixed contract. However, they stop counting towards the targeted proportion, so we have to hire more impaired workers. In the end, you will end up with a ministry of impaired workers, that is not the objective".

Managers responded to this by making use of certain exceptions in the Job Agreement Act by contracting impaired workers through job secondment constructions. In this approach, the impaired workers do not have a contract with the Ministry, but with their official employer (often a sheltered workshop) and are posted to, or hired by, the Ministry. In this way, the impaired worker contributes to the Ministry's total even if they earn more than the minimum wage. It also makes it easier for managers to end a posting, a process that is much more lengthy and complex when employees have regular contracts. The job secondment construction was also being used for other reasons. One being that in this way managers could outsource most of the managerial tasks related to the impaired worker: 
"I have them seconded through [organisation] to avoid all the surrounding fuss, such as how do you supervise these people, how are subsidies arranged, what happens if someone drops out, those kinds of things. It is very awkward if the employer has to arrange all these things" (Manager 4).

A coordinator further explained:

"Since it was a lot of work, and this kept increasing, we outsourced the recruitment and selection tasks. Our contact person places new vacancies, talks with the manager, and ensures a candidate is found and placed.... Now we are at the phase [where we are addressing] all sorts of practical stuff like subsidies, testing how labour-impaired they are, that is quite tricky. And who does what? Who initiates it? Is that the task of the HRM advisor? Well, this organisation arranges everything for you. Then you know exactly what it will cost as well. Otherwise, we have to arrange all of this ourselves" (Coordinator 5).

Several managers, on learning that impaired workers who earn more than the monthly minimum wage do not count towards the goal, reacted by actively starting to look for employees who could be paid less than the minimum wage. However, this was a complex strategy since, by law, employers are not allowed to offer a salary that is below the minimum wage. As a consequence, they offered only part-time work to impaired workers so that their total income would not reach the monthly minimum wage. Hence, even though their hourly salary was in accordance with the minimum wage regulations, the number of hours worked was sufficiently low that their monthly salary was below the monthly minimum wage, thus ensuring that these impaired workers counted as such.

To summarise, even though organisational actors were limited by the hiring process for impaired workers, and felt their flexibility threatened in doing so, they found ways to maintain a certain level of flexibility. This was the case when hiring impaired workers through job secondment constructions, even if this meant paying them a substantially higher salary, as long as this gave them greater control over the type and duration of the contract. This approach was clearly an example of organisational actors pushing the boundaries of the new HRM policy.

In the summer of 2016, the Minister of State responsible for the Participation Act and increasing the employment of impaired workers published quantitative results for 2015. The results were not measured on the level of specific ministries, but reported for all 
Dutch public sector organisations. The conclusion was positive: the goal of hiring 3,000 new impaired workers in 2015 had been exceeded by 2,453 employees. Even though most impaired workers were employed through a job secondment construction, the Minister reacted positively to the results: "A possible explanation could be that employers need to get used to impaired workers, or that employers see job secondment as a good way to obtain first experiences.... Hence, in my opinion, a job posting is not by definition a nonsustainable job" (Klijnsma, 2016, p. 3). This positive attitude by the Minister of State came as a surprise to several stakeholders, as they saw job secondments as non-sustainable.

Therefore, in this episode, elements that did not match existing norms and hampered the hiring of impaired workers were being reshaped by the behaviour of line managers. As the reshaping of HRM practices does not happen overnight, this is a process of reshaping. This reshaping was provoked by the hitting the boundaries demarcated by the HRM practice's norms, and enacted in order to make it possible to hire candidates from the target group.

\section{Implementation episode 6: Orchestrated HRM practice}

In this final episode of the implementation of new HRM practice that we observed, we saw how the actions of organisational actors including line managers in the previous episode now influenced formal norms (written behavioural rules) of the HRM practice, possibly over time leading to modified institutional elements (stable behaviour over time and space). Moreover, policymakers made use of their authoritative facilities to elicit line manager actions.

In the previous episode, several concerns had led to managers making use of job secondment mechanisms and/or outsourcing operational tasks such as recruitment and selection, management, and also administrative tasks. One of those concerns was the fear that after a long and costly process of recruiting an impaired worker, he or she would drop out due to health issues. To an extent, the fact that an employee is labelled as 'impaired' creates the idea in some managers that the risk of absenteeism or dropping out might be quite high: "In the beginning I was told that 20\% would drop out in the first weeks" (Manager 2). To counter this, the employee insurance agency created an insurance policy that would cover the salary of impaired workers in the event of illness. The objective of this insurance policy was to stimulate employers to hire impaired workers on a long-term basis rather than through job agency secondment.

A second way in which the behaviour of those actors responsible for bringing in impaired workers influenced the eventual design of the policy is also related to the job secondment approach. In October 2017, a new national government took over in the Netherlands and one of their decisions stated in the coalition agreement was that impaired 
workers earning more than the monthly minimum wage would no longer lose their 'impaired worker' status:

\begin{abstract}
"Impaired workers who have come to earn more than the minimum wage, will continue to count (the ' $t+2$ ' regulation). This will avoid employers being discouraged to invest in their people" (VVD, CDA, D66 \& ChristenUnie, 2017, p. 26).
\end{abstract}

This shows that the widespread use of job secondments - going against the goal of the policy that was to create sustainable jobs for impaired workers - stimulated policymakers to modify the policy so that the jobs created for impaired workers would be more sustainable. However, perhaps surprisingly, policymakers have also created an organisation that actually enhances the use of job secondments: the newly designed Governmental Participation Organisation (GPO). This holds a database of impaired workers whom governmental employers can hire through job secondments (Ministerie van Binnenlandse Zaken en Koninkrijksrelaties, 2017). Through this route, employers are able to outsource all sorts of operational tasks such as recruitment and selection, supervision, training and the administration tasks associated with impaired workers. However, it also institutionalises the previously created practice of job secondments. One difference with the previously described job secondments is that impaired workers contracted through the GPO are formally employed by the Ministry, whereas this was not the case with earlier job secondments where impaired workers were often still employed through sheltered workshops - relatively isolated from the rest of the society.

A third way in which the actions of line managers contributed to the modification of the intended HRM practice is found in the so-called 'activation of the fine'. The initial years of the Job Agreement were designed to be enacted in a voluntary, non-obligatory way. This meant that organisations were responsible for hiring sufficient impaired workers, but that the government would not sanction those organisations who did not meet their targets. However, the Minister of State would evaluate the process by sector (public and private) each year. If progress in a sector was below par, she had the option of converting the Job Agreement into an obligation. If so, each organisation would be given its own target and could be fined $€ 5000$ for each place it had not filled. In September 2017, the then Minister of State informed the Dutch government that she had decided to activate this procedure for the public sector since overall they were almost $45 \%$ behind their target. As a result, the reluctance, and struggles, of line managers in the public sector to actively locate and hire impaired workers directly contributed to the HRM practice being recreated. The underlying idea behind the fine is not that the amount of $€ 5,000$ is really punishing - 
recruitment and selection procedures can cost $€ 30,000$ - but that public opinion plays a role and therefore the government should be seen as doing something. A coordinator explained it as follows:

\footnotetext{
"In a management meeting, I heard comments such as 'Why don't we just pay the fine of $€ 5,000$ ?' So I responded: 'Then you can explain to the deputy secretary why he has to answer to the secretary-general why we paid sixty times $€ 5,000$.' It doesn't work that way, in the government you have a responsibility"
}

Clearly, policymakers were hoping that, by giving more freedom and security in hiring impaired workers, they could inspire line managers to actively start looking for people to meet their target. Furthermore, by activating the fine, they instigated an approach that would provoke a less voluntary design of the HRM practice.

As such, the final episode of the implementation of the HRM practice that we observed during our fieldwork amounted to the orchestration, or bundling, of the interests, understanding and actions of organisational actors. Hence, the reshaping that was visible during the previous episode evolved into a modified, orchestrated HRM practice that was in line with those interests and actions, as well as with the original goals that had been designed in the first episode.

\subsection{DISCUSSION}

In this study, the evolution of HRM practices during their implementation, as well as the mechanisms that played a role during this process, stood central. This study of the HRM implementation process at a ministry demonstrated the dynamics that can take place during the adoption of a new HRM practice. By applying a temporal bracketing strategy (Langley, 1999), we were able to identify six so-called 'episodes' of HRM implementation, each resulting in a specific progression in the HRM practice evolution. These episodes allowed us to focus in on the actions of various actors within the Ministry and demonstrated how their combined efforts contributed to the development of the specific HRM practice, and finally to articulate changes that occurred to the HRM practice. By making use of insights from structuration theory (Giddens, 1984), we were able to analyse progressive mechanisms which connected the episodes with each other and contributed to the advancement from one episode to the next, and allowed the HRM practice to evolve from anticipation to orchestration.

The case at the Ministry has also provided insights into the dynamics regarding the key actors involved in each episode. Whereas policymakers were the leading actors during 
the first and last phases, others dominated in the intermediate episodes. In the second and fourth episodes, coordinators and HRM professionals were busy creating awareness and allocating resources such as tools and information. In the third and fifth episodes, line managers played a major part. This demonstrates the key change-agent role that line managers have during the HRM implementation process. It was not until they started to go beyond the boundaries of the HRM practice that things started to evolve. Even though policymakers had put considerable effort into designing a new HRM practice, including the development of facilities to make it easier to hire impaired workers, and HRM professionals and coordinators had taken initiatives to decrease the distance between line managers and impaired workers, the line managers still encountered too many obstacles to hiring the intended number of impaired workers. It was necessary for policymakers to move along with the line managers to create a fitting HRM practice.

The multilevel nature that was visible during the HRM implementation process at the Ministry (Figure 6) suggests a relationship which reminds us of the macro-micro-macrolevel relationships proposed by Coleman (1990). This model is colloquially known as Coleman's boat, or a 2-1-2 mediation. His proposal is that macro-level changes are best explained by micro-level processes. His work has already inspired HRM scholars and is easily recognisable in many HRM studies (Bowen \& Ostroff, 2004; Ogbonnaya \& Valizade, 2016; Vermeeren, 2014). The first macro-level events in this case are to be found on the overarching level of the Ministry's policymakers, which even included ministers and ministers of state, who pronounced and formalised the goal of hiring more impaired workers. The micro-level events are found in the actions of line managers who were responsible for the actual hiring. Subsequently, the orchestration of the HRM practice, and hence the modification of the formal norms of the HRM practice, was again carried out on the macro-level by policymakers. As such, this chapter demonstrates that when it comes to the evolution of HRM practices, it is necessary to study processes which take place on both the macro- and micro-levels.

\section{Contributions to HRM literature}

These findings contribute to the HRM implementation literature by demonstrating that practices do not automatically fit their organisation at the moment they are adopted. Instead, it might be necessary to adapt them to the interpretive schemes of stakeholders such as line managers and provide facilities that fit their needs.

In the case of the anti-bullying practice discussed in the introduction (Woodrow \& Guest, 2014), several managers did not apply the practice as intended, and the number of reported bullying incidents actually increased. Our study suggests that the implementation process for this anti-bullying practice had probably not yet finished and could still achieve 
its objectives. Even though the practice had been found effective elsewhere, it could also be that it did not fit with the interpretive schemes and informal norms of the managers of the hospital in question. In our case study at the Ministry, line managers indicated that impaired workers would not fit in the ministerial world, let alone in their department. This demonstrates that institutionalised structures, such as organisational culture and habits, and individual perceptions are hard to change. We saw in our case study that the efforts of coordinators and HRM professionals were mainly focused on changing those institutions, in this case the hiring focus of line managers.

We have also contributed to the HRM implementation literature by demonstrating that HRM implementation does not consist of clearly demarcated stages (Guest \& BosNehles, 2013; Wright \& Nishii, 2013), but of, what we labelled, episodes that take place parallel to each other, and in which different mechanisms and organisational actors play key roles. The difference between stages and episodes is that stages have clear moments at which they begin and end. Moreover, stages, we would argue, do not overlap with each other but occur sequentially. Conversely, episodes can take place simultaneously and often overlap, as was the case in this study. An example of this was the fact that during episode 3 ('Misaligned HRM practice') policymakers were already undertaking initiatives to investigate the impact of the potential fine that could be imposed. Hence, during this episode, policymakers were making modifications to the HRM practice which materialised in episode 6 ('Orchestrated HRM practice').

We observed the recursive influence of behaviour on the practice in the adjustments to regulations undertaken by policymakers. Here, the policymakers redesigned the HRM practice to stimulate employers to hire impaired workers using direct contracts rather than indirect job secondment mechanisms. In terms of structuration theory, we have clearly seen that all aspects of the theory (institutional elements, action, interpretive schemes, resources and norms) have played a role in the HRM implementation process. These findings add to earlier work by Van Mierlo, Bondarouk and Sanders (2018), who theorise a continuous recursive cycle between HRM practices on the one hand, and the behaviours of all organisational actors on the other.

These findings might raise the question as to whether there will always be six episodes, and if these will develop in the same way as in our case study. The organisation that we studied is located in a ministerial context and, therefore, it seems likely that organisations active in similar contexts will probably go through similar HRM implementation processes. However, aspects such as the length of the implementation process and its intensity might differ. We perceive these questions as very relevant for future research, and would encourage researchers to investigate the dynamics of HRM 
implementation in other organisations, both in similar and different contexts as the Ministry.

\section{Contributions for practitioners}

In this study, we have made several contributions that can inform and assist practitioners in future HRM implementation processes.

First, the main message of this chapter is that HRM practices evolve during their implementation process. Much of the existing literature is focused on keeping the gaps between intended, actual and perceived HRM as small as possible (Bowen \& Ostroff, 2004; Ostroff \& Bowen, 2016; Wright \& Nishii, 2013). Conversely, we claim that gaps between intended and actual HRM are not only unavoidable during the HRM implementation process, but also that these are desirable and necessary to achieve widely supported and fitting HRM practices. As the events during episodes 3 and 5 demonstrated, the facilities designed by HRM professionals and coordinators were aimed at supporting and motivating line managers to hire impaired workers. However, line managers soon found that these facilities were not applicable with many candidates, clashed with their own routines or were not very useful given their own situation. Therefore, the HRM implementation process should be viewed as a transition period (Van Mierlo \& Bondarouk, 2015) during which welldesigned and well-fitting elements of new HRM practices are distinguished from mismatches and misaligned aspects. Another approach that HRM practitioners could adopt is instead of creating facilities in advance to only do so only when line managers ask for them.

Second, as HRM practices evolve during their implementation, it is important to avoid formalising them until they have become aligned, or orchestrated, with all the stakeholders involved. Unless the dynamic and evolutionary nature of HRM practices is taken into account, the creation of formal rules will be seen as a hindrance rather than a catalyst.

Finally, the previous contributions underline the importance of thoroughly monitoring the entire HRM implementation process. Although this might not be a new idea, the evolution of HRM practices that we have seen does demonstrate that continuous monitoring is necessary for assessing HRM implementation episodes. Only if the current stage of development, or evolution, of an HRM practice is clear can practitioners assess whether it is already necessary to make adjustments to norms or facilities, or whether a hands-off approach is preferable at this point. The latter would be the case if line managers were still experimenting with the new HRM practice. 


\subsection{CONCLUSIONS}

In this chapter, we have studied the dynamics of a novel HRM practice during its implementation, and identified episodes that occur during this process and mechanisms connecting them. The research question that guided us was: in what ways do HRM practices evolve during their implementation process, and which mechanisms contribute to this evolution?

Our findings show that, in the HRM implementation process, organisational actors continuously shape and reshape the HRM practice through behaviours within but also beyond the intended HRM practice's outlines. The analysis of the implementation process at a ministry demonstrated how HRM practices start with the announcement of goals and assigning roles and tasks. However, the largest evolutionary steps that HRM practices make during their implementation are visible at the moments when those actors who are responsible for the actual introduction - in our case line managers - make attempts to do so. The misalignments that then become apparent between the anticipated HRM practice and the goals, interests, routines and responsibilities of line managers play a vital role in identifying design flaws in the HRM practice. The process of adaptation and negotiation that was visible during our case study, particularly in episodes 3 to 5 , eventually contributes to a broadly supported, orchestrated HRM practice. Further, each of the six episodes that we identified can be characterised by having different key actors, different characteristics and a different shape to the HRM practice. At the 'go live' moment of the anticipated HRM practice, the HRM practice is not the finished item. Rather, a process of adaptation and negotiation starts involving a dynamic back-and-forth between policymakers, HRM professionals and line managers.

Our findings have also demonstrated that all of the mechanisms that we had identified based on structuration theory (Giddens, 1984) (institutional elements, action, interpretive schemes, resources and norms) played a role in this HRM implementation process. Interestingly, formal norms and institutional elements played a major role in both the first and the last episodes of HRM implementation. Policymakers decided to develop the new HRM practice by creating a clear vision of what they wanted the new HRM practice to look like and divided tasks at the beginning of the HRM practice introduction process. It seems that they wanted to have formal norms in place to create understanding and awareness and to start influencing institutions. Also in the final episode, formal norms played a key role, when policymakers decided to modify several aspects of the HRM practice. In the intervening episodes, other aspects mainly played the key roles. HRM professionals and coordinators made considerable efforts to influence the understanding and opinions of line managers regarding the recruitment and selection of impaired workers. However, line managers often showed resistance towards structural aspects of the HRM 
practice, or faced practical issues in seeking impaired workers. Here, to aid the maturity of the HRM practice, line managers were able to use their allocative resources to eventually reshape the HRM practice in such a way that it was both in line with their own interests, and those of the Ministry's policymakers. This means that for HRM practices to evolve from one stage of their evolution to the next, not only clear communication is necessary (Bowen \& Ostroff, 2004; Nishii et al., 2008), but also investment in line managers' abilities and in aligning the HRM practice's characteristics with the interests and goals of the line managers. As Nehles et al. (2006) identified, a key role in this is to be found in HRM professionals' tasks.

One element that was not emphasised much during the episodes, but which played a key role in the implementation, was the role of authoritative facilities. Frequently, during the entire HRM implementation process, coordinators and HRM professionals indicated that they had no formal way to oblige line managers to hire impaired workers. Therefore, they needed to rely on the voluntary commitment and dedication of line managers to enact the HRM practice. In some cases, line managers did indeed start actively looking for impaired workers, but the vast majority became disenchanted with the new HRM practice because of its misalignment with their own goals and interests. HRM professionals and coordinators were not able to force line managers to hire impaired workers. As a result, they started hiring impaired workers themselves to both achieve their organisation's quota, and to enable organisational actors to become more familiar with impaired workers and what they could contribute. As such, it appears that one of the key mechanisms that play a role in the evolution of HRM practices, is the presence, or absence, of authoritative facilities for HRM professionals over line managers. 



\section{CHAPTER 4}

\section{The roles of organisational actors in HRM implementation}

In this chapter the focus lies on the roles that organisational actors play during the adoption of a new hiring routine. The policymakers of the company had taken the decision to focus on hiring a large number of disadvantaged workers. This made it necessary for actors such as line managers and HRM professionals to create new hiring routines. Therefore, the chapter contributes to answering the second part of my overall research question: 'Which role do organisational actors play in the HRM implementation process?'

This chapter is based on the manuscript that has been accepted for publication in a special issue on Routine Dynamics in Research in the Sociology of Organizations. A previous version of this chapter was presented at the 33rd EGOS Colloquium, 6-8 July 2017, Copenhagen, Denmark. 


\begin{abstract}
Large corporate policy changes usually take place based on a top-down approach with clearly envisioned steps and an implementation plan. However, in this chapter we report a study of a bottom-up approach in which organisational actors of a company, called Dutch Cleaners, created a new hiring routine that supported a company-wide new HRM hiring policy implemented without any prior envisioned plan or guidelines. We used the literature on routine dynamics to examine in detail through which actions and dynamics the new routine was created by key members in this organisation. Through in-depth interviews, we found that line managers, HRM professionals, and middle-level managers started to create their own routines. This included resourceful workarounds of existing routines and the establishment of new external networks by line managers, the expert support from HRM professionals and the "new routine stabilising" efforts of the middle management. The end result was a broadly-supported hiring routine which even lead to achieving the overall goals faster than expected by top management. With this study, we contribute to the literature on routine dynamics by elaborating on the actions and internal dynamics involved in the creation and re-creation of organizational routines. Finally, we discuss how change managers can benefit from our findings when confronted with large corporate policy change.
\end{abstract}

Keywords: routine dynamics; routine-in-action; HRM implementation; bottom-up; HRM practices

\title{
4.1. INTRODUCTION
}

It is commonly assumed that policy change in organisations requires clearly envisioned patterns of action stemming from the top managers and implemented throughout the whole organisation. However, in this chapter we present a study of a policy change of hiring practices in a large organisation which was done by making use of a bottom-up approach, that is, without the usage of a clear plan of action from the top management. The results of the change exceeded the prior expectations of top managers, which makes this case a sensible one for understanding the dynamics and patterns of actions that contributed to that success.

The literature on routine dynamics is particularly useful to profoundly examine the patterns of action involved in the creation and re-creation of organisational routines (Feldman, 2000; Feldman \& Pentland, 2003). Within this stream of literature, scholars have examined how organisational actors develop new routines by envisioning a particular set of actions or even envision a more specific template of how to perform the routine (Berente, Lyytinen, Yoo, \& King, 2016; Bertels et al., 2016; D’Adderio, 2014; Lazaric \& Denis, 2005; 
Rerup \& Feldman, 2011). While sensitive to the patterns of actions involved in routine emergence, these contributions examined how routines are created based on a top-down approach and thus reflect the way in which organisational actors first define the envisioned routine (Rerup \& Feldman, 2011), prior to bringing it to life through specific performances. In these cases, routine participants envision how to perform the routine and enact patterns of action in relation to this envisioned routine. However, to our knowledge within the routine dynamics literature there are only a few notable studies addressing the way in which actors develop new patterns of action without envisioning a template of how to create routines first (Cohendet \& Simon, 2016; Salvato \& Rerup, 2017). These studies show that it is not necessary to envision a routine prior to enacting it in practice.

We build our argument on the limited number of empirical studies about ways in which routines emerge through unplanned actions, to deepen our knowledge on how exactly this happens, and which actions are critical in the appearance and development of a new routine. This chapter takes up the perspective of emerging routines by closely examining the specific performances of organisational actors in the development of a new hiring routine in an organisation located in the Netherlands, called Dutch Cleaners. Our research efforts were driven by the following research question: How do the different points of view of routine participants contribute to building new patterns of action in the absence of an envisioned routine?

Building on the routine dynamics literature, we draw on a case of the successful implementation of a new hiring routine at Dutch Cleaners, a large cleaning services corporation with various sub-units located in the Netherlands and with a total number of about 10.000 employees. In 2015, this company stated its desire to become an inclusive employer, where disadvantaged workers are given the same job opportunities as so-called 'regular' job candidates (Van Leeuwen, 2015). However, in contrast to hiring regular workers, the hiring of disadvantaged workers involves specific hiring procedures and dealing with legal and social security issues which jointly, were new to most actors of Dutch Cleaners. Despite the novel character of this policy and its strategic importance for the entire corporation, the top management of Dutch Cleaners decided to achieve the change without an envisioned pattern of action of how to accomplish do this. This implied that, except from a few targets set by the top management, relevant staff members such as HRM professionals, unit leaders and line-managers where not bounded to pre-defined hiring guidelines or procedures. In other words, within the restrictions of the law, they were free in finding out their best way of hiring disadvantaged workers. The only recognisable patterns to these actors were the ones provided by the existing hiring routines of regular job candidates. 
We started collecting the data inductively to explore the various individual and collective actions performed by actors in their endeavour to bring the new hiring routine to life at Dutch Cleaners and reach the targets set by top management. By engaging in the inductive observations, we accumulated knowledge to map emerging organisational routines that guided the new hiring process. Thus, similar to Turner and Rindova (2012) we focused on the patterns of action and described the process of how these patterns came into existence. In so doing, we drew mainly on interviews using snowballing techniques depending on how the patterns of actions unfolded in the development of this new hiring routine.

We demonstrate how the creation of a new hiring routine went through processes of trial and error, partly building on existing routinized elements when considered useful but also workarounds in case they were not. We also show how the creation of the new hiring routine was surrounded by developing new connections outside the organisation and is accompanied by sometimes contrasting role perspectives of routine participants. Finally, we show how mutual adaptation and stabilisation of a new hiring routine even led to the company attaining the managerial target one year earlier than envisioned.

This chapter contributes to the literature on routine dynamics in various ways. We show that even large-scale change operations in organisations do not always require an envisioned pattern of action. In fact, our study demonstrates that such plans may be detrimental for cultivating responsibility-taking spontaneous actions and possibilities explored in the creation and re-creation of organisational routines. Moreover, we present the nature and the characteristics of the generative mechanisms that enabled this organisation to develop a pattern of action that by far surpasses the initial targets for hiring disadvantaged workers. We demonstrate how building a new pattern of action also involves building the engagement of new connections outside the organisation such as employment agencies and local schools as well as setting up new connections between HRM professionals and line managers and use each other's expertise and networks to establish external connections. As such, we expand on existing studies interested in routine emergence through performances without prior envisioned plans (Cohendet \& Simon, 2016; Salvato \& Rerup, 2017).

The remainder of this chapter is structured as follows: first, we provide the theoretical background that guides our empirical research. In more detail, we review the current literature on the specific actions and differences between studies that examined the creation or re-creation of routines top-down and bottom up. Next, we describe our research methods and more detail on the case at Dutch Cleaners. After that, we turn to the findings and elaborate on the specific actions of organisational actors like HRM 
professionals, middle-level managers, and line managers. Finally, we discuss our findings and contributions followed by the conclusions.

\subsection{THEORETICAL BACKGROUND: ROUTINE DYNAMICS AND EMERGENT PATTERNS OF ACTION}

Rather than viewing organisational routines as sources of inertia and stability only, (Gersick \& Hackman, 1990; Weiss \& Ilgen, 1985), scholars taking the perspective of routine dynamics consider routines as potential sources of flexibility and change (Feldman, Pentland, D'Adderio, \& Lazaric, 2016, p. 505). Or, as Feldman (2000, p. 626) notes "routines are not inert, but are as full of life as other aspects of organizations" where people are the central agents in routine change. Feldman et al. (2016) highlight that even though routines often demonstrate recognisable and repetitive patterns of action, these patterns are temporal and can potentially change from one performance to the next. Danner-Schröder and Geiger (2016, p. 3) emphasize the role of organisational agents in routine dynamics: "each routine performance can vary from one iteration to the next, and stability as well as change of routines is the result of an effortful accomplishment of routine participants". Routines are not only modifiable and dynamic (Bertels et al., 2016; D’Adderio, 2014; Howard-Grenville, 2005), but are also sources of change and innovation (Cohendet \& Simon, 2016; Rerup \& Feldman, 2011; Sonenshein, 2016).

The source of stability and change both in routines themselves and in their creative and innovative capacity, is related to the routine's 'internal dynamics' (D'Adderio, 2014) found in the duality between the ostensive and performative aspects of routines (Feldman \& Orlikowski, 2011; Feldman \& Pentland, 2003). In this, we follow the recognised tradition in the routines literature by considering the performative aspects of routines as the specific actions that actors perform at specific times and at specific places, and ostensive aspects of routines as the generalised pattern of a routine that is used by actors to guide and to refer to specific actions (Feldman, 2015). It is through actions of organisational actors that ostensive aspects are created and re-created over time (Feldman, 2015; Jarzabkowski, Lê, \& Feldman, 2012). These ostensive and performative aspects are always mutually constitutive (Feldman, 2015; Feldman \& Orlikowski, 2011), meaning that they influence each other recursively and that the one cannot exist without the other. However, ostensive aspects tend to be more stable over time than performative aspects since they pertain to the regularities experienced across multiple performances (Feldman \& Pentland, 2003; Howard-Grenville, 2005), while each participant's experience of a routine will depend on his or her role and point of view (Feldman \& Pentland, 2003, p. 101). Nevertheless, it would be misleading to associate ostensive aspects of routines with objective phenomena: "It is tempting to conceptualize the ostensive aspect of the routine as a single, unified object, like 
a standard operating procedure. This would be a mistake, because the ostensive incorporates the subjective understandings of diverse participants" (Feldman \& Pentland, 2003 , p. 101). These formalised aspects such as written rules, tools and standard operating procedures of routines are called its 'artefacts' (Danner-Schröder \& Geiger, 2016). Artefacts matter in the sense that they represent a routine and at the same time influence both its performative and ostensive aspects (D’Adderio, 2008; Pentland \& Feldman, 2008).

\section{The creation and re-creation of organisational routines}

Various scholars have examined routine dynamics in the context of organisation-wide implementations of new practices. This has led to valuable insights demonstrating the patterns of action by which organisational actors contribute to the creation and modification of organisational routines. For instance, Dönmez, Grote and Brusoni (2016) explored how product development teams balance stability and flexibility by simultaneously implementing software packages in interdependent organisational routines. In their study, they found that the interdependencies among routines were coordinated by members of software development teams manipulating the level of 'protection' afforded in each routine, where less protection creates flexibility and greater protection more stability. Deken, Carlile, Berends, and Lauche (2016) examined how multiple actors carry out interdependent routine performances while aiming for novel outcomes. They found that changing interdependencies across routines requires breakdowns that lead to "routine work". Here, routine work refers to flexing, stretching and inventing of performances that essentially results in novel outcomes and change.

In the creation of routines in practice, we can often observe how organisational actors are being guided by a template designed by key stakeholders in their organisation. For example, D'Adderio (2014) studied the process in which a large manufacturing company intended to transfer its production routines from their American production site to a newly acquired site in the United Kingdom. Leading in this transfer were the simultaneous organisational goals to both replicate and innovate. This created for the organisational actors to the need for both an exact copy of the existing routine and innovation by deviating from it. In this case, organisational actors had to choose between adhering to a template or deviate from it. Adhering to a template led to actions related to the notion of 'mirror image', also referred to as the 'golden image' described in the routine's artefacts: "routines were codified and written down as a set of detailed step-by-step production sequences" (D'Adderio, 2014, p. 12). On the other hand, actors were under the constant pressure of a need for innovation and managed to deviate from the template and were nonetheless able to use the template to some extent. In another study, Berente et al. (2016) studied the implementation of an ERP system at NASA. The authors showed how the integrative 
flexibility of local work practices functions as a "shock absorber" that helps in the coordination of implementing an enterprise software system into ongoing and co-existing organisational routines. Their key insight for this study was that relaxing the requirements and allowing some deviation from the plan of action allowed a successful implementation of the ERP system, after two failed attempts.

The study of Berente et al. (2016) suggests that a less hands-on approach from policymakers can substantially contribute to the successful creation and re-creation of new organisational routines. However, only few studies have focused on cases in which actors are free in creating and re-creating new routines. Cohendet and Simon (2016) demonstrated how an internal disruption in a large video game company turned into a reconfiguration of their existing development routines. In this, the company's topmanagement decided to allow freedom to line managers and employees to create new patterns of action in terms of videogame development. This led to an unscripted creation of new routines in the process of game development. In line with this, Salvato and Rerup (2017), studied how designers and engineers of an Italian utensils producer coped with, and contributed to conflicting goals. Interestingly, they observed how engineers made use of the formulation of a new managerial goal to reach a larger audience by allowing designers to use cheaper materials in the design of new products. Engineers took this opportunity and started raising issues related to efficiency in the design process, therewith enlarging their role in the process.

The findings from the studies above inform our study that the (re)formulation of an organisational goal without envisioning how to reach it, can lead to a reshuffling of actors' relationships and responsibilities, as well as their daily routines. In our empirical work we have explored the actions of organisational actors in such a non-envisioned routine creation. But, as we demonstrate, the different points of view of organisational actors as well as the creation of new connections took a central role in this process. Through their actions, organisational actors contributed to a successful and broadly supported new hiring routine. In the next section we explain the setting and data collection.

\subsection{METHODS}

We conducted a qualitative study at Dutch Cleaners (we use a pseudonym for sake of confidentiality), which is a large cleaning service firm in the Netherlands with multiple regional business units providing cleaning services to schools, hospitals, large companies and small offices. In total, Dutch Cleaners employs approximately 10.000 people nationwide. The company has six regional offices which all are managed by a regional manager. An HRM professional is assigned to each regional office to take care of employeerelated issues in their region. To ensure proximity and provide excellent cleaning services 
to the customers in the region, there are multiple sub-units from which the daily service operations are coordinated. These are managed by middle-level managers. The line managers are responsible of daily operations on location as well as hiring and firing of cleaners in the offices of the company's clients.

Our research involvement started in 2016, at the moment that Dutch Cleaners made the decision to increase the number of disadvantaged workers amongst their workforce. In 2015, senior managers of Dutch Cleaners stated the desire to become an inclusive organisation, consisting for a substantial part of disadvantaged workers. The reason for aiming to become an inclusive organisation, was that Dutch Cleaners aims to be a diverse organisation which is both a reflection of society and stimulates equal opportunities, regardless of cultural, social and ethnical background (Van Leeuwen, 2015). With disadvantaged workers are implied those people who are considered to have a distance to the labour market due to reasons such as physical and/or mental disabilities, have merely a basic educational level or a migrant background.

Instead of designing an organisation-wide implementation plan to enact this new way of hiring, top management decided to leave it to the regional offices and sub-units and let the managers decide on what works best. As indicated by the company's HR director, earlier implementation processes at Dutch Cleaners were also executed by making use of a similar, bottom-up approach. Hence, organisational actors were already experienced with developing new routines in a non-envisioned way.

The original goal of Dutch Cleaners' senior management was to have all of their sub-units reach the highest scale on the so-called Participation Scale - a measurement tool that determines the inclusiveness of organisations and their units - in 2018. On a workforce of almost 10,000 employees, to reach the highest scale it is necessary that at least $3.7 \%$ consists of disadvantaged employees. However, the company exceeded its expectations by already fulfilling this goal in 2017. These achievements kept on growing, and in June 2018 the total number of disadvantaged employees at Dutch Cleaners was 1,377, which was equal to $14 \%$ of the total workforce.

\section{Data collection}

We followed Turner and Rindova's (2012) suggestion to familiarise ourselves with the research setting in other to understand existing routines. We conducted interviews with HRM professionals, who are viewed as experts in legal issues and also with line managers who are responsible for hiring and firing of employees. During the interviews, we enquired about how hiring and firing takes place in that particular unit and who else is involved. We asked the regional HRM professionals about the general HRM policy at Dutch Cleaners and 
in what instances their help was required for local HRM related matters. For an overview of the interview protocol, see Appendix C.

Based on the previous stage, we developed a research design intended to obtain data providing insights into ways in which organisational actors developed new patterns of action aimed at hiring disadvantaged workers. We began by collecting and studying relevant documents from the company's intranet, promotional leaflets and internal newsletters in which the new hiring practice, including their benefits for the company and their customers was announced to all organisational members as well as to other organisations like clients and other companies. After this, we focused on the actions involved in the enactment of the new hiring routine. In doing so, we mainly draw on semi-structured interviews with organisational actors who had a key role in bringing the new routine to life. Most respondents were identified through a snowballing technique (Flick, 2009) in which respondents connected us to other actors in their region or unit. In total, we interviewed 28 participants: 4 HRM professionals, 1 higher manager, 1 regional manager, 8 middle-level managers, 10 line managers, 1 supervisor, and 3 'disadvantaged' workers. For an overview, see Table 6.

Data sources

\begin{tabular}{l|l}
\hline Key informants & $\begin{array}{l}\text { Middle-level managers, line managers, HRM } \\
\text { professionals }\end{array}$ \\
\hline Document analysis & 10 documents: policy documents \\
\hline Number of people interviewed & 28 (23 hours in total) \\
\hline Observations & Walking-the-floor notes \\
\hline
\end{tabular}

Table 6: Overview of data sources Dutch Cleaners

All our interviews were recorded, transcribed and verified by the interviewees to increase the trustworthiness of the data (Flick, 2009). Following this, the first and second author hand-coded the interview transcriptions independently. The coding system was straightforward: we coded the actions of each actor first and later how they were connected with each other internally, at Dutch Cleaners, and externally with third parties who contributed to the emergence of this new hiring routine. To boost the credibility of our findings, the first and second author compared their independent analyses having each carried out the coding and pattern segmentation processes. Any irregularities or differences in their classifications were discussed and agreed based on a consensus of all the authors. This led to the identification of several action patterns. For an overview of these action patterns, see Appendix D. Below, we first describe in more detail the existing hiring routine 
at Dutch Cleaners, after which we continue with the actions involved in the new hiring routine.

\subsection{FINDINGS}

Before we turn to our findings, we first describe the traditional (hence for regular employees) hiring routine at Dutch Cleaners that is utilised at the regional subunits. The hiring routine for regular employees at Dutch Cleaners can be characterised as straightforward. In general, most managerial responsibilities, such as the hiring and firing of employees, managing and assessing their performance, as well as several administrative tasks, are performed by the line managers. Since workforce demand can fluctuate rapidly in the cleaning business due to the acquisition and loss of clients, Dutch Cleaners has chosen to create a database of job candidates. These job candidates get an opportunity to upload their CV to the company's website after which it is stored within the database. At the moment that a line manager needs to hire a new employee, he or she can consult the database and invite candidates to apply, or directly invite them for a job interview. The interview itself, as well as the final decision regarding who will be the new employee is also the responsibility of the line manager. The role of the HRM professionals is restricted to administrative tasks and providing support to the line managers in case those ask for it. The role of middle-level managers is limited to the approval of vacancies, but in practice, this is a formality with the middle-level managers relying on the line managers' discretion.

The company's desire to become a more inclusive organisation meant that many elements of these existing hiring routines would not work for the new target group. For instance, when recruiting, it is unclear whether a candidate is listed as disadvantaged or not, as - logically - candidates do not state whether they are disadvantaged in their cv. Furthermore, participants indicated that if they have a mix of disadvantaged and nondisadvantaged candidates, the choice would in most cases fall on the non-disadvantaged candidates. Reasons for this are that, in general, disadvantaged candidates have less work experience and need more supervision from their line manager. Therefore, the regular hiring routine would not fit the goal to become a more inclusive organisation. Furthermore, for legal reasons, it is not possible to place a job ad in which the company announces that they are looking for a 'disadvantaged employee'. This means that, to give disadvantaged employees a bigger opportunity to be hired by Dutch Cleaners, the company's existing routines needed to be replaced by new ones.

\section{The emergence of a new HRM hiring routine}

In a discussion with the first author of this paper, the company's HR director indicated that he prefers to empower the company's professionals by allowing them to create their own 
approaches. At the beginning, the HRM professionals located at the regional offices felt responsible for creating new approaches to hiring disadvantaged workers. However, not only the local HRM professionals, but also line managers and middle-level managers began seeking their own ways to hire disadvantaged people. Sometimes, they relied on the existing hiring routine, but in most occasions they reinvented it because the new HRM policy was perceived as substantially different from the previous approach to hire new employees.

Below, we describe the actions of these members to bring the new HRM hiring routine to life as viewed from their own perspectives. We start with the actions of the HRM professionals, followed by the line managers and, finally, the middle-level managers.

\title{
HRM professionals' perspective: taking responsibility to avoid risk
}

The first step the HRM professionals took was to set up an infrastructure that would allow line managers to find candidates and start the hiring process. In the Netherlands, certain organisations are specifically aimed at creating databases with disadvantaged workers who are looking for a job. These databases contain their vitae's and specific information regarding their (dis)abilities. Examples are the Dutch employee insurance agency (an autonomous administrative authority responsible for implementing employee insurances and providing information and services regarding the Dutch labour market), employment agencies, and municipalities. Instead of leaving the acquisition to the line managers as happened in the previous routine, the HRM professionals indicated that they themselves would establish contact with these agencies. As an HRM professional remarked, he has increased the possibility that a new employee will be a disadvantaged worker:

\begin{abstract}
"All new job vacancies have to be reported to me, after which I contact the agencies that have a database [of disadvantaged workers]. We then give those agencies a week to provide suitable candidates with whom the [line managers] can schedule interviews. So basically, I have increased the likelihood that a new employee will be [a disadvantaged worker] by manipulating the recruitment process" (HRM professional 1).
\end{abstract}

Another HRM professional described a similar approach and provided the argument that she perceived the line managers' network to be insufficient for finding suitable and a sufficient number of disadvantaged workers: 


\begin{abstract}
"Vacancies have to be reported to me first, so that there is no other way for the line managers. So, I start by placing the job ad, and then the line manager gets into contact with a number of candidates. So, in that sense, they receive support in finding disadvantaged workers. It would have been different if they had to look for these connections themselves, because where do they find disadvantaged workers? That is an area where line managers lack some knowledge" (HRM professional 2).
\end{abstract}

These two HRM professionals indicate that, by getting themselves involved into the recruitment process, the probability that a new employee will be a disadvantaged is larger, as the line manager has merely disadvantaged candidates to choose from. Hence, by this approach, line managers take up a bigger role in the hiring process, compared with the previous hiring routine.

There was another reason why HRM professionals put themselves in the lead and took over the responsibility of line managers. This is because the hiring of disadvantaged workers involves legal issues which they believed line managers would be unaware of, or at least would struggle with. Further, HRM professionals were reluctant to let line managers decide whether someone should be counted as a disadvantaged worker. As one HRM professional explained:

\footnotetext{
"Everyone always gives a different definition of 'disadvantaged workers', and therefore everyone may look for different candidates" (HRM professional 3).
}

This HRM professional explained that hiring disadvantaged people is complicated because people who are unable to find a job with an adequate salary, whether this is due to a disability or not, have the right to apply for social benefits, i.e. a monthly allowance. However, finding a paid job can have negative consequences for the right to those benefits; candidates might risk losing their monthly state payments by accepting work, which would cause substantial financial declines for those candidates. Some HRM professionals felt that this was too complex for line managers to do all this and decided to become more involved in the hiring process of disadvantaged workers. An HRM professional made this clear by giving a practical example of a case that she had recently encountered: 
"Yesterday I went to a location and had a talk with a disadvantaged
worker who now has a contract for 12.5 to 15 hours per week. The
employee insurance agency has all these rules that state that 'if you
have to do extra work, then we will cut your benefits'. So, even though
she is working, she doesn't have more income per month than when she
only had her benefits. That is not very motivating" (HRM professional 4).

Clearly, the HRM professionals at Dutch Cleaners are rather proactive in developing this new routine. As such, it is different from their previous role in which they were mere advisors and administrators, as they now have become active intermediaries in hiring new people at the work floor level. In so doing, these HRM professionals have created an expert position for themselves in hiring disadvantaged workers.

Line manager's perspective: maintaining the lead in the hiring process

Even though the HRM professionals had claimed their role as experts in hiring disadvantaged workers through their actions, those actions were perceived somewhat differently by the company's line managers. For example, the following line manager downplayed the role of the HRM professional considerably by still putting them in their role of merely the HRM services provider and advisor on legal issues:

\footnotetext{
"When I start with a new trial period, or the disadvantaged worker will be the first placed that location, then I ask the HRM professional to check the trial agreement. I do so because I don't know the legal terms. That is her sole role in the entire process" (Line manager 1).
}

Another line manager describes a similar process and makes use of employment agencies contacted by himself to seek for disadvantaged workers: 
"If I ask the HRM professional to do it, then I will receive 12 letters from people who do not meet the requirements that we have. Now we have decided to invite people from those agencies [with databases of disadvantaged workers] to the locations so they can see the work place and learn what kind of people we are looking for. That approach is so much more effective than going through the HRM professional's network first. We can work with these parties structurally. I also see the same approach by my colleagues and they have become very involved in creating their own networks. The HRM professional can give us updates of how the outside world is doing this and negotiate financial matters" (line manager 2).

Also the following line manager indicates that he only asks for advice from HRM professionals in cases of doubts regarding legal issues or when negotiations around subsidies for disadvantaged workers are needed. However, HRM professionals were not asked to intervene in the hiring itself:

"I have a contact at the employee insurance agency and tell her that I am looking for a disadvantaged worker with these and these competencies. Then I receive e-mails from candidates, do the talks, and inform the HRM professional about the new employee. She can then give me information about financial models, the type and magnitude of 'how disadvantaged' a candidate is, the potential subsidy connected to that percentage, really providing deeper knowledge of disadvantaged workers." (line manager 3).

Hence, we observed how, at some units and locations, line managers were doing most recruitment and selection tasks. At those locations, line managers felt empowered to initiate contacts with external employment agencies with databases of disadvantaged workers seeking job opportunities. Contrary to the HRM professional's efforts to establish different patterns in this new hiring routine that emphasised their role, the involvement of the HRM professional in the hiring process at these locations was less crucial than stated by them. In fact, line managers downplayed the HRM professional's contribution to that of a mere HRM service provider. One line manager even explained that, these days, employment agencies who have databases of disadvantaged workers are approaching her directly to offer suitable candidates rather than line managers contacting them for potential candidates as used to be the case in the existing hiring routine: 
"Since I have worked a lot with disadvantaged workers, and have created a lot of contacts with employment agencies with databases of disadvantaged workers, they now know what I am looking for and what my demands are. So nowadays they call me "I have found a suitable person. Do you have a place to accommodate him?'.

A middle-level manager took part in this interview and he spontaneously remarked that:

"The system has turned upside-down. First, we would go to them [employment agency] and tell them we need people, but nowadays, they say: we need to talk to ['name of the line manager']" (Middle-level manager 1).

Apart from working with these specific employment agencies, we also observed that line managers began looking for alternative sources to find suitable candidates. As a line manager explained, many graduates from lower educational levels experience difficulty finding a suitable job and have a rather large distance from the labour market. As such, these graduates can also be seen as disadvantaged candidates. The following line manager explains:

\footnotetext{
"I needed new employees, and got hardly any support from the company itself. So, I started looking myself, and identified an opportunity at the lower secondary professional education level. I started thinking about how to approach them, because our line of business is not really 'sexy'. I went to their school and asked them 'who likes to start early in the morning?' Nobody responded positively. So I asked 'Who likes to finish early? Because then you should start working for me.' Well, all of them were enthusiastic about that prospect. So you constantly have to look for ways to make it interesting for them to work for Dutch Cleaners" (Line manager 2).
}

It was clear that HRM managers and line managers both had their own perspectives and importance of certain actions. Although opposing each other to a large extend, it seemed that new patterns emerge which are important for the success of the development of the routine for hiring disadvantaged workers. Especially the liberty that these line managers took upon themselves in seeking for sources and ensuring a match between worker and 
requirements appeared to be important. We now turn to the perspective of the middlelevel managers and highlight their contributions to create this new hiring routine.

\title{
Middle-level manager's perspective: self-involvement
}

Interestingly, whereas the company's HRM professionals explain that middle-level managers are hardly involved in both the previous and the new hiring routine, the middlelevel managers themselves described this differently. As such, they seem to be more involved in the hiring process than described by the HRM professionals. For instance, the decision to fill a vacant position with either a regular employee or a disadvantaged one was sometimes taken by middle-level managers:

"When a vacancy opens up, I analyse whether we could fill it with a
disadvantaged worker or not. If there are already some disadvantaged
workers at that location, I think that we should provide the opportunity
for a regular candidate, a housewife for example. You should have a mix,
not all employees should be disadvantaged" (Middle-level manager 3).

Another middle-level manager explained that HRM professionals are too distant from the work floor to understand which disadvantaged workers are suitable for which jobs:

\begin{abstract}
"You should consider when you need an HRM professional. Do you need her as a contact person with job agencies? Not really. What you need them for is to motivate the line managers to actively look for disadvantaged workers. In addition, their role can be relevant when it comes to legal issues, what can I do, what can't I do? In that, the HRM professional has a clear role, but managing on the shop floor, I think that this should be organised as low as possible - on the shop floor level (Middle-level manager 1).
\end{abstract}

He adds to this that the process of hiring disadvantaged workers through the HRM professional would take far too long: 
"If I call the HRM professional to tell her that I have a vacancy, then she will discuss that with an agent at national level, who connects her to a regional agent, who connects her to a local agent, who tells her that her or she will have a suitable candidate in 6 to 8 weeks. That is a bit too late I guess..."

A further difference in interpretation between HRM professionals and the middle-level managers is found in the degree of freedom assigned to the line managers in hiring suitable candidates. Whereas HRM professionals explained that the line managers were free to choose the best candidate, in practice this differed between locations. Some middle-level managers indicated that the final decision was taken by the line managers and themselves while at other locations, the HRM professional or the supervisor was also part of this process:

"I pick five candidates, after which the line manager and I have interviews with them. Then we discuss 'he qualifies, but he doesn't'. Later, the line manager makes a follow-up appointment with two of them and invites them to the work place so they can see what they would be doing. So I definitely influence the hiring process by deciding which five candidates we will interview in the first place" (Middle-level manager 4).

Another middle-level manager offered a different interpretation of the process:

"I make the final choice together with the line manager. I state my preference, and he or she can do the same. Usually we agree" (Middlelevel manager 3).

The middle-level managers' influence does not end there. A middle-level manager explained that he continues to play a role in the process even after the disadvantaged worker has begun working at Dutch Cleaners: 
"I keep monitoring: How is the coaching going? Do the disadvantaged workers receive guidance? Do they get appraisal talks? I also have a consultant training the line managers. And gradually you see that if we organise it this way, that we can decentralise responsibilities and it becomes just like regular employees" (Middle-level manager 4).

This brings an interesting point, as the middle-level manager indicates to strictly monitor the hiring process, as well as other HRM practices such as training and development and appraisal talks, until the moment that he can decentralise it, hence, leave it to the responsibility of the line managers themselves. Hence, the middle-level manager claims to have a larger role in the new hiring routine, but also that he decreases his involvement once line managers have adopted it to his satisfaction. This indicates the evolutionary and temporal character of routines, as it suggests that the routine will continue to evolve in the near future.

In a similar vein, another middle-level manager explained that a recent negative experience regarding a disadvantaged worker has caused him to become more involved in future hiring processes of disadvantaged workers, hence showing an opposite trend to what the previous manager had reported:

\footnotetext{
"Next time I want to be more involved. The introductory interview [the line manager and the HRM professional] can do without me, but when it becomes concrete, I want to get a seat at the table. Supervising those employees costs a lot of time and energy, so I think we should make a well-considered choice" (Middle-level manager 2).
}

Finally, another middle-level manager explained how he tried to motivate line managers to hire disadvantaged workers by highlighting the possible financial benefits:

\footnotetext{
"I tell my line managers 'if you are looking for someone, you first contact one of the employment agencies'. There you can get employees free for two or three months, or for a low hourly wage. So, I always discuss the financial consequences of their choice with them. That should be an incentive to put time and effort into making the policy succeed" (Middlelevel manager 5).
}

The HRM professionals were supportive in making this new routine work. They tried to establish an infrastructure first as they were aware of the legal issues and peculiarities of 
hiring disadvantaged workers and considered the line managers of no experts in this regard. However, the concern of the line managers is that the HRM professionals were not aware or the requirements on the shop floor. As a consequence, the line managers established their own relationships with special employment agencies and even schools to attract suitable candidates while leaving merely the financial and legal issues to the HRM professionals. Hence, line managers contributed to the development of the new hiring routine by establishing relevant networks with organisations who could bring them into contact with suitable disadvantaged workers. In turn, the middle-level managers performed actions to make sure that they remained considered as decision makers to ensure that a right balance between the number of advantaged and disadvantaged workers is maintained at the local level. As such, positioned themselves between the HRM professional and line manager causing a stabilizing effect which was important for stabilising the new routine.

\subsection{DISCUSSION}

In this chapter, we have observed closely how members of an organisation enact a new routine aimed at hiring disadvantaged workers. We observed a remarkable range of actions in the way in which the desire to become an inclusive organisation by adding a large number of disadvantaged workers to the company's workforce was translated into new practices. Given that no envisioned pattern of action was created at the moment of taking the decision to become an inclusive organisation, the policymakers' approach was largely bottom-up, aiming for practice to create policy rather than the other way around. However, we should take into consideration that top managers of Dutch Cleaners deliberately chose for a bottom-up approach. Therefore, top managers took the role of an 'invisible policy setter', who decided to devolve actual sense-making of the hiring routines to organisational actors like HRM professionals, middle-level, and line managers. The result was that several groups of actors - HRM professionals, line managers and middle-level managers - were trying to gain control of the process by placing themselves at its centre.

We have also shown, as suggested by Berente et al. (2016), that a certain flexibility in local work practices is needed; in this case to realise an HRM policy change in organisational routines. We add that this also implies changes in the specific roles of organisational members involved in the execution of a new HRM practice. Moreover, as indicated by the middle-level manager who started monitoring the observation of HRM activities such as the delivery of appraisal talks and training opportunities for disadvantaged workers, but also remarked that this temporary involvement would be of a lesser degree once line managers would do so satisfactorily. This suggests that routines continue to evolve, since organisational actors develop their roles over time. This is in line with Berente 
et al. who state that "routines continue to adapt..., and this dynamic adjustment can be expected to continue" (2016, p. 567).

Ironically, we also observed how members ignored their colleagues' efforts of the newly introduced HRM policy, but nevertheless managed to exceed the overarching organisational goal by working around such efforts and continuing to rely on existing HRM hiring practices. By studying these workarounds we add to the findings of Bertels et al. (2016) who observed how actors of a Canadian oil company worked around strategies of action that were misaligned with the espoused routine. This led to a strategy of action that did align with the espoused routine. As in the case of Dutch Cleaners, the actors in the study of Bertels et al. (2016) were driven by a clear objective, leaving them no choice but to work around the strategy. We have demonstrated how, by working around each other's efforts, organisational actors created a stable, routinized and successful practice which also entailed the change of roles and the establishment of new connections outside the organisation.

By means of our in-depth case study we have contributed to the literature on routine dynamics by providing empirical evidence about the process in which organisational members create, maintain and transform organisational routines (Feldman \& Pentland, 2003). Instead of policy and practices that are created by people far from the shop floor, the bottom-up emergence of routines has created organically grown and fitting practices for hiring disadvantaged workers. This led to relatively little resistance to the new policy and the new group of employees, because the organisational actors who were responsible of hiring disadvantaged workers, were involved intensively in the entire process.

Our findings also contribute to the HRM implementation literature by demonstrating the dynamics involved in bringing HRM policy to life and we have shown that there is more to this than a straightforward top-down process. Moreover, we have provided empirical insights into the process in which new HRM policies and practices develop from an idea into fully working organisational HRM instruments or tools (Van Mierlo et al., 2018). In most HRM implementation literature, the implementation of HRM policy is largely conceived as a top-down initiated, linear process (e.g. Bowen \& Ostroff, 2004; Wright \& Nishii, 2013), suggesting that HRM implementation can be planned and enacted by following pre-defined stages with actors having clearly defined roles (Guest \& Bos-Nehles, 2013). Based on this premise, scholars have proposed clearly demarcated roles and responsibilities for a variety of actors during the HRM implementation process (Valverde et al., 2006) suggesting that they are in charge of the HRM implementation process, rather than also being a part of it. Such an assumption dictates that without a predefined implementation plan, HRM practices do not get alive in organisations. We have demonstrated that the creation of new HRM practices is not solely the task of policy makers or HRM professionals, but also of middle-level and line managers. This bottom-up creation 
of HRM makes sense; after all, line managers are often made responsible for the introduction of most HRM practices. We particularly revealed that implementing a new HRM policy does not necessarily need to be planned in detail from the start, but that it can develop by actually doing it, hence by using a bottom up approach. This way, organisational actors at Dutch Cleaners who were involved in hiring disadvantaged workers managed to meet - and even exceed - their company's objectives.

\section{Limitations and future research}

We are fully aware that even though our study has provided empirical insights into the way in which organisational routines can be developed without an envisioned pattern of action, it also has its limitations. At the same time, these limitations provide opportunities for future studies.

Since we mainly relied on interviews instead of observations, we were unable to observe the emergence of routine dynamics in real-time. Hence, the performative aspects of routines were not directly observable for us. However, through the usage of retrospective questioning during the interviews, we were able to reconstruct the actions to bring new routines to live. Future studies could contribute by incorporating observations and maybe other techniques like diary-keeping in the data collection process. Another limitation of this study is that we executed it in an organisation in which a culture of nonenvisioned policy implementation was already to some extent present. As such, some organisational actors might have obtained experience with this kind of policy change prior to the one aimed at hiring disadvantaged workers. Therefore, we encourage scholars to study the emergence of non-envisioned routines in different contexts in which this approach is less common, like governmental organisations and large companies. We also believe it would be valuable to study routine emergence in single-unit organisations, instead of in decentralised business-units, as was the case in this study. Lastly, it would be very valuable to further study the role of multiple points of view in the development of routines.

\subsection{CONCLUSIONS}

We analysed the emergence of a new hiring routine by asking ourselves how they are created without a clear implementation plan. We found that the absence of such a plan opens up opportunities for key actors involved in the creation of this routine followed by specific actions. Examples are the HRM professionals, who saw and took the opportunity to create a central position for themselves by calling themselves experts, middle-level managers, who used their hierarchical authority to intervene and stabilise the new routine, and the line managers, who appeared to be creative in engaging parties outside Dutch Cleaners to seek for the right match, a task that they took upon them without the consent 
of the HRM professionals. Indeed, we also showed that this process entailed workarounds on behalf of the line-managers to circumvent the involvement of these HRM professionals who attempted to justify their importance by their expert knowledge of this worker category. Although each of these actors maintained their own perspective on the responsibilities and actions needed by others to make this new hiring routine work, the end result is that they still managed to stabilise the routine and achieve outcomes beyond the expectations of their top managers. In line with this, we see that changing organisational policies provides organisational actors opportunities to renegotiate their roles in the organisation by making use of their particular knowledge and expertise. This led to HRM professionals making use of their network for finding disadvantaged workers, line managers of their knowledge regarding operational tasks, and middle-level managers of their strategic knowledge of operational tasks and their authority over the line managers.

Our overall conclusion is that - even though the lack of formal aspects of a new HRM policy at the start of its implementation can lead to misunderstandings in what needs to be done and by whom - a bottom-up approach definitely has its advantages. Through all of the efforts of organisational actors, they all have obtained experience with hiring disadvantaged workers. As a result, they had the opportunity to freely depart from existing routines whenever deemed necessary in the pursuit of realising the goal of the organisation. 


\title{
CHAPTER 5
}

\section{Action research and HRM}

\author{
Experience without theory is blind, but theory without \\ experience is mere intellectual play
}

\section{- Immanuel Kant}

Throughout this dissertation, I have demonstrated the complexities and dynamics related to the HRM implementation process. Just as HRM implementation, action research involves stages such as idea generation, design, implementation, and monitoring. In this chapter, I claim that adopting an action research approach can create even better insights into the HRM implementation process than merely a deductive or inductive research approach. Furthermore, by adopting an action research approach, HRM scholars can contribute considerably to HRM theory building as well as organisational problem solving.

This chapter is under R\&R at an ISI international journal. The manuscript is currently in the process of being revised and resubmitted based on the feedback of editors and reviewers. 


\begin{abstract}
In this chapter we review the current use of action research in the field of Human Resource Management (HRM), and we assess its further potential contribution to the field. We show that action research works best and to its utmost capacity if researchers and practitioners co-operate intensively to resolve an organisational issue and inform academic knowledge. Although action research is used in only a handful of HRM papers (from our analysis of 3000 manuscripts), its contribution for those papers is substantial. Action Research is not without challenges. That is why, to inspire and support HRM scholars, we offer guidelines for conducting HRM action research projects. We believe that action research gives HRM scholars the opportunity to undertake research that has a great potential to develop new scholarly questions and to contribute to theory development. It also gets them out of their comfort zone and it actually matters for practice.
\end{abstract}

Keywords: HRM; Action Research; Societal Relevance; Theory Development; Guidelines

\title{
5.1. INTRODUCTION
}

There is a well-articulated understanding that the objective of the academic discipline of Human Resource Management (HRM) is to develop knowledge that informs organisations in choosing, designing and implementing HRM policies and practices in ways that can positively influence multilevel outcomes. Indeed, over past decades, HRM scholars have expended a lot of effort investigating the relationship between HRM and individual-level outcomes, such as job satisfaction, innovative work behaviour, and employee performance, as well as investigating organisational-level outcomes, such as productivity, profit, and customer satisfaction (e.g. Beer, Boselie, \& Brewster, 2015; Chang \& Chen, 2011; Huselid, 1995; Takeuchi, Lepak, Wang, \& Takeuchi, 2007). However, we have made two observations which indicate that scholars in the academic discipline of HRM have not managed to make as much progress as can be expected.

The first observation is that academic knowledge in the field of HRM is often of a general character, aimed mainly at advancing scholarly knowledge (e.g. Kaufman, 2012). As a consequence, organisations may adopt HRM policies without really knowing whether they match the organisation's structure or culture, which would decrease the possibility that they could produce the desired results. Conversely, HRM scholars often design and reinvent theoretical models that have the potential to inform organisations and help them to adopt a more efficient HRM policy. Nonetheless, often their solutions are not easy to put into practice because practitioners either: rarely consult academic journals (Pullin, Knight, Stone, \& Charman, 2004); prefer consulting other practitioners for practical issues (Rynes et al., 2002); or do not speak the same language as scholars (Simón \& Ferreiro, 2017). As a 
result of the lack of exchange between academic knowledge and practitioners, a lot of effort of HRM scholars has not informed organisational HRM policies and practices to the desired extent (Beer, 2017). As a result, a great gap exists between HRM scholars and HRM practitioners.

Giving attention to the gap between academic research in the field of HRM and its application by practitioners is far from new. For instance, Rynes, Giluk and Brown (2007) observed that HRM practitioners are scarcely interested in the topics about which HRM researchers report. Bailey (2016, p. 1) remarked that "Given the focus on engagement amongst both practitioners and academics, it would seem that this would be one topic on which there would be scope for a free flow of information between the two communities". This does not seem to be the case. Kaufman (2012, p. 12) judges the effort of HRM researchers with a " $D$ to F grade" because they have been incapable of developing accurate theory that can contribute to HRM practice, and providing an accurate historical overview of HRM. He continued to state that HRM scholars are "continuously telling the practitioners they need to become business partners, focus on vertical and horizontal fit issues, and get a seat at the strategy table, and yet five of the big six research findings have very little connection to the strategy/business partner role." (p.16). Finally, in his reflection on the 30year development of HRM research, Beer (2015) calls on HRM scholars to produce useful, actionable knowledge, in order to close "the widening gap between academic normal science and practice" (p. 418). He suggested the gap might be closed by doing action research; a scientific approach for inquiry aimed at solving real-world problems, as well as advancing scholarly knowledge (Coghlan, 2011). In this paper we follow up on this suggestion.

The second observation is that most of the core HRM models and concepts were formulated in the 1980s, or were borrowed from larger theories from other disciplines from the 1970s. This is the case, despite a massive growth in the number of HRM journals and articles, the prevalence of HRM discourse in the general management literature, and the influence of talent management in modern society. If we paraphrase what Davis (2010, p. 691) wrote about organisational theory, we can say that HRM studies sometimes appear to be a "living museum of the 1980s". We see that, as an academic discipline, HRM heavily builds on theories from other disciplines. The replicated models resemble more an analytical exercise, rather than concepts that capture the rich manifestation of practical HRM in organisations. The discipline of HRM scholarship has been known for importing theories from other fields: Resource Based View (Boxall, 1996; Maatman, Bondarouk, \& Looise, 2010; Wright, McMahan, \& McWilliams, 1994), Intellectual Capital (Meijerink, Bondarouk, \& Kees Looise, 2012), Transaction Cost Analysis (Klaas, McClendon, \& Gainey, 1999; Lepak \& Snell, 2002; Y. Yin, Wang, \& Lu, 2018), and Attribution Theory (Bowen \& 
Ostroff, 2004; Nishii et al., 2008; Ostroff \& Bowen, 2016). For more than three decades, HRM research reflects a picture of a discipline that has somewhat borrowed theories, research questions and methods from other fields, but we argue that by opening its perspective on the use of different research approaches, the field of HRM can evolve to the next level.

In this paper, we make a plea for HRM researchers to treat HRM practices and policies as a subject of inquiry in their own right; instead of merely new empirical sites to test, prove, and modify old models. Probably, when HRM models were in their early stages of formation (Beer, Spector, Lawrence, \& Mills, 1984; Fombrun, Tichy, \& Devanna, 1984), there was an energetic discussion about the growing significance of strategic people management in organisations. But nowadays, every CEO speaks of the importance of talent as a source of business success. Unfortunately, a serious underestimation of the significance of speed of change in modern HRM and a lack of deep attention to its complexity, influence, power, and interconnectedness with other business functions, has resulted in the observation that HRM concepts do not keep pace with real change, and do not inform practice enough.

As we will demonstrate in this paper, we consider action research as a research strategy, which, through its problem-based nature, allows scholarly research to find new questions, keep up with changes in HRM and inform HRM practice. Thereby, its adoption has the potential to advance the academic discipline of HRM.

Action research is already an accepted strategy approach in numerous other academic fields, for example, information systems (e.g. Baskerville, 1999), information technology (e.g. Dymek, 2008), and healthcare management (e.g. Chiu, 2007). Furthermore, both the SAGE Handbook of Action Research (Reason \& Bradbury, 2001) and the Action Research Journal have gathered a substantial readership (Bradbury Huang, 2010). However, as we will show in this paper, the academic discipline of HRM does not benefit from all advantages of this method as yet. Meanwhile, empirical studies based on action research in HRM are, at best, uncommon (Zhang, Levenson, \& Crossley, 2015).

A recent study of Zhang et al. (2015) provided examples of action research in the field of management research. Most striking was that, while scanning their selection of articles, we were unable to find the term 'action research' in most publications. Subsequently, to obtain insights into the reason for the near absence of action research in HRM, we consulted leading HRM and action research scholars as well as editors of HRMfocused journals in person. Some of them suggested that, due to the reluctance shown by HRM journals for publishing action research studies, HRM scholars might have decided to avoid labelling their action research studies as such. Given the lack of clarity on the actual 
use of action research in the field of HRM, as well as the potential added value it could bring, it is well worth looking into this more in depth.

Therefore, our research aim is threefold. Firstly, we want to theorise the potential contribution of action research for both HRM scholars and practitioners, demonstrating how the research strategy could contribute to a more informed understanding of human behaviour within organisations and the application of HRM models. Secondly, we want to provide an overview of the present use of action research as a research strategy in HRM literature. Finally, we offer guidelines for implementing HRM-related action research projects, aiming to inspire HRM scholars to conduct empirical studies inspired by action research, and to provide practitioners with a sound motive for opening their doors to action research-based HRM studies.

This paper is organised as follows. Firstly, we will give an overview of action research and provide our own definition. Secondly, we present findings of our review of the current use of action research in academic HRM journals. Thirdly, we analyse several stages of action research, after which we provide guidelines for researchers who might consider doing an HRM action research study. Lastly, we draw conclusions and offer recommendations for both scholars and practitioners.

\subsection{KEY PRINCIPLES OF ACTION RESEARCH}

The term 'action research' was introduced by 'founding father', Kurt Lewin, in 1946 (e.g. Coughlan \& Coghlan, 2002). Inspired by a growing interest in using scientific methods for supporting the inclusion of minority groups in education and society (Wallace, 1987), Lewin defined the term 'action research' as "a comparative research on the conditions and effects of various forms of social action and research leading to social action" (Lewin, 1946, p. 35). Knowledge of the specific situation, Lewin suggested, was to be obtained from interaction with that actual situation, whilst taking the influence of uncontrollable factors into account. Therefore, instead of isolating a single element of a complex system from its natural environment and studying it in a closed-off facility, such as a laboratory or research facility, Lewin was convinced that it needed to be studied in its natural habitat, thereby taking the influence of all of its unpredictable elements into account (Dickens \& Watkins, 1999).

Lewin did not have much time to work his ideas out very thoroughly; he died one year after the publication of his 1946 study. As a consequence, scholars were forced to interpret his ideas idiosyncratically and build upon them (for an overview of (sub-)streams of action research, see Coghlan (2011, pp. 67-68)). Dickens and Watkins (1999) saw the lack of a broadly accepted definition and form of action research both as a strength, as well as one of its main weaknesses. For even though it does allow the researcher to adopt the elements most suitable for his or her study, the wide array of definitions and forms of action 
research makes it vulnerable to misinterpretation. Moreover, Baskerville and Wood-Harper (1996) note that poorly executed action research has impoverished its reputation. As a consequence, over 70 years after its birth, action research serves more as an umbrella term, than one of a unified scientific research approach. Therefore, to clarify our own interpretation of action research, and for the purpose of this study, we propose the following definition:

Action research is a participative research strategy consisting of cycles of stages in which scholars and practitioners collaborate using academic literature and research methods in both solving actual organisational problems and advancing scholarly knowledge.

Action research is grounded in the idea that people are more likely to adopt new ways of working if they actively participate in the decision-making process (Baskerville \& WoodHarper, 1996). Consequently, people are more likely to use and adopt research results if they are actively involved in the research process. Therefore, action research is participative. This implies that researchers do not function as outsiders who are - what they call - 'objectively' observing the phenomenon, but rather they become actively involved and as intervening stakeholders who influence the subject of study by their behaviour and role as insiders (Brannick \& Coghlan, 2007). Action research merges theory with praxis and includes "an involvement with members of an organization over a matter which is of genuine concern to them" (Eden \& Huxham, 1996, p. 75). So, rather than starting from an aim to fill a theoretical gap, action researchers depart from the aim to solve existing organisational problems by using scientific methods and theory: "Only when the strategic issues of the organization are incorporated as part of the basis for doing the work does it typically become action research" (Zhang et al., 2015, p. 162). However, the goal is not merely to improve the situation of study or to derive knowledge from it, but both (Coughlan \& Coghlan, 2002). Therefore, an important element of action research is that its outcomes also inform academic literature.

Its heavy focus on creating applied solutions for urgent organisational problems is what distinguishes action research from other empirical research strategies, which are seen by some as mostly aimed at advancing scholarly knowledge and, in most cases, do not even consider implications for practice (Doh, 2015). Similarly, action research distinguishes itself from consultancy because of its extensive usage of academic literature (Zhang et al., 2015), scientific methods, and a less linear approach to organisational problems than those generally applied by consultants (Coughlan \& Coghlan, 2002). 


\subsection{STAGES OF ACTION RESEARCH}

As we emphasize in our definition, action research consists of several stages. Inspired by Baskerville and Wood-Harper (1996), we identify six interconnected stages of action research processes, possibly repeated until the organisational problem has been solved satisfactorily and scholarly knowledge has been advanced. We have visualised these stages in Figure 7. In the remainder of this section we will explain the potential benefits of action research more into detail based on these stages.

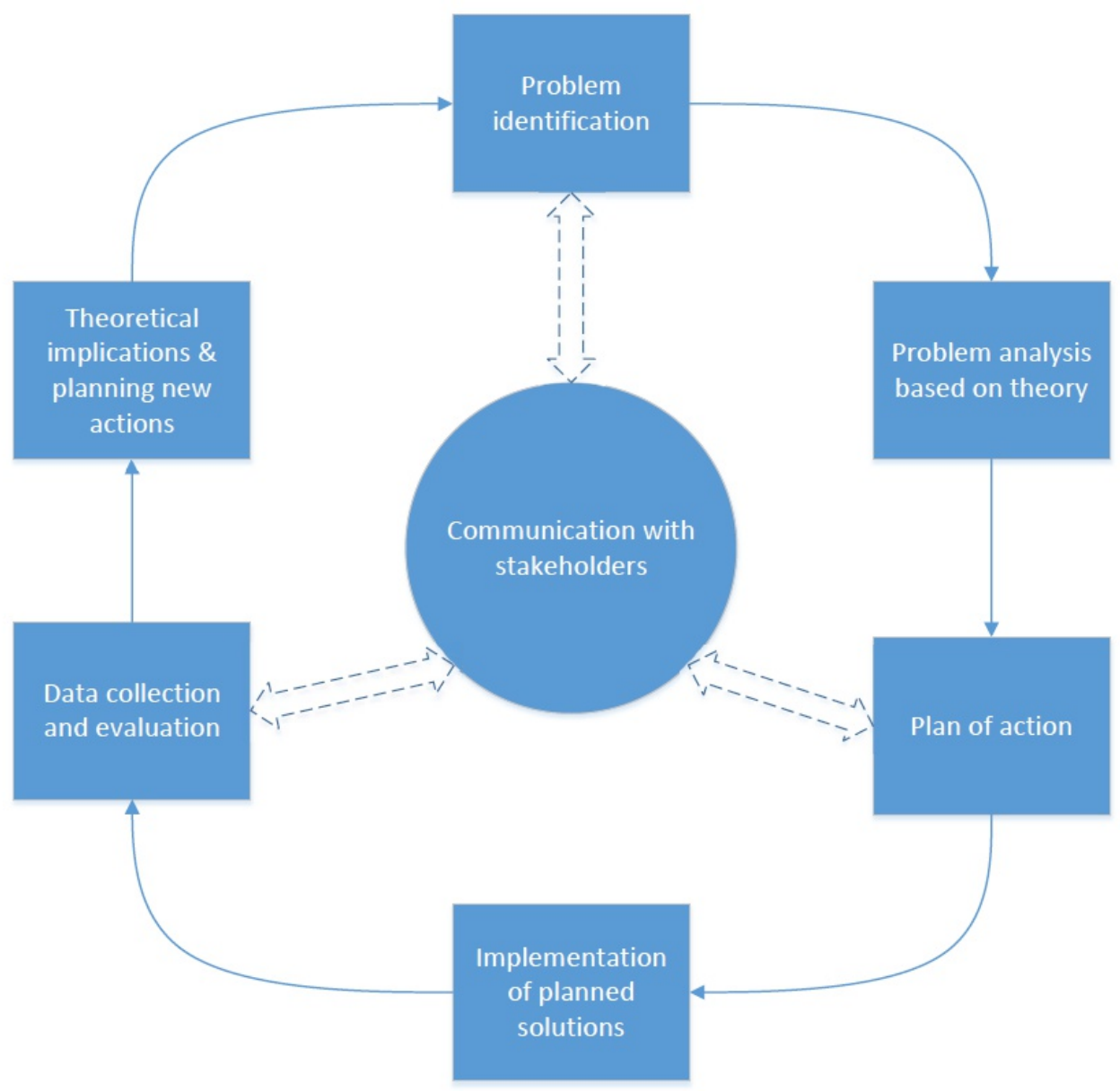

Figure 7: Stages of action research.

\section{Stage 1: Problem identification}

In the first stage of an action research project the focus lies on identification of the organisational problem and development of the research question(s). One of the key 
characteristics of action research, as well as one of its main strengths, is its participatory character. This means that collaboration between researchers and practitioners takes place throughout all stages of the research process (Coghlan, 2011). This is also the case during the initial identification of the problem, in which both parties work together to identify the problem and develop research questions around it: "[T]he research questions...are designed in cooperation with the organization with an objective of making the research results as applicable as possible" (Zhang et al., 2015, p. 153).

Involving practitioners in developing the research question might contradict with the modus operandi of mainstream researchers, who consider the development of research questions to be the sole responsibility of the researcher. However, the researchers will be able to safeguard the methodological quality, as well as the academic relevance of the research. The problem-based development of the research question also has the advantage that the researcher has less influence over what he or she will investigate compared to regular research endeavours. Therefore, the involvement of practitioners, in the first stage of the action research cycle, gives researchers the opportunity to become acquainted with the academic literature and theories that they might be less familiar with.

\section{Stage 2: Problem analysis}

In the second stage of the action research cycle, scholarly knowledge will serve to analyse thoroughly the organisational problem and potential solutions. Different views exist among action researchers about whether an extensive literature review, before entering the phase of data collection and analysis, is necessary or not. For instance, Zhang et al. (2015) opted for a grounded theory approach that emphasised the need for empirical observation of the organisational problem in the beginning of the research process. On the other hand, Huang and Martin-Taylor (2013) showed that the preliminary use of theory - in their case the Technology Acceptance Model - added to their action research process. We argue that both approaches are possible, and both have the possibility to lead to revealing results. Starting from a grounded approach allows the researcher to enter the field in an unbiased, open manner, to create a conceptual framework of the organisational problem in an early stage. This helps both researchers and practitioners to give meaning to the phenomenon during the follow-up of the research process. Researchers may derive such a framework by comparing empirical observations with state-of-the-art theories and academic literature regarding the topic of investigation. Depending on the research approach adopted (stage 6) the theory that was used will be reflected upon. 


\section{Stage 3: Plan of action}

In the third stage, researchers develop a plan of action which contains possible solutions for the identified problem, again in close cooperation with the practitioners. These solutions can be created by using participatory research methods, such as workshops (Fox \& Cowan, 2015), focus groups (Benschop, van den Brink, Doorewaard, \& Leenders, 2013; Servon \& Visser, 2011), participatory modelling (Bleijenbergh \& Van Engen, 2015; Grössler \& Zock, 2010), or other decision support systems (Franco \& Rouwette, 2011). In this stage, the collaboration between researchers and practitioners is necessary to create consensus about and commitment to the proposed plan of action (Franco \& Rouwette, 2011).

The main advantage of making use of an action research approach in this stage is that researchers will be more aware of the organisation's possibilities and limitations because of their prior involvement with the organisation. Furthermore, basing the implementation (stage 4), not only on 'gut feeling', but also on rigorous theoretical sources and recognised (participatory) research methods distinguishes action research from implementation done by most hired consultants or members of the organisation itself.

\section{Stage 4: Implementation}

In the fourth stage, the researchers will follow, or even support, the implementation of the plan of action designed in the third stage. This means that the practitioners and researchers will be involved in a real-life experiment of implementing the planned solutions with the objective to end the organisational problem. Often, it is advisable that researchers collect baseline information before the implementation starts $(T=0)$, in order to observe its results. The knowledge the researcher has obtained throughout the process contributes to the implementation. The researcher will be able to provide tailor-made advice on how to handle implementation obstacles and act in case of problems of any kind.

\section{Stage 5: Data collection and evaluation}

In the fifth stage, researchers and practitioners collect empirical data that supports them in determining whether the organisational problem has been resolved. A large variety of (quantitative or qualitative) data collection methods are suitable for obtaining empirical data during action research projects (Coughlan \& Coghlan, 2002). Hence, results can be based on questionnaires, interviews, focus groups, collection of documents, or (participant) observations. The advantage of applying action research in this stage is that it allows the researcher to analyse the data by making use of prior knowledge of the organisational culture, terms, day-to-day routines, and habits that organisational members demonstrate. Therefore, they will be able to assess the information in a much more efficient way than if they did not have this knowledge. Moreover, it allows them to place findings in perspective. 
If the organisational problem has been resolved, is it important to determine whether this was the result of implementing the plan of action, or whether other explanations are possible. In case the problem was not resolved entirely, the researchers and practitioners may have to start a new action research cycle and go back to the phase of problem identification and problem analysis. This process can be repeated until the problem has been solved.

\section{Stage 6: Theory development and looking ahead}

In the sixth stage, development and dissemination of scholarly knowledge about HRM policies stands central. Researchers may be involved in three types of dissemination. Firstly, the researchers can communicate findings to higher management of the organisation in which the action research was performed. Subsequently, they can decide if, and to what extent, they are satisfied with the results and whether to continue with the research process. Secondly, the scholars can use the findings and communicate them to other practitioners via, for example, professional journals. The findings might serve as best practices for other organisations. Finally, action research may, not only contribute to problem solving, but also to developing theory. Therefore, scholars may share their research findings in the form of academic papers at conferences or in academic journals.

The advantage of having used an action research strategy will pay off in this stage. Authors (Beer, 2015; Kaufman, 2012; Vosburgh, 2017) elaborated on the importance of doing research that was both academically and practically relevant, as well as rigorous. Furthermore, whereas the balance might lean more towards the academic relevance in most research, this is not the case with well-executed action research projects. Another advantage is that the outcomes of the action research project are based on an extremely intensive examination of organisational actors' day-to-day realities. Hence, the researchers can contribute with very detailed descriptions of their phenomenon of interest.

\subsection{HRM-FOCUSED ACTION RESEARCH}

We performed a literature review to determine the actual contribution of action research to the field of HRM. In total, we have reviewed more than 3000 papers published between the year 2000 and 2017 in four HRM-focused journals (Human Resource Management, Human Resource Management Journal, The International Journal of Human Resource Management, Human Resource Management Review), and the journal Action Research. The HRM journals were assessed on the keyword 'Action Research', whereas the journal Action Research was scanned on 'Human Resource Management', 'HR', and 'HRM'. We found the combination of 'action research' and HRM occurred in total 44 times (for a complete overview, see Appendix E). In some papers in which the search terms coincided, action 
research was not used as a research strategy, but was merely mentioned or used as a reference to an action research study.

Something that caught our attention was the large number of authors that have tried to motivate or inspire other HRM researchers to make use of action research in the field of HRM throughout the years. This was most often the case for authors suggesting future action research endeavours (15 times). We also found authors trying to set a research agenda for action research in the field of HRM (7 times). Therefore, in almost half the papers in which our search terms coincided, this was the result of authors suggesting the use of action research in the near future. Hence, it seems that some leading HRM scholars like Michael Beer (Beer, 2015, 2017; Beer \& Cannon, 2004), Cascio (2015), and Levenson (Levenson, 2017; Zhang et al., 2015) were convinced about the potential benefits of doing action research for the discipline. However, only a few HRM scholars have felt the need or seen the opportunity to do so, as is illustrated by the fact that we found only a handful of papers that applied action research in the field of HRM. A consultation of HRM handbooks shows a similar pattern; there was no place for action research in them (an exception is the work of Thornhill, Lewis, Millmore and Saunders (2000)).

An overview of the HRM-action research papers can be found in Table 7. Furthermore, we provide an analysis of the added value of action research for their research contribution. 


\begin{tabular}{|c|c|}
\hline Author(s) & Topic and added value of having used action research \\
\hline $\begin{array}{l}\text { Doherty \& Dickmann } \\
\text { (2012) }\end{array}$ & $\begin{array}{l}\text { The authors described a process in which } 9 \text { companies } \\
\text { worked together into developing ROI measurement systems } \\
\text { for employees on international assignments. The action } \\
\text { research element was that researchers and practitioners } \\
\text { worked closely together. The implementation of the } \\
\text { measurement system was not discussed. } \\
\text { The authors indicated that doing action research was vital for } \\
\text { the contextualisation of their ROI measurement systems. To } \\
\text { understand the organisation's context, the involvement of } \\
\text { organisational actors played an important role in the study } \\
\text { of Doherty and Dickmann. This also safeguarded the interest } \\
\text { of the organisation in the project, as well as the suitability of } \\
\text { its outcomes: "while previous research on ROI has tended to } \\
\text { be driven by an academic impetus and agenda, the research } \\
\text { reported here adopts a process of active engagement with } \\
\text { practitioners" (p. 3440). Finally, the authors indicated that, } \\
\text { applying action research greatly improved the rigour and } \\
\text { relevance of their research, creating actionable insights for } \\
\text { the organisation in question. }\end{array}$ \\
\hline Hodges \& Martin (2012) & $\begin{array}{l}\text { The authors describe an action research project that } \\
\text { attempts to create a leadership branding culture. They } \\
\text { expressed the added value as: "critical in signalling and } \\
\text { establishing a more dialogical relationship...The gradual } \\
\text { emergence of this dialogical relationship thus helped create } \\
\text { the conditions for identity work to begin" (p. 3808). The } \\
\text { stages of the action research process were described well, as } \\
\text { were their findings. However, the authors noted that the } \\
\text { action research project did not solve the organisational } \\
\text { problem. This suggested that another action research cycle } \\
\text { would be beneficial for all parties involved. }\end{array}$ \\
\hline
\end{tabular}




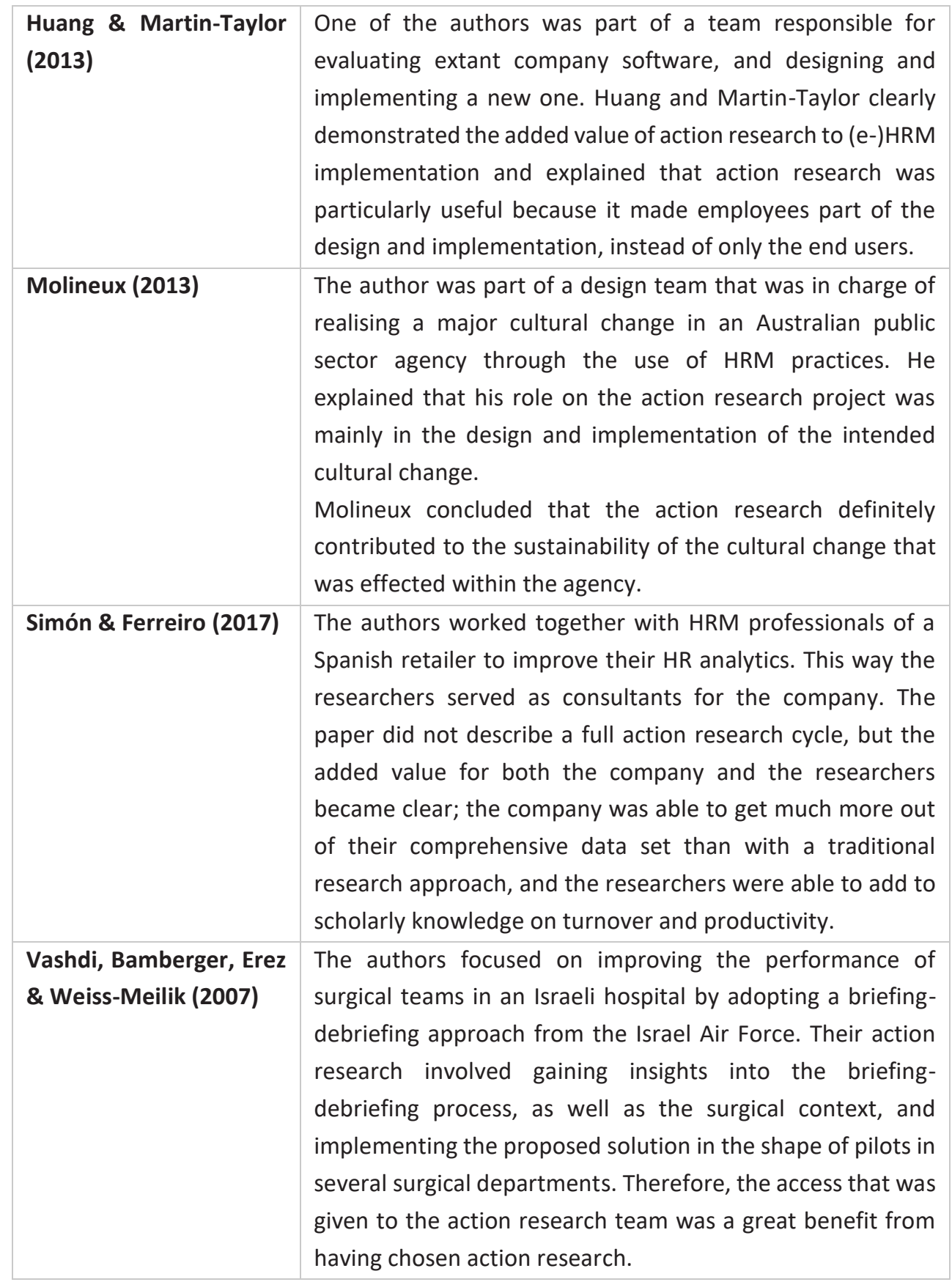

Table 7: Overview of HRM-action research papers 
The overview in Table 7 makes it clear that action research gave these HRM scholars great benefits, which they might not have had if they had not chosen this research strategy. As the example illustrate, action research supported them into doing research that was of the genuine interest for the organisation in question. Furthermore, it assured them that their solutions were both tested and adopted, thereby making a real impact in the organisation of their study.

\subsection{GUIDELINES FOR HRM-FOCUSED ACTION RESEARCH}

In this section we will provide a series of guidelines to inspire and support HRM scholars in designing HRM-focused action research. The guidelines are based on the six stages of action research and on the approaches in the action research studies in the field of HRM discussed in the previous section.

1) Discuss the organisational problem with key organisational stakeholders, such as HRM practitioners and key decision makers. To gain access to the organisation, it helps to involve well-known researchers with a good reputation among influential organisational actors (Brannick \& Coghlan, 2007).

2) Make sure to involve all organisational stakeholders. As action research encompasses stages like problem identification, designing possible solutions and implementation, a large number of stakeholders are involved. Therefore, it is essential that all of them are involved in these stages. For instance, as discussed by Mirfakhar et al. (2018) it is important to involve line managers in developing HRM practices. Moreover, Van Mierlo and Bondarouk (2018) identified the involvement of different organisational actors during the HRM implementation process. Hence, it is essential to not only involve policymakers or top managers, but all relevant stakeholders.

3) Propose a research strategy that involves empirical observation in the real life setting in order to make sure you will get an emic perspective on the organisational problem. For the field of HRM, this will possibly mean studying HRM practitioners as they perform their job or studying employees operating in their natural work environment. Such intensive empirical observations can make it difficult to gain access to the field. This stresses the importance of finding key stakeholders (guideline 1) who can serve as a gatekeeper for getting access to the organisation. Furthermore, the observations should be carefully planned, including the ethical dimensions of guaranteeing confidentially and privacy, when needed.

4) Propose a research strategy that involves participatory research methods, such as workshops, focus groups, participatory modelling and other decision support systems in developing a plan for action in close collaboration between researcher 
and (HRM) practitioner. This approach also entails that the researcher needs to integrate into the mind-set, culture and habits of the organisation to reduce the distance with the practitioners.

5) Communicate the need for a relatively large time investment of employees and (HRM) practitioners in the research process. However, the development of tailormade scholarly knowledge about the human resource management in the particular organisation and the opportunity for organisational learning will potentially compensate for this.

6) Communicate the need for a relatively long research process, since it is not possible to know in advance how many cycles of the action research process are needed to solve the organisational problem. Especially in the field of HRM, peoplerelated changes take a long time to become implemented successfully (Van Mierlo et al., 2018). Therefore, it is important to stress that action research is not appropriate for cheap solutions or 'quick fixes' of organisational problems. Moreover, it is a demanding approach for both researcher and organisation. This makes it necessary to organise the research process in such a way that resources are available for you as a researcher to invest this time. However, adopting an action research approach contributes to a working and sustainable organisational solution.

7) Make a habit of continuously reflecting on the research process. Hence, not only looking forward to the next stage or next activity, but also to continue learning during the process itself.

8) In reporting, create a clear structure of the various stages and cycles of the action research process. A good example can be found in the paper of Huang and MartinTaylor (2013) who clearly show their action research cycles, as well as the inventions of each cycle.

9) Action research claims to be closer to practice than 'mainstream' research strategies in HRM. Therefore, it is important (maybe even more than in non-action research studies) to not only describe the process of data collection, but also the contribution to scholarly knowledge.

\subsection{DISCUSSION}

In this paper, we demonstrated the potential benefits of action research for the field of HRM, and gave an overview of the present use of action research in HRM journals. Despite increasing attention for action research in organisational research, this paper shows that the research strategy of action research has not yet established itself in the field of HRM. 
The few papers that we found clearly demonstrated the added value of applying action research for scholarly knowledge and the participating organisation.

Baskerville and Wood-Harper (1996) concluded that researchers interested in action research (in an information systems context) "must recognize its tenuous stature as a scientific method" (Baskerville \& Wood-Harper, 1996, p. 237). Hence, to apply action research with the goal of getting a publication out of it, often involves a long and frustrating - but potentially very rewarding - journey. The indication that several HRM scholars purposefully avoided the term 'action research' in their papers, for the sake of being able to publish them, is striking. However, this is not surprising, given the conservative nature of the field of HRM, that holding on to mainly positivistic research traditions in which little space exists for less straightforward research philosophies, such as interpretivism and phenomenology, as well as qualitative research strategies, such as case study research.

By embracing participatory research strategies, such as action research, HRM might be better able to reward itself for the relevance of its work to real organisations and take the next step. Therefore, this paper makes a double-edged call. The first addresses HRM scholars: think about the societal relevance of your work. It is great to contribute to discussions in your field by theorising that $\mathrm{x}$ leads to more $\mathrm{y}$. However, as Lewin stated: "Research that produces nothing but books will not suffice" (Lewin, 1946, p. 35). The field of HRM is a highly relevant field, and we as HRM scholars have a privileged place in society. We have the ability to create, understand and improve the very HRM practices that our universities' policy-makers apply to enhance our performance. Therefore, we call on researchers to bring practical relevance to the forefront of HRM research.

Our second call goes out to editors of HRM journals. Throughout this paper, we have demonstrated, not only the potentially benefits of action research for HRM, but we also identified the present lack of publications applying it. As a consequence, we are missing out on great opportunities to answer the goal of Michael Beer (2015) to start really contributing to our field. As we have shown, action research has the possibility to contribute to practice and scholarly knowledge in each of its stages. Therefore, editors: open your doors for HRM-oriented action research. And while you are at it, why not start with a special issue?

We suggest that the discipline of HRM would particularly benefit from action research, in comparison with other fields of management research. The benefits of action research for scholars, practitioners and organisations in the field of HRM are found in its human-centred nature. Given the fact that human behaviour is extremely hard to plan meticulously or reliably, and always works out differently than anticipated (Avison, Lau, Myers, \& Nielsen, 1999), the implementation of new HRM practices may often not develop as planned and, as a result, the outcomes may not be as positive as expected; they may 
even be negative. Instead of rejecting the HRM practice, adopting an action research perspective could uncover unanticipated mechanisms that obstruct the HRM practice in achieving its full potential. This could involve a number of situations, for instance: it might turn out that managers lack the motivation to implement the HRM practice properly (Boxall, Hutchison, \& Wassenaar, 2015); managers do not possess the necessary skills to do so

(Nehles et al., 2006); or the new HRM practice should have been given more time to become incorporated, validated and legitimised (Van Mierlo et al., 2018). Also, the proposed solution might not fit the context of the particular organisation. By adopting action research, such issues could be uncovered earlier in the research process than with a regular research approach.

\subsection{CONCLUSIONS}

This research had the following aims: to theorise the potential contribution of action research for both HRM scholarship and practice; to provide an overview of the present use of action research as a research strategy in human resource management literature; and to offer guidelines for implementing HRM-related action research projects. Such a project could inspire HRM scholars to conduct action research-inspired empirical studies, as well as provide practitioners with a sound motive for opening their doors for action research-based HRM studies.

Action research comprises of: cycles of problem identification, problem analysis, creating a plan of action, implementation, data collection and evaluation, and theory development. This is carried out in a dynamic, participative, and problem-based research strategy. Instead of looking at organisations and their problems from an outsider's perspective in a way that somehow tries to avoid interfering with the situation, the action researcher adopts an insider perspective and interacts with the situation and its participants. Action research breaks through the strict divide between knowledge production and organisational changes, and ends up incorporating both. This difference with regular gap-based research provides great opportunities for HRM scholars to advance scholarly knowledge. Since action research is problem-based, it stimulates, and even obliges, researchers to look further than those strands of literature with which they are most familiar (Doherty \& Dickmann, 2012). In other words, since it is problem-based, action research helps academics get out of their comfort zone. Whereas this indeed might be perceived as treading thin ice - after all, it means looking at unfamiliar problems and making use of 'new' theories - it also provides the opportunity to contribute to theory development.

Therefore, the potential contribution of action research for HRM scholars is threefold. Firstly, by doing research relevant for practitioners, action researchers reduce 
the science-practice gap and will find their research results used more to improve organisational reality than would otherwise be the case. Secondly, by employing problembased research, action researchers enrich their own knowledge. Thirdly, by opening their scope and touching upon unfamiliar literature and theories, at a higher level, action researchers can contribute to theory development. Further benefits exist for practitioners who can profit by learning more about how HRM policies can be adapted to their specific organisational context and academic methods. Moreover, organisations benefit by obtaining access to tailor-made academic literature relevant to their particular situation and employees who have had an opportunity to learn by participating in the action research process. 


\section{CHAPTER 6}

\section{Discussion}

In this dissertation, the goal has been to obtain insights into the dynamics of the HRM implementation process, and the role that organisational actors play in it. To do so, in Chapter 2, a conceptual framework was presented in which we theorise a recursive, continuous interaction between HRM practices and organisational actors such as HRM professionals, line managers and employees. Subsequently, Chapters 3 and 4 discussed two studies that drew on empirical insights obtained during fieldwork in a ministry and in a cleaning company, both based in the Netherlands. Finally, in Chapter 5, we proposed action research as an alternative strategy for studying the HRM implementation process, which also takes into account also the contributions of external actors.

In this chapter, I will first summarise these chapters, after which I will compare both case studies with each other, assessing their similarities and differences to assess the development of a hiring practice during its implementation process. Subsequently, I will answer the overall research question and discuss theoretical and practical implications. Finally, I assess this research's limitations and provide suggestions for future research. 


\subsection{SUMMARY OF KEY FINDINGS}

\section{Chapter 2 - The dynamic nature of HRM implementation}

In Chapter 2, the aim was to conceptualise the HRM implementation process whilst taking interactions between HRM practices, employees and organisational context into consideration. Building on the key premises of structuration theory (Giddens, 1984), we developed a framework (Figure 4) that analyses the process that HRM practices go through during their implementation. Structuration theory claims a continuous interplay between structure and action. In this case, we see HRM practices as structure, as they consist of rules and resources, and therefore have the capacity to influence the daily life of organisational actors. Our framework, which also served as the starting point for Chapters 3 to 5 , portrays the continuous interaction between structure (HRM practices) and the actions of organisational actors involved in HRM implementation, and how interpretive schemes, facilities and norms play a role for each of these actors. This continuous interaction reflects a recursive process in which organisational context and organisational actors mutually influence each other during the HRM implementation process until a relatively stable version of the new HRM practice has been formed. In order that a new HRM practice becomes stable, we argued that, when an HRM practice is adopted, it needs to become inscribed into organisational actors' interpretive schemes, resources need to be allocated and the practice needs to become legitimised. In other words, organisational actors need to be aware of HRM practices, need to know what behaviour is expected from them and need to obtain the necessary means to do so. For instance, if line managers are made responsible for the application of new HRM practices, norms need to explain their responsibilities and they require several resources such as budgets and information. Moreover, their interpretive schemes will result in them translating the new HRM practice idiosyncratically. This will influence the way in which line managers actually apply the new HRM practice to the target group, often the organisation's employees. Following structuration theory's debate on the constant interaction between structure (HRM practices) and action (behaviour of organisational actors), one expects line managers to recursively influence the structure, and hence the HRM practice during its implementation. If their actions are in line with the structure, they will reinforce it; but, by routinely moving beyond the structure's boundaries, they can modify it. The same is true for employees (the proposed target group of HRM practices): norms describe their expected behaviour, and facilities cover issues such as their manager's higher hierarchical position. Employees filter all this through their interpretive schemes, after which the HRM practice has the capacity to influence their daily behaviour. With their behaviour, employees have the capacity to influence the HRM practice. For instance, if they do not follow their manager's intentions by changing their behaviour, the manager might decide to adopt a different approach. We 
argue that when a new HRM practice is implemented, it needs to become inscribed into organisational actors' interpretive schemes, resources need to be allocated and the practice needs to become legitimised.

Figure 4 in Chapter 2 was based on our interpretation of structuration theory (Giddens, 1984). After applying it in an empirical setting, I can conclude that, even though the framework is complex, it provides a highly insightful tool for studying the dynamics and contributions of organisational actors during the HRM implementation process. The findings obtained during the fieldwork described in Chapter 4 particularly highlight the substantial role that interpretive schemes and informal norms play in organisational actors' behaviours during this process. Especially because actors such as managers and HRM professionals understood the envisioned practice differently, their actions needed to evolve into a broadly supported and stable HRM practice. Furthermore, by defending their own interests (HRM professionals had to achieve their region's targets, middle-level managers wanted to fulfil senior management's strategic goals, and line managers saw financial possibilities in the new policy), organisational actors made use of their resources to defend their informal norms.

\section{Chapter 3 - The evolution of HRM practices}

This chapter focused on the evolution of HRM practices during their implementation process. The goal was to identify episodes in the HRM practice evolution as well as mechanisms that connect these episodes with each other. To identify episodes in the evolving HRM practice, structuration theory served as a lens. More specifically, the concepts of institutional elements, norms, facilities, interpretive schemes and action were used to identify mechanisms that contributed to the HRM practice advancing from one episode to the next. From findings obtained during a case study at a Dutch ministry, I was able to identify six episodes of HRM practice evolution. The fieldwork at the Ministry took place at a time when policymakers had taken the decision to focus heavily on boosting the inflow of impaired workers to their organisation. As the Ministry made use of a top-down strategy to implement an HRM practice aimed at hiring impaired workers, many actions were already taken at the start of the implementation process. Hence, even before the moment of actually starting to look for impaired candidates, many policy documents had been written, information bulletins were distributed, and even tools were designed in advance. Through these actions, policymakers and HRM professionals wanted to facilitate the hiring process as much as possible. Throughout the implementation process, the hiring practice evolved from an anticipated version, which - as it turned out in practice - was not aligned with aspects such as personal goals, interests, habits and the daily tasks of line managers, towards an orchestrated version of the HRM practice. In the final version of the HRM 
practice, the hindrances that were impeding line managers in hiring a satisfactory number of impaired workers had largely been removed by policymakers. The period from the anticipated to the orchestrated HRM practice was characterised by a process of adaptation and negotiation between HRM professionals and coordinators on the one hand, and line managers on the other. The findings of this chapter highlighted that the HRM implementation process does not involve clearly demarcated stages, which can be neatly separated with clear beginnings and ends. Rather, the episodes that we identified demonstrate that events can occur simultaneously involving various actors at the same time. Further, the gaps that occur during the HRM implementation process are not only unavoidable, but also necessary for highlighting misalignments between the HRM practice's design and characteristics such as the interests, work routines and responsibilities of organisational actors. Hence, for a smooth HRM implementation process, instead of aiming to minimise the gaps between intended, actual and perceived HRM, it is important to acknowledge that gaps will arise during the process. Then, these gaps, which come into existence because of the hindrances and the concerns of organisational actors, can be monitored and the HRM practice adjusted accordingly.

\section{Chapter 4 - The roles of organisational actors in HRM Implementation}

In Chapter 4, the object of interest was the implementation process of a new HRM hiring practice at a Dutch cleaning company. Similar to the case described in Chapter 3, the company ('Dutch Cleaners') had recently taken the decision to focus on hiring disadvantaged workers. Unlike the approach taken at the Ministry, policymakers at Dutch Cleaners decided to avoid creating extensive policy documents, and opted for a decentralised, bottom-up implementation approach. In this approach, instead of following a pre-envisioned approach, organisational actors would create the practice - the actual actions that were undertaken - as part of their job. That is, the routinised actions of organisational actors create the overarching HRM practice, rather than there being a preenvisioned HRM practice designed to change the actions of organisational actors. The objective of this research was to obtain insights into the roles that organisational actors play in the HRM implementation process. More specifically, in this approach, the actions of actors stood central in their attempts to create a new hiring routine. By making use of insights from the organisational routine dynamics tradition (Feldman \& Pentland, 2003), which theorises that, rather than being static and inert, routines in organisations are constantly modifiable and sources of innovation, it was possible to meticulously study the actions of actors in the HRM implementation process. These actions were reported from the perspectives of three groups of organisational actors: middle-level managers, line managers and HRM professionals. Even though their experiences regarding their role in the 
process differed, each of the actors contributed in different ways to the implementation of the new hiring routine. All three groups of actors explained how they had been able to take control of the new hiring routine. HRM professionals placed themselves in the centre of the recruitment process by taking control of the outside network of candidates; middle-level managers involved themselves in the selection procedures; and line managers worked around these initiatives by creating their own external network to remain largely independent of other organisational actors in their actions. Nevertheless, all of these efforts eventually led to a broadly supported and successful new hiring practice at Dutch Cleaners. With this conclusion, this chapter has contributed to the HRM implementation literature by demonstrating that, in new HRM practices becoming an incorporated and institutionalised element of the day-to-day routines of organisational actors, each stakeholder contributes in a different, but crucial, way to the implementation process. Furthermore, the findings have also demonstrated that it is not necessary to plan new HRM practices in detail from the start, but that they can be, or rather will be, modified during their implementation process.

\section{Chapter 5 - Action research and HRM}

As my research progressed, it became clear that HRM implementation is too complex for purely internally focused studies. With so many actors and organisations involved, a study that is only aimed at the organisation itself cannot portray the complete HRM implementation process. Therefore, we have proposed action research as an alternative to contemporary deductive or inductive research endeavours. The insights obtained in this dissertation, regarding dynamics that occur during the HRM implementation process, are equally important for action research endeavours. That is, both overlap in stages such as idea generation, design of a solution, introduction of the solution, monitoring its progress, and possibly repeating the process. Therefore, in Chapter 5 , we built on insights from action research (Lewin, 1946) to create both a research agenda and to give researchers and organisations guidelines for executing action-research-inspired HRM projects.

Action research is a research approach that aims to bring the worlds of research and organisations together. The founding father of action research, Lewin, remarked that theory has to inform practice and contribute to it. This led to a research approach that consists of cycles which need to be repeated until the organisational problem has been satisfactorily resolved. Action research is regularly used in research fields such as health care and education but, as we demonstrated in this chapter, rarely in HRM. In this chapter, we made a plea for its adoption based on the potential contributions that action research could make to HRM research as well as to HRM departments. First, action research could help narrow the gap between HRM scholars and practitioners. Often researchers express 
concerns regarding the low level of overlap between what HRM practitioners do in organisations and what researchers investigate and recommend. Even though research into this gap is far from new, and numerous solutions have been suggested, we argue that action research could substantially contribute to closing it. Second, as action research is problemdriven rather than driven by the researcher's interest, we claim that adopting an action research strategy can extract HRM scholars from their comfort zone regarding the theories they regularly use and the topics on which they focus. In this way, action research can contribute to theory development and advance the field of HRM.

\subsection{INSIGHTS FROM THE CASE STUDIES}

The case studies at the Ministry (Chapter 3 ) and Dutch Cleaners (Chapter 4) have brought valuable and very diverse insights into the HRM implementation process. Even though both cases were focused on the implementation of HRM practices aimed at hiring workers at a distance from the labour market, there were many differences in terms of both the implementation approach used by the organisations and the context (see Table 8). Below the table, these differences in the context and implementation process are explained. After this, similarities during the process of implementing a new hiring practice in the two case studies are explained.

\begin{tabular}{l|l|l} 
& The Ministry & Dutch Cleaners \\
\hline $\begin{array}{l}\text { Reason for adopting new } \\
\text { HRM practice }\end{array}$ & Public / civil duty & Business case \\
\hline Financial result & Mainly costs money & Mainly saves money \\
\hline Main task & Job creation & Network creation \\
\hline $\begin{array}{l}\text { Design of jobs for target } \\
\text { group }\end{array}$ & $\begin{array}{l}\text { New and existing job } \\
\text { design }\end{array}$ & Fits existing job design \\
\hline $\begin{array}{l}\text { Role of non-impaired } \\
\text { employees }\end{array}$ & $\begin{array}{l}\text { Some regular employees } \\
\text { were not ready }\end{array}$ & $\begin{array}{l}\text { Regular employees did } \\
\text { not mind }\end{array}$ \\
\hline $\begin{array}{l}\text { Risk of not-hiring impaired } \\
\text { workers }\end{array}$ & $\begin{array}{l}\text { Fine paid by public } \\
\text { money }\end{array}$ & $\begin{array}{l}\text { Fine paid by private } \\
\text { money }\end{array}$ \\
\hline
\end{tabular}

Table 8: Cross-case differences

\section{Implementation approach}

Whereas policymakers at the Ministry opted for a top-down implementation approach, at Dutch Cleaners this was done in a bottom-up manner. The top-down approach at the Ministry meant that policymakers decided how the hiring of impaired workers would take place and assigned organisational actors to facilitate this. Conversely, the bottom-up 
approach at Dutch Cleaners meant that policymakers took the decision to focus on bringing in more disadvantaged workers, but relied on HRM professionals and line managers to determine how this should be done.

A reason why ministerial policymakers had chosen to create a lot of documents and resources such as newsletters and job-carving/job-creation training is that this is the implementation approach commonly used in the Ministry. In fact, policymakers stated that the Ministry's organisational actors would be confused and uncertain how to act if no clear approach was communicated by the Ministry. Policymakers at Dutch Cleaners chose to implement the new HRM practice in a bottom-up manner as this approach had been used previously for the implementation of HRM practices such as the development of a mobile app. Furthermore, the company's regional offices operate in a semi-autonomous way. Therefore, it made sense for policymakers to abstain from interfering with that semiautonomous division of tasks and rely on the discretion of the regional office's HRM professionals.

\section{Reasons for adopting the new HRM practices}

Behind the decisions of both organisations was the Participation Act introduced by the Dutch government with the objective of finding employment for a further 150,000 impaired workers, with the aim of creating opportunities for all citizens to participate in society. The government's coalition agreement also stated that they foresaw substantial financial savings by employing impaired workers (Dutch Federal Government, 2012). This was also indicated by several respondents from the Ministry during the fieldwork, who stated that they regarded the Participation Act as an expenditure cut. With a different perspective, policymakers at Dutch Cleaners expressed their desire to become an inclusive organisation and started focusing on hiring disadvantaged workers for that reason (Van Leeuwen, 2015).

Interestingly, the results at the Ministry seemed to be quite the opposite. According to respondents, hiring impaired workers turned out to be relatively expensive as the hiring process required the involvement of specialised advisors and recruiters. Alternatively, outsourcing the recruitment and selection process would also be a costly method. Therefore, at the Ministry, the motivation for organisational actors such as line managers and coordinators to participate is more to be found in their sense of civic duty than in cost savings. Further, a sense of political sensitivity also played a role in this as well, as the potential fine for failing to hire sufficient impaired workers would be paid out of public tax revenues. At Dutch Cleaners, potential financial savings were also a motivator as generous subsidies could be obtained from the national government for hiring impaired workers. Indeed, the company managed to earn a substantial amount of money through their employing impaired workers. 


\section{Main activities}

The main activities of the organisational actors who were made responsible for the implementation of the new hiring policy - coordinators at the Ministry and HRM professionals at Dutch Cleaners - differed in nature. At the Ministry, the coordinators' main activities were to create suitable jobs and acceptance among other organisational actors. The necessity of this became clear in interviews with respondents at the Ministry when they explained incidents such as when a panic attack on one of the impaired workers caused shocked reactions among several colleagues. The reserved attitudes among organisational actors that became apparent during such incidents are probably explained by a respondent's comment that impaired workers have been largely separated from Dutch society over recent decades and are hardly active in the Dutch bureaucracy. Therefore, Dutch citizens, including organisational actors at the Ministry, have grown unfamiliar with interacting with them. The situation was quite different at Dutch Cleaners where a culture exists of diversity in terms of nationality, ethnicity, educational background and mental and physical abilities. As such, the main tasks and issues the HRM professionals at Dutch Cleaners had to address was to create a sustainable network of contacts among employment agencies and municipalities, and to learn how to supervise disadvantaged workers. Despite this recognition, and as described in Chapter 4, the line managers bypassed these actions by the company's HRM professionals by creating their own networks, thereby maintaining their autonomy.

\section{The design of jobs}

In their implementation of the HRM practice to hire disadvantaged workers at Dutch Cleaners, HRM professionals and line managers had relatively little trouble finding suitable jobs for disadvantaged workers. Even though their performance in terms of aspects such as productivity, working hours and level of responsibility differed from that of regular employees, disadvantaged workers were able to fulfil most cleaning tasks. This was a quite different situation to at the Ministry where there were only a few tasks appropriate for impaired workers - largely the result of the previous policy of outsourcing the more straightforward tasks such as cleaning, gardening and catering. However, some functions perfectly matched the abilities of some impaired workers. For example, workers with autism were not only capable of performing programming and other IT-related tasks, but were even able to do so faster and more efficiently than regular employees. Nevertheless, it is fair to state that, at the Ministry, the creation of appropriate new jobs was one of the main challenges for stakeholders such as coordinators and line managers. 


\section{The development of HRM practices}

As described in Chapter 3, six episodes of HRM implementation were identified at the Ministry. Even though the objective of the research undertaken at Dutch Cleaners was not to similarly identify episodes, it is possible to analyse episodes while they implemented their new hiring practice.

\section{Implementation of a hiring practice: similarities between the cases}

As described in this section, there were several differences in aspects such as the approach and motivation of the Ministry and of Dutch Cleaners in their attempts to create a more inclusive workforce. However, even though several aspects differed, it is possible to also find similar patterns in both cases. Such similarities demonstrate that even in polar cases (Eisenhardt \& Graebner, 2007) - i.e., cases which are opposite to each other in many aspects - similar patterns are visible. As Glaser and Strauss (2017) explain, similar patterns in cases which are different from each other can help identify solid theoretical insights that are applicable in different organisational contexts. Here, these insights are based on the process through which both organisations went in their attempts to implement a new HRM practice. After a turbulent period, both organisations achieved reasonable stability in their newly adopted hiring practice. Therefore, in terms of the topic of this dissertation, they were successful in implementing their new HRM practice.

\section{Key actors shift throughout implementation process}

Both cases have demonstrated that the key actor changed throughout the HRM implementation process. Top-managers and policymakers had the largest roles at the beginning and at the end of the HRM implementation process. In the beginning, top managers took the decision to adopt a new hiring practice, assign responsibilities and decide on the implementation approach. After this, HRM professionals, who in both cases were designated as the actors responsible for implementing the new hiring practice, needed to support their line managers, who were responsible for the actual hiring of people from the target groups. In fact, even though key actors changed, in both cases the key 'change agent' was the line manager. That is, as noted by Bos-Nehles (2010), it was the line managers that had to make 'the difference'. Without their efforts, it would not have been possible to implement the new hiring practices. In practice, even though actors such as coordinators started hiring impaired workers at the Ministry, and at Dutch Cleaners HRM professionals did the same, the number of people hired by them was relatively low and served more as sources of inspiration for the line managers. Furthermore, as particularly demonstrated at Dutch Cleaners, line managers made the decision to hire a disadvantaged 
worker or not. Therefore, their commitment to the HRM practice was crucial, and their actions made the difference in whether the implementation would be successful or not.

\section{Early enthusiasts}

The above pattern is linked to a further similarity. A crucial step in the development of these HRM practices was that line managers needed to start hiring impaired or disadvantaged workers. As explained in Chapter 2, HRM implementation does not involve a click on a button leading to instant change. Rather, it is vital that actors who perceive the new HRM practice as valuable, necessary or important participate. However, in both cases, HRM professionals - the actors who were responsible for overseeing the implementation process - had no formal leverage over line managers. As such, one of the main tasks for HRM professionals was to convince and inspire line managers to hire candidates from the target group. This was challenging given that the HRM professionals could not exert direct authoritative resources over line managers. Therefore, they needed to seek out early enthusiasts: line managers who were committed to the HRM practice. These early enthusiasts were often line managers who were either personally committed to the target group, or simply wanted to have the first choice of candidates from the target group. In our interviews, these early adopters indicated that their commitment to the new hiring practice was spurred by the efforts of HRM professionals. As such, this interaction between HRM professionals and early enthusiasts played a crucial role in the process leading towards orchestrated HRM practices.

\section{Deviant action leading towards orchestration}

When the first actors started working with the new HRM practice, it was still in its most premature unmodified form. As became clear from the case studies, at that moment certain aspects, such as the line managers at Dutch Cleaners having adequate knowledge, were lacking. Other elements also did not fit the existing culture or individual's work routines. An example of this is the tools provided to line managers at the Ministry that were perceived as having little or no added value. This led to some line managers avoiding the new HRM practice, while others started to find other ways to work with it. We saw, in both the Ministry and Dutch Cleaners, line managers pushing and crossing the boundaries of the HRM practice to cope with the misalignments. One such deviation was in the target group: line managers initially focused on candidates whose distance to the labour market was smaller than anticipated by policymakers when taking the decision to adopt the new hiring practice. At Dutch Cleaners, when the practice had stabilised and policymakers had started to formalise the approach, they acknowledged that they were satisfied with the way in which actors had been hiring disadvantaged workers but that the next step would be to 
attract 'more difficult' candidates, meaning people at an even greater distance to the labour market. As such, closing the gap between intended and actual HRM was not a key focus throughout the implementation process. Rather, it was left untouched, only to be corrected afterwards. The same was true at the Ministry, in which the hiring approaches adopted by line managers, characterised by job secondment constructions rather than direct formal employment as intended in the initial HRM practice, were later formalised by top management and hence effectively justified by policymakers.

This similarity demonstrates that in the period between launching an HRM practice and subsequently formalising a modified version of it, organisational actors such as HRM professionals and line managers will try out several approaches, thereby deviating from the anticipated HRM practice to find out what does and what does not work for them. These try-outs were crucial in identifying design flaws and mismatches between organisational and individual interests and daily routines, and, over time, contributed to the process leading to the orchestration of the new hiring practices at the Ministry and at Dutch Cleaners.

\subsection{ANSWER TO THE OVERALL RESEARCH QUESTION}

Combining the insights from the research discussed in this dissertation's chapters, enables an answer to the overall research question of this dissertation: 'What do the dynamics of the HRM implementation process look like, and which roles do organisational actors play in it?'. The answer to this research question makes it possible to draw conclusions that are applicable to the implementation of HRM practices in general.

As stated in the introduction to this dissertation, even though little attention has been paid to the dynamics of the HRM implementation process, they have been dominant throughout this study. As theorised in Chapter 2, we have seen a continuous interaction between HRM practices and the actions of organisational actors such as policymakers, HRM professionals, line managers and employees. This ongoing interaction underpins the evolution of HRM practices during their implementation process. Through their behaviour, organisational actors create and recreate the HRM practices which, recursively, influence them in their daily organisational actions.

During their implementation process, HRM practices evolve from an anticipated HRM practice towards an orchestrated HRM practice, which is aligned with the routines, understandings and interests of all stakeholders. As demonstrated in the implementation of a new hiring practice at the Ministry, it is possible to identify several episodes in the HRM implementation process. Throughout these episodes, HRM practices are at different stages of development. As depicted in Figure 6 (Chapter 3), the anticipated form is the most 
preliminary version of the HRM practice. Whether this anticipated form of the HRM practice is developed in detail, as in the case of the Ministry, or rather superficially as in the case of Dutch Cleaners, it consists of goals and roles. Information and tools are created to facilitate actors and support the introduction of the HRM practice. However, in both cases, we saw that neither the anticipated HRM practice nor the facilities provided entirely fitted with the individual interests and routines of the actors responsible for the actual application. This leads to a process in which the actors adapt their actions to the HRM practice, while the HRM practice itself is also adapted to those actions. Both cases also demonstrated that, by routinely pushing and crossing the borders of the anticipated HRM practice, it will, over time, be modified. This revised version, which has become aligned with the routines and interests of all stakeholders, is the orchestrated HRM practice.

This demonstrates that, in principal, HRM implementation is a process of adaptation and modification. Not only do organisational actors need to adopt new everyday routines and adapt their existing ones, the norms of HRM practices also need to be modified during their implementation process. Furthermore, the facilities which are designed to enable the adoption of new HRM practices have to be adapted, while new facilities have to be adopted. As Feldman and Orlikowski (2011, p. 1246) explain, "resources...are just potential resources until somebody uses them". Hence, misaligned facilities do not support organisational actors in their attempts to enact a new HRM practices and are mere, potentially costly, things. This underlines that, in the HRM implementation process, all the modalities identified by Giddens (1984) are central to the creation and recreation of HRM practices, and play important roles. However, the insights obtained from the Ministry highlight that these modalities, which serve as mechanisms connecting HRM implementation episodes with each other, are of differing importance throughout the HRM implementation process. In the initial and final episodes, formal norms are the main mechanisms, whereas during the more turbulent middle episodes, interpretive schemes and facilities are more prevalent.

The interactions among the HRM practice's characteristics, such as the embodied formal norms, the way in which stakeholders interpret and translate them into their daily organisational routines, and the facilities which they mobilise to be able to do so, lie at the heart of the misalignments and gaps that are frequently referred to in the HRM implementation literature (Khilji \& Wang, 2006; Makhecha et al., 2016; Piening et al., 2014). However, rather than being an issue that should be anticipated and prevented, these misalignments, and the actions taken in response by organisational actors, are essential in the process of achieving orchestrated HRM practices that fit the organisation as well as the stakeholders involved in their implementation and daily use. 
This leads me to conclude that, after the adoption of new HRM practices, a dynamic process begins during which the practices evolve continuously. These dynamics are necessary to achieve a broadly supported, fitting and efficient HRM practice. The HRM implementation process is what it says it is: a process. As such, HRM implementation is not an instantaneous event, it takes time to complete. This process will include unexpected and unanticipated problems, different levels of commitment to the HRM practice by various organisational actors, as well as differing perceptions by the stakeholders. The case studies at the Ministry and at Dutch Cleaners have demonstrated that it is impossible to create an HRM practice in advance that will have the desired effect on strategic outcomes, match the interests and work routines of all the organisational actors involved, be perfectly understood by those actors and have all the necessary resources in place to support them in completing their new tasks and responsibilities. Therefore, instead of viewing the HRM implementation process as an unavoidable and undesirable part of adopting a new HRM practice, policymakers could start regarding it as a necessary element in adopting sustainable HRM practices.

The interactions that were visible during the fieldwork at both the Ministry and Dutch Cleaners, demonstrate that all of the organisational actors involved contribute to the implementation of HRM practices in their own way. HRM professionals were primarily preoccupied with communicating new HRM practices throughout their organisation and creating initiatives to make them function. However, even though we saw that line managers were the actors who had to 'do' it, they were often unaware of the underlying reasons why their senior management had taken the decision to adopt the new HRM practice. This, in combination with a lack of hierarchical power between HRM professionals and line managers, was often a cause of frustration for the former, and resulted in a lack of motivation to start hiring workers at a distance to the labour market for the latter. In this, a role for the middle-level manager is to be found, as a link between senior management and line managers.

As such, the roles of organisational actors during the HRM implementation process seem to be as follows. Top-managers, recently identified as 'the missing stakeholder in HRM literature' (Boada-Cuerva, Trullen, \& Valverde, 2018), and policymakers play a crucial role in the decision to adopt an HRM practice, but also in deciding how to do this. As shown in the case studies, a top-down approach is undertaken when policymakers intend to leave little discretion to other stakeholders such as HRM professionals and line managers. As a consequence, the latter become largely preoccupied with finding ways to orchestrate the anticipated HRM practice such that it aligns with their existing routines and interests. Conversely, by deciding on a bottom-up approach, top-managers rely on the discretion and operational knowledge of these other stakeholders and do not elaborate extensively on 
how they should implement. As such, in HRM implementation, the role of top-managers and policymakers is that of invisible policy setters whose decisions directly influence the rest of the implementation process. Further, middle-level managers, as they have more of a strategic overview than line managers, who are mostly focused on meeting the goals of their unit or team, motivate line managers and provide the reasons behind the underlying rationale for adopting the new HRM practices. These line managers are responsible for delivering the HRM practices to their employees, precisely because of their operational knowledge and expertise. Finally, the role of HRM professionals is to support line managers in this by providing information and assistance. However, we also saw how these roles shifted during the HRM implementation process. For instance, several HRM professionals and coordinators in the Ministry took initiatives to take on the task of hiring impaired workers in the early stages of adopting the policy. In later stages, the experience and knowledge that they had thus obtained allowed them to motivate and support line managers in their own attempts to look for and hire impaired workers. At Dutch Cleaners, middle-level managers temporarily monitored HRM activities such as appraisal talks and training of disadvantaged workers, until the moment they felt this was done satisfactorily. At that moment, they indicated, their monitoring role would be like before. These examples illustrate the evolution of the roles of organisational actors during the HRM implementation process.

\subsection{THEORETICAL CONTRIBUTIONS}

In this dissertation, several contributions have been made to the HRM literature, which are discussed in this section.

First, by taking into account the evolution of HRM during its implementation, this research has contributed to the concept of HRM as a process (Bowen \& Ostroff, 2004; Ostroff \& Bowen, 2016). In Chapter 2, we theorised on the evolutionary nature of HRM practices during their implementation process, and Chapter 3 provided empirical insights into this process in a real-life situation. As the study took place in a ministerial setting, which was specifically selected because of the large number of stakeholders and its overall size, as well as the public attention to the inflow of impaired workers, it was of little surprise that we observed many dynamics during the process of implementing an HRM practice aimed at hiring impaired employees. In our research, we were able to observe the development of these practices from the earliest stage through towards an evolved and more stable version. This process included more turbulent episodes during which the actions of several different organisational actors contributed to modifying structural elements of the HRM practice. Through this, various actors contributed to the development of HRM practices by shaping and reshaping them during the HRM implementation process. 
I argue that, from this research, it has become clear that HRM implementation does not finish at the moment it is 'perceived' by employees, but that this process continues until new HRM practices have become a stable, routinised aspect of the day-to-day activities of stakeholders. This contribution also reflects on research problem 1 (that the concept of HRM-as-a-process is incomplete') identified in Chapter 1. As observed, HRM scholars have paid little attention to what happens to HRM practices and how they evolve after their introduction to organisational actors such as employees (e.g. Makhecha et al., 2016; Nishii et al., 2008; Wright \& Nishii, 2013). Even though the notion that practices evolve over time, and that actors play a role in this, is recognised by researchers in fields such as information systems (Orlikowski, 1992; Walsham \& Han, 1990), information technology (Bondarouk \& Ruël, 2009a; Whittington, 2006), management accounting (Busco, 2009; Coad \& Herbert, 2009; Macintosh \& Scapens, 1990), strategy (Jarzabkowski, 2008) and public administration (Barrett, 2004; Moynihan \& Landuyt, 2009), it is fair to say that HRM scholars had not yet taken this evolutionary nature of HRM practices fully on board.

Second, by demonstrating the way in which HRM practices are created and recreated through the behaviour of organisational actors, as well as the ongoing feedback that exists between HRM practices and organisational actors, this research has contributed to the literature that views HRM implementation as a two- or three-step programme from intended HRM through actual HRM towards perceived HRM (Bowen \& Ostroff, 2004; Guest \& Conway, 2011; Khilji \& Wang, 2006; Purcell \& Hutchinson, 2007; Wright \& Nishii, 2013). The arguments and empirical findings in this dissertation contradict the suggestion that HRM implementation is a mechanistic and one-directional process in which there is hardly any place for a proactive role and recursive influence of stakeholders over HRM practices (Bowen \& Ostroff, 2004; Nishii et al., 2008; Ostroff \& Bowen, 2016). The framework (Figure 4) developed in Chapter 2 portrays how organisational actors, such as line managers and employees, contribute to the HRM implementation process in a bottom-up manner. It demonstrates how these actors have an ongoing capacity to influence HRM practice through their behaviours. The empirical insights described in Chapters 3 and 4 provide support for this framework, and address research problem 2 (that 'HRM implementation is viewed as a one-directional process').

Third, my research described in this dissertation contributes significantly to exploring the assumed strict separation of roles in HRM implementation (e.g. Bos-Nehles et al., 2013; Bowen \& Ostroff, 2004; Khilji \& Wang, 2006; Wright \& Nishii, 2013) described in research problem 3 (that 'roles are strictly separated in HRM implementation'). Throughout the case study at Dutch Cleaners (Chapter 4), we observed many efforts by HRM professionals, middle-level managers and line managers to collectively create appropriate practices for hiring disadvantaged workers. HRM professionals helped create a network on 
which line managers could rely when looking for disadvantaged candidates. Line managers, being the operational experts with day-to-day interactions with shop-floor employees, used their people knowledge in selecting the best-fitting candidates and supervising them. Middle-level managers contributed by adding a strategic overview, an aspect that most line managers were less aware of. Through this, they were able to motivate and support line managers in looking for disadvantaged candidates. Moreover, by identifying top-managers as 'invisible policy setters', describing their important role as the actors who determine the implementation approach and, hence, directly influence the implementation process, I respond to the call by Boada-Cuerva, Trullen and Valverde (2018) to identify topmanagement's role in HRM. Nevertheless, as already mentioned, the roles of organisational actors evolve during the HRM implementation process. This highlights the importance for researchers to involve all HRM stakeholders when studying the HRM implementation process.

Fourth, structuration theory (Giddens, 1984) has served as the main theoretical backbone of this dissertation. Nevertheless, there are other theories that can be used to study the development of social phenomena over time. For instance, adopting an institutional approach would have been valuable in studying the development of an HRM practice. However, given that institutional theorists perceive structure (in this dissertation: HRM practices) as something external to people (Scott \& Davis, 2007), this approach would have neglected the role of organisational actors in developing structure. Hence, the action perspective, which is eminent in structuration theory (Giddens, 1984), would be underexposed by adopting an institutional approach. A similar limitation is found in making a link between macro-level and micro-level processes (Coleman, 1990). In Coleman's model, he explains how macro-level processes are often linked with each other through micro-level events or actions. As such, Coleman draws attention to a multi-level approach, thereby enabling different levels of HRM implementation to be combined. However, in Coleman's perspective, structure is also viewed as an objective phenomenon, external to the actors and independent of their actions. Therefore, as with the institutional approach, Coleman's perspective would have failed to portray the dynamics with which organisational actors modify HRM practices during their implementation process. Nevertheless, Coleman's model would have been a valuable addition to structuration theory (Giddens, 1984) for demonstrating the process through which intended HRM practices (macro-level) lead to actual HRM practices enacted by line managers (meso- or micro-level) that, over time, lead to modified institutionalised practices (macro-level). Overall, while this perspective would have been valuable in explaining the multilevel process in which HRM influences organisational performance through meso- and micro-level events (Renkema, Meijerink, \& Bondarouk, 2017), it would have been less useful in explaining HRM implementation. 
Conversely, adopting a practice lens only (Cetina et al., 2005) would have underemphasised the influence of structure over the day-to-day behaviour of organisational actors. Similarly, a sensemaking perspective (e.g. Weick, Sutcliffe, \& Obstfeld, 2005) could provide valuable insights into the process during which organisational actors such as line managers interpret intended HRM practices and assess how to respond. Although insightful, this perspective would again only shed light on one aspect of HRM implementation.

Therefore, I argue that the strength of structuration theory is that it combines both structure and action and, hence, allows one to study the entire HRM implementation process, including the dynamics that occur and the way in which HRM practices evolve during that process. Therefore, even though structuration theory can be seen as a relatively 'old' theory, it is still relevant for explaining the creation and development of social systems - in this case the HRM implementation process. Even though structuration theory has informed HRM scholars in the past (Bondarouk \& Ruël, 2009b; Festing \& Maletzky, 2011; Kroon \& Paauwe, 2014; Meijerink, 2014), this dissertation underlines the potential this theory still has to contribute to the field of HRM.

Finally, to claim that I have contributed to structuration theory would be too bold a statement. In this dissertation, structuration theory has merely served as a lens through which to study the HRM implementation process, rather than structuration theory itself being a topic of investigation. Moreover, to criticise shortcomings of the theory would also go beyond the scope of my research, and these have been addressed elsewhere (e.g. Held \& Thompson, 1989). Therefore, I see it as more valuable to discuss the limitations of structuration theory that were apparent in my attempts to conceptually and empirically make use of its key insights. First, even though Giddens discusses routines and routinised action as having the capacity to modify structure, structuration theory failed to provide me with satisfactory insights and means into the way in which these routines themselves develop. Giddens does explain that, in our everyday behaviour, routines provide a sense of ontological security. In other words, routines create predictability and a feeling of security. $\mathrm{He}$ also states that routines can change due to exogenous shocks in the form of "extreme disruption of accustomed forms of daily life" (p.61). However, as Feldman and Orlikowski (2011) observe, organisational routines also change during periods of apparent stability. Further, for the analysis of routines at such a detailed level, I argue that structuration theory is not ideal. The top management at Dutch Cleaners had taken the decision to start focusing on hiring disadvantaged workers even though there was no extreme disruption within the company, nor in its environment. Therefore, to overcome this limitation of structuration theory, I adopted a routine dynamics perspective to study the development of a new hiring routine at this company in Chapter 4 . Second, the previously mentioned complexity of structuration theory, and its main concepts, means that it is particularly problematic to 
translate these into empirically valid constructs, and this places a serious limitation on its usability. It is true that Giddens has repeatedly stated that structuration theory is not intended to be a research method, but should rather be seen as a research inspiration (Giddens, 1984, 1989). Moreover, his claim that structuration theory should not be used in isolation, but as a sensitising device is also valid. However, both its empirical complexity and Giddens' "eclectic approach to method" (1989, p. 296) severely limit the ability to compare insights provided by researchers who report on empirical studies inspired by structuration theory. This is because, even though they use the same theory, they might all be making use of different concepts. For instance, the structuration process, including the modalities that serve as mechanisms between structure and action, were at the heart of a large part of this dissertation. In some other studies, the various forms of consciousness lead and, in others, the various forms of resources can be the main constructs. Nevertheless, this limitation also demonstrates the versatility of structuration theory as a concept for theorising on the production and reproduction of all sorts of social systems, as well as for obtaining powerful theoretical generalisations (Feldman \& Orlikowski, 2011).

\subsection{PRACTICAL CONTRIBUTIONS}

The insights derived from both theoretical sources and the two case studies allow me to formulate several recommendations that can contribute to future implementations of HRM practices in organisations. The practice-related theories (structuration theory and organisational routine dynamics) that have been prominent throughout this dissertation, as well as their usage during the case studies, allow the identification of powerful mechanisms (Feldman \& Orlikowski, 2011) that play a part in the HRM implementation endeavours of practitioners.

First, involving enthusiastic and proactive line managers to function as pioneers in the implementation of new HRM practices can contribute to the process. In both case studies, in departments where line managers had an emotional interest in bringing in workers at a distance to the labour market, for instance because a family member was part of the target group, the implementation of the new HRM practice went more smoothly than in departments in which this was not the case. Therefore, it appears to be helpful to actively look for line managers who are willing to take the lead in adopting new HRM practices.

The case studies demonstrated that the organisation-wide adoption of HRM practices can lead to chaotic situations in terms of confusion regarding the responsibilities of organisational actors and the consequences this has for their work routines. Organisations can learn from this by making use of the expertise of each organisational actor, especially during the sometimes confusing implementation process. 
Acting proactively can also provide opportunities for the line managers themselves by creating advantages and opportunities to empower themselves. In the case study at Dutch Cleaners, we observed that proactive line managers both created competitive advantages for themselves and managed to strengthen their position within their organisation and broaden their responsibilities. That is, by being the forerunners in terms of hiring disadvantaged workers, line managers were able to create a solid network with employment agencies and municipalities who could put them in contact with disadvantaged workers. Furthermore, as the line managers had worked previously with these agencies and municipalities, these bodies were aware of the job characteristics that disadvantaged workers would have to satisfy. This made the recruitment process shorter than it would otherwise have been. It also created a competitive advantage for the proactive line managers because most disadvantaged workers are partly subsidised by the Dutch Government and therefore relatively cheap to employ. Therefore, they were able to hire more employees, thus increasing their unit's productivity. Their proactive approach also helped line managers to strengthen their position in the company by becoming experts on a policy to which the company had attached great importance. Furthermore, line managers indicated that they had come to realise that specialising in hiring and supervising disadvantaged workers had evolved into an ambition for a future job within their company. At the Ministry, we also noted that organisational actors who acted proactively were best able to hire well-fitting impaired workers in the region. One line manager indicated that she was afraid that certain impaired workers would turn out to be very popular among other ministerial departments and other organisations. In particular, well-educated impaired workers were targeted by many organisations. Therefore, those actors who started looking for highly skilled or well-trained impaired workers in the earliest stages of the policy implementation, had the best chance of hiring well-fitting employees.

Second, this dissertation has contributed to practice by demonstrating that a hands-off approach - allowing deviations from the anticipated HRM practice's norms during the initial stages of the HRM implementation process can smooth this process as well as encourage stakeholders such as line managers and employees to take initiatives. The case studies demonstrated instances where initiatives came to a premature end because they were not fully in line with policy, which created a lot of frustration and often led to less-entrepreneurial attitudes being adopted by organisational actors. Conversely, when initiatives were encouraged and supported by HRM professionals, this coincided with key stakeholders such as line managers clearly showing a high degree of commitment to and involvement in the new HRM practice. Moreover, as the framework (Figure 4) presented in Chapter 2 demonstrates, organisational actors such as line managers and employees have the capability to modify HRM practices through their behaviour. From the case study at the 
Ministry, it became clear that, by routinely crossing the boundaries of the new HRM practice, deviant behaviour by line managers (making use of job secondments) became, over time, an accepted and institutionalised practice. Therefore, rather than functioning as referees who check whether line managers are following the rules of new HRM practices, HRM professionals could support line managers during the implementation process by allowing them some leeway and the space to experiment.

Third, the case study at Dutch Cleaners demonstrated the benefits of a bottom-up approach to implementing HRM practices. Instead of practices designed by organisational actors or consultants at a large distance from the work floor, who are often unfamiliar with daily operational dynamics, in a bottom-up approach the operational specialists - most often line managers - play a major role in their design. This can lead to an organically grown HRM practice that fits the culture and routines of the work place. Hence, in such cases, rather than policy creating practice, policy follows from the actions of those organisational actors actively involved in the implementation process. Therefore, less effort is needed in initiating new HRM practice adoption. In the bottom-up approach, details concerning the how and the who are of less importance, and organisations can instead start from a set of objectives or a goal.

However, when adopting this approach, pioneers can suffer from a lack of information and knowledge. The study at Dutch Cleaners demonstrated that pioneers, those organisational actors who started implementation in the early stages, often struggled with a lack of information and knowledge. With bottom-up HRM implementation, roles are initially not described in much detail and we saw that respondents often discussed their frustration and doubts regarding their expected role and whom they should approach with questions or issues. Their lack of experience with hiring and supervising disadvantaged workers also created issues on the work floor, with line managers indicating that they were unequipped to deal with issues that arose. Growing experience over time and reading about certain disabilities could help them deal with this. HRM professionals could also help line managers by providing information on topics such as disabilities and subsidies, and also by communicating best practices from other units or areas of the company. What we saw was that these pioneers had to create a route for other actors to follow.

Fourth, as demonstrated in this dissertation, HRM practices continue to develop throughout their implementation process. This means that organisations need to be patient when adopting new HRM practices. Poorly working HRM practices might in fact be potentially well-functioning practices, but simply misaligned with the organisation. Therefore, organisational actors need to find and develop their roles in the new practice. Similarly, best practices adopted from other organisations also have to become incorporated within the organisation, and this process does not happen overnight. 
Finally, by making a plea and providing guidelines for designing HRM action research studies (Chapter 5 ), this dissertation can involve practitioners in future projects. Practitioners can make use of an action research approach to solve HRM-related problems within their organisations. By involving scholars in identifying, studying and solving HRMrelated problems, practitioners can make use of the latest scholarly insights in the field, as well as valid data collection and analysis approaches. This creates an extra dimension beyond involving external consultants and/or the efforts of internal organisational actors.

\subsection{LIMITATIONS}

There have been several occasions where decisions had to be made that had the potential to negatively influence the outcomes of this dissertation. These limitations were sometimes unavoidable trade-offs, and others can be seen as errors of judgement or forced by unanticipated events. I have identified the following limitations in this dissertation.

The first limitation is that, even though I claim a central role for employees in the HRM implementation process and explicitly mention them in the framework presented in Chapter 2, I have not observed their actual contributions in either case study. A few employees were interviewed but their role in implementing the HRM practice in question was marginal. As we argued in Chapter 2, the situation would have been different with other HRM practices, such as employee mobility-enhancing practices or appraisal cycles. In such cases, the evolution of HRM practices will be influenced by the actions of employees. However, the fact that, in both case studies, the end-users of the new HRM practice were not work-floor employees but line managers - given that the objective was to influence their recruitment and selection behaviour - shows the versatility of the framework. This supports our claim that the framework can be applied to different organisational actors. In this case, the actors creating the 'intended' practice were policymakers who were guided in their designing by the institutional context of the new Participation Act. Next, we saw how HRM professionals interpret the new policy and translate it to their own department. This influences the hiring behaviour of line managers, who would either hire impaired workers or not. With other HRM practices, the situation might be closer to the 'classic' HRM pattern with HRM professionals as policy makers, line managers who apply the actual HRM practice, and employees whose behaviour is modified by this practice.

A second limitation of this research is that, when looking back at the recommendations we made in Chapter 5, it would make sense to include also external actors such as researchers and consultants in the framework (Figure 4) that was presented in Chapter 2. It is, of course, always possible to think of other actors who play a role in the HRM implementation process such as shareholders, publishers of professional HRM magazines and even trainers of HRM professionals. In our framework, we deliberately chose 
to focus solely on organisational actors, those internally employed by the organisation of interest, particularly because of their involvement with the organisation's structural elements.

A third limitation is that some of the data were collected through retrospective methods. Even though this approach is generally seen as acceptable in process studies (Jarzabkowski, 2008), it has its weaknesses. For instance, it made it impossible to study the concrete steps that actors took in developing a new hiring practice. Longitudinal observations might have revealed other, valuable, insights. Nevertheless, especially in the case study of the Ministry, we were able to use various data sources such as interviews, documents and walking-the-floor observations. This made it possible to triangulate our data, increasing its trustworthiness.

A fourth limitation is related to the operationalisation of structuration theory. As discussed earlier in the thesis, the modalities, norms, facilities and interpretive schemes were separated from institutional elements and action. One concern is that the last of these, action, is somewhat broad, with Giddens identifying three 'realms' of action: legitimation, sanction and communication. However, to avoid making both the framework depicting the dynamic nature of HRM implementation (Figure 4) and the process of HRM implementation at the Ministry (Figure 6) overly complex, I operationalised action as a single concept.

\subsection{FUTURE RESEARCH}

Even though the ambition of this dissertation was to cover as many aspects of HRM implementation as possible, many elements remain that warrant further research.

One potential research opportunity relates to the first limitation mentioned in the previous section: it would be very valuable to study the actual roles and contributions of work-floor employees in the HRM implementation process. Here, researchers could investigate the way in which these employees' behaviours strengthen or change HRM practices that are aimed at modifying their behaviour. It would make sense to initially study this aspect with relatively 'simple' HRM practices. A good example is the employee appraisal cycle, in which HRM professionals or other HRM policymakers design formats that need to be used by line managers in assessing their employees' job performance. Such an uncluttered HRM practice would prove very insightful when investigating the contributions of employees to the appraisal cycle.

A second opportunity for future research is to assess the duration of HRM implementation episodes. In the cases studied in this dissertation, I did not address this in detail. However, it would be very valuable since both scholars and practitioners could benefit. For instance, scholars could estimate when is likely to be the best time to study the perceptions of specific groups of organisational actors regarding a new HRM practice. It 
clearly does not make sense to investigate this before they have experienced the new HRM practice, but it could also be that interviewing them during the turbulent episodes of HRM implementation might provide an overly negative perspective on the practice. However, if one had a better understanding of the duration of the HRM implementation episodes, scholars could take this into account when planning their data collection. Similarly, practitioners would be able to estimate the amount of time HRM implementation takes, and when best to evaluate its success and contribution to achieving their organisational goals.

A third possibility would be for scholars to study the HRM implementation process from the start: from the moment the decision is taken to adopt a new HRM practice. Studying the concrete actions that organisational actors undertake to adopt a new HRM practice could reveal in more detail how they develop new routines, or modify existing ones. Close, real-time, day-to-day observations have been shown to provide valuable insights into implementation processes elsewhere (Barley, 1986; Danner-Schröder \& Geiger, 2016).

Throughout this dissertation, I have made several pleas for making use of structuration theory when studying HRM phenomena. As I argue, structuration theory has proven to be able to provide excellent insights into the HRM implementation process. However, I have merely used one part of the theory. Other aspects of the theory could be used to study other HRM phenomena. For instance, the different forms of consciousness practical and discursive - could provide insights into the process through which employees interpret their manager's instructions. This could shed more light on employees' perceptions of HRM. Further, as Budjanovcanin (2018) has already demonstrated how employees use various forms of power to influence their working environment, structuration theory could provide insights into the ways in which employees also make use of various forms of facilities in this process.

Another future HRM research opportunity would be to carry out an action research study. As discussed in Chapter 5, although action research appears a very promising approach for the field of HRM, it is hardly used at this moment. As this dissertation stresses, implementation is more than the introduction of new HRM practices, it also involves activities such as their design, perception, evaluation and re-application. Therefore, action research could contribute significantly to organisational problem solving by making use of the insights provided in this dissertation regarding the dynamic HRM implementation process, and the contributions of organisational actors to this process. 



\section{Publications and conference papers}

Van Mierlo, J., Loohuis, R.P.A. \& Bondarouk, T. (forthcoming). The role of multiple points of view in non-envisioned routine creation: taking initiative, creating connections and coping with misalignments. In M. Feldman, L. D’Adderio, K. Dittrich \& P. Jarzabkowski, Routine dynamics in action: replication and transformation. Research in the Sociology of Organizations. Bingley, United Kingdom: Emerald.

Van Mierlo, J. \& Bondarouk, T. (2018). The Process of Implementing HRM Practices: a Case Study in the Dutch Federal Government. Presented at the 78th Annual Meeting of the Academy of Management, 10-14 August 2018, Chicago, Illinois, United States.

Van Mierlo, J., Bondarouk, T. \& Sanders, K. (2018). The dynamic nature of HRM implementation: a structuration perspective. The International Journal of Human Resource Management, to appear in Vol. 29 no. 22, 2018.

https://doi.org/10.1080/09585192.2018.1443957

Heilbron, J., \& Van Mierlo, J. (2018). Internationale farmacie in Oss. In J. Burgers \& J. Heilbron (Eds.), De Zaak Organon (pp. 17-59). Amsterdam: Prometheus.

Van Mierlo, J. \& Bondarouk, T. (2017). The struggle towards maturity: the evolution of HRM practices in the Dutch federal government. Presented at the 10th Biennial International Conference of the Dutch HRM Network, 8-10 November 2017, Nijmegen, the Netherlands.

Van Mierlo, J., Bondarouk, T. \& Loohuis, R.P.A. (2017). The emergence of a new HRM routine: Balancing between ostensive and performative aspects. Presented the 33rd EGOS Colloquium 'The Good Organization', 6-8 July 2017, Copenhagen, Denmark.

Van Mierlo, J. \& Bondarouk, T. (2017). HRM professionals in the public sector: Fighting for legitimacy. Presented at the 10th International Critical Management Studies Conference, 3-5 July 2017, Liverpool, United Kingdom.

Meijerink, J., Van den Heuvel, S., Korotka, M., Bos-Nehles, A., Renkema, M., Bondarouk, T., Van Mierlo, J., De Leede, J., Herawati, S., Looise, J. C.; Ruël, H., \& Wognum, I. 
(2016). HRM, technologie en innovatie: terug naar de toekomst. HR\&Business Magazine, 28-31.

Bondarouk, T., \& Van Mierlo, J. (2016). It's Relevant! Action Research and HRM. Symposium organised at the 76th Annual Meeting of the Academy of Management, 5-9 August 2016, Anaheim, United States.

Van Mierlo, J. \& Bondarouk, T. (2015). Revisiting HRM systems strength: Conceptualising the dynamic nature of HRM implementations. Presented at the 9th Biennial International Conference of the Dutch HRM Network, 11-13 November, 2015, Utrecht, the Netherlands.

Bondarouk, T. \& Van Mierlo, J. (2015). Action research in the HRM field: A critical perspective and Guidelines. Presented at the 9th Biennial International Conference of the Dutch HRM Network, 11-13 November, 2015, Utrecht, the Netherlands.

Davelaar, M. \& Van Mierlo, J. (2013). Cliënten keuren de dagbesteding. Verwey-Jonker Instituut, Utrecht, the Netherlands. 


\section{Summary}

Over the past decades, scholars have increasingly become interested in the adoption of new HRM practices in organisations. This has led to HRM implementation as a separate and acknowledged subfield in Human Resource Management research. During their implementation process, HRM practices evolve from an idea or goal into a working instrument, often aimed at enhancing the contribution of organizational actors to their organization.

Scholarly attention has brought valuable insights into this process. The key insights are that, to reach HRM practices' full potential, it is not only important which practices organisations adopt, but also how these are implemented. More specifically, the way that the end users of HRM practices - most often these involve employees - perceive those practices, influences their behaviour. Therefore, researchers claim that it is important to implement HRM practices in a strong way. Researchers have also focused on the gaps that come into existence during the HRM implementation process between the way that policymakers intended new HRM practices to be, the way in which these are implemented by line managers, and the perceptions of employees.

However, there are several aspects of HRM implementation which, to date, have received less or incorrect attention by scholars. This dissertation is focused on three research problems, which are analysed by making use of the insights from structuration theory (Giddens, 1984) and organisational routine dynamics (Feldman \& Pentland, 2003). Firstly, the concept of HRM-as-a-process is incomplete. In most studies, the HRM implementation process seems to finish after employees have perceived HRM practices. As such, little is known about what happens to HRM practices during the HRM implementation process and the way in which they evolve. Secondly, in its current state, HRM implementation seems to be a one-directional, mechanistic process which logically leads from point $a$ to $b$. This suggests that HRM implementation is a plannable, step-by-step process which mainly involves ticking boxes. Herewith, the dynamics that come along with this complex process are overlooked. Thirdly, in HRM implementation literature a strict separation exists between roles of organisational actors in HRM implementation. In this, policymakers design HRM practices, line managers implementation, and employees perceive. However, this clear separation of 'who does what' seems to provide an overly simplistic division of tasks. One example is that not only employees perceive HRM practices, but policymakers and line managers as well. These research problems lead to the following overall research question: What do the dynamics of the HRM implementation process look like, and which roles do organisational actors play in it? 
To gain insights into the dynamics of HRM implementation, a conceptual framework was created, based on the main outlines of structuration theory. This dynamic framework, presented in Chapter 2, theorises how the actions of organisational actors such as HRM professionals, line managers and employees a vital in the development of new HRM practices. The framework demonstrates how new HRM practices continue to develop based on these actions until they have become structured. In this, their norms, forms of power, and views and understandings play a key role. This structuration process of HRM practices continues until they have become inscribed into the interpretive schemes of organisational stakeholders, facilities have become distributed, and the stakeholders see the practice as legitimate.

To gain insights from practice, and study what actually happens during HRM implementation, two case studies were done. The first study was focused on the adoption of a new hiring practice at a Dutch ministry, with the objective to hire a large number of impaired workers. The objective was to gain insights into the dynamics that took place during the implementation process, and to identify different implementation episodes. We were able to identify 6 episodes during which the hiring practice was at a different stage of development. During each of these episodes, different key actors were active. More specifically, in the first and last episodes policymakers played important roles in the development of the HRM practice, whereas this was the case for line managers and HRM professionals in the middle episodes. Throughout the episodes, the HRM practice continued to develop based on the actions of the stakeholders. This evolved into a more stable practice that was orchestrated to the actions and interests of the stakeholders in the HRM implementation process.

In the second case study, performed at a Dutch cleaning company, the focus was particularly on the roles of organisational actors in creating a new hiring routine. The company's objective of developing a new hiring routine was to hire a large number of disadvantaged workers. By adopting an organisational routine dynamics perspective, we were able to study step by step how different groups of organisational actors - HRM professionals, middle-level managers and line managers - developed the new hiring routine. In this, each actor contributed to developing the routine by making use of his or her expertise and knowledge. We found that HRM professionals took initiative to get involved into operational tasks in the hiring process, such as making a preselection of candidates and creating connections with employment agencies for finding disadvantaged candidates. However, line managers preferred being in control of the hiring process, and created their own outside connections. Middle-level managers also involved themselves in the process by participating in the job interviews and creating partnerships with employment agencies. Interestingly, even though the perspectives of the roles of 
organisational actors in the hiring process differed, each actor managed to contribute to a new hiring routine which even exceeded the prior expectations of the company's board members.

In this dissertation I also provided an action research perspective on HRM implementation. Action research is a research approach which is aimed at bringing the fields of research and practice more closely together. The objective of action research studies is to do research that solves actual organisational issues and advances scholarly knowledge. Researchers can do this by getting involved in the organisational change process and working closely together with organisational stakeholders. In HRM, action research is rarely applied. However, those HRM-action research studies that were done, clearly demonstrated the added benefits of this approach. By making a plea for HRM-action research projects, we both aim to inspire scholars, thereby narrowing the gap between HRM research and HRM practice, and we argue that a problem-driven research approach can contribute to theory development.

The theoretical insights and empirical findings which have been discussed in this dissertation demonstrate that during their implementation process, HRM practices continue to develop. At the moment of taking the decision to adopt a new HRM practice, the practice is rather an anticipated one, instead of an end product. During its implementation process, the practice is influenced by the actions by organisational actors such as policymakers, HRM professionals, middle-level managers, line managers, and employees. This insight means that HRM practices do not only influence the actions of organisational actors, but that recursively the same happens. As such, the HRM implementation process is one of adaptation and modification until the HRM practice fits organisational and individual routines and is in line with stakeholders' interests and objectives.

During the dynamic HRM implementation process, HRM practices evolve until leading to an orchestrated version. This process is necessary for a supported, fitting and efficient HRM practice. Rather than seeing this process as an unwanted effect of the involvement of a large number of stakeholders in HRM implementation, it is a necessary element which can actually contribute to creating a sustainable HRM practice. Each organisational actor contributes in his or her own way to this process. However, in all, top managers decide whether and how to implement HRM practices. As demonstrated in the case study at Dutch Cleaners, a bottom-up implementation approach leads to a totally different process than a top-down approach. HRM professionals are seen as responsible for communicating new HRM practices, as well as reasons behind their adoption. Line managers are responsible for executing HRM practices, while middle-level managers have the task of motivating line managers to implement HRM practices. 



\section{References}

Akdere, M. (2009). A multi-level examination of quality-focused human resource practices and firm performance: evidence from the US healthcare industry. The International Journal of Human Resource Management, 20(9), 1945-1964.

Athanasopoulou, A., Moss-Cowan, A., Smets, M., \& Morris, T. (2017). Claiming the corner office: Female CEO careers and implications for leadership development. Human Resource Management.

Avison, D. E., Lau, F., Myers, M. D., \& Nielsen, P. A. (1999). Action research. Communications of the ACM, 42(1), 94-97.

Bailey, C. (2016). Employee engagement: do practitioners care what academics have to sayand should they? Human Resource Management Review.

Barley, S. R. (1986). Technology as an occasion for structuring: Evidence from observations of $\mathrm{CT}$ scanners and the social order of radiology departments. Administrative Science Quarterly, 31(1), 78-108.

Barley, S. R., \& Tolbert, P. S. (1997). Institutionalization and structuration: Studying the links between action and institution. Organization Studies, 18(1), 93-117.

Barrett, S. M. (2004). Implementation Studies: Time for a Revival? Personal Reflections on 20 Years of Implementation Studies. Public Administration, 82(2), 249-262. https://doi.org/10.1111/j.0033-3298.2004.00393.x

Baskerville, R. L. (1999). Investigating information systems with action research. Communications of the AIS, 2(3es), 4. 
Baskerville, R. L., \& Wood-Harper, A. T. (1996). A critical perspective on action research as a method for information systems research. Journal of Information Technology, $11(3), 235-246$.

Battilana, J., Leca, B., \& Boxenbaum, E. (2009). 2 How Actors Change Institutions: Towards a Theory of Institutional Entrepreneurship. The Academy of Management Annals, 3(1), 65-107.

Bednall, T. C., Sanders, K., \& Runhaar, P. (2014). Stimulating informal learning activities through perceptions of performance appraisal quality and human resource management system strength: A two-wave study. Academy of Management Learning \& Education, 13(1), 45-61.

Beer, M. (1997). The transformation of the human resource function: Resolving the tension between a traditional administrative and a new strategic role. Human Resource Management (1986-1998), 36(1), 49.

Beer, M. (2015). HRM at a Crossroads: Comments on "Evolution of Strategic HRM Through Two Founding Books: A 30th Anniversary Perspective on Development of the Field". Human Resource Management, 54(3), 417-421.

Beer, M. (2017). Developing strategic human resource theory and making a difference: An action science perspective. Human Resource Management Review.

Beer, M., Boselie, P., \& Brewster, C. (2015). Back to the future: Implications for the field of HRM of the multistakeholder perspective proposed 30 years ago. Human Resource Management, 54(3), 427-438.

Beer, M., \& Cannon, M. D. (2004). Promise and peril in implementing Pay-for-performance. Human Resource Management, 43(1), 3-48. 
Beer, M., Spector, B., Lawrence, P. R., \& Mills, D. Q. (1984). Managing Human Assets: : The Groundbreaking Harvard Business School Program. New York, NY: Free Press.

Benschop, Y., van den Brink, M., Doorewaard, H., \& Leenders, J. (2013). Discourses of ambition, gender and part-time work. Human Relations, 66(5), 699-723. https://doi.org/10.1177/0018726712466574

Berente, N., Lyytinen, K., Yoo, Y., \& King, J. L. (2016). Routines as Shock Absorbers During Organizational Transformation: Integration, Control, and NASA's Enterprise Information System. Organization Science, 27(3), 551-572.

Berry, J. W. (1989). Imposed etics-emics-derived etics: The operationalization of a compelling idea. International Journal of Psychology, 24(6), 721-735.

Bertels, S., Howard-Grenville, J., \& Pek, S. (2016). Cultural molding, shielding, and shoring at oilco: The role of culture in the integration of routines. Organization Science, $27(3), 573-593$.

Björkman, I., Ehrnrooth, M., Mäkelä, K., Smale, A., \& Sumelius, J. (2014). From HRM practices to the practice of HRM: setting a research agenda. Journal of Organizational Effectiveness: People and Performance, 1(2), 122-140.

Bleijenbergh, I., \& Van Engen, M. (2015). Participatory modeling to support gender equality: The importance of including stakeholders. Equality, Diversity and Inclusion: An International Journal, 34(5), 422-438.

Boada-Cuerva, M., Trullen, J., \& Valverde, M. (2018). Top management: the missing stakeholder in the HRM literature. The International Journal of Human Resource Management, 1-33. 
Bondarouk, T., Bos-Nehles, A. C., \& Hesselink, X. (2016). Understanding the congruence of HRM frames in a healthcare organization. Baltic Journal of Management, 11(1), 220.

Bondarouk, T., \& Brewster, C. (2016). Conceptualising the future of HRM and technology research. The International Journal of Human Resource Management, 27(21), $2652-2671$.

Bondarouk, T., Kees Looise, J., \& Lempsink, B. (2009). Framing the implementation of HRM innovation: HR professionals vs line managers in a construction company. Personnel Review, 38(5), 472-491.

Bondarouk, T., \& Ruël, H. J. M. (2009a). Electronic Human Resource Management: challenges in the digital era. The International Journal of Human Resource Management, 20(3), 505-514.

Bondarouk, T., \& Ruël, H. J. M. (2009b). Structuring the IT-enabled transformation of HR: An HRM frames analysis in an international company. In P. Sparrow (Ed.), Handbook of international human resource management: Integrating people, process, and context (pp. 271-292). Chichester, United Kingdom: Wiley.

Bondarouk, T., Trullen, J., \& Valverde, M. (2016). Special Issue of International Journal of Human Resource Management: Conceptual and empirical discoveries in successful HRM implementation. The International Journal of Human Resource Management, 27(8), 906-908.

Boselie, P., Dietz, G., \& Boon, C. (2005). Commonalities and contradictions in HRM and performance research. Human Resource Management Journal, 15(3), 67-94. 
Bos-Nehles, A. (2010). The line makes the difference: Line managers as effective HR partners. Zutphen, The Netherlands: CPI Wöhrmann Print Service.

Bos-Nehles, A. C., \& Bondarouk, T. (2017). HRM implementation in Europe-the need for a dialogue between HR and line management. European Journal of International Management, 11(5), 511-514.

Bos-Nehles, A. C., Bondarouk, T., \& Labrenz, S. (2017). HRM implementation in multinational companies: the dynamics of multifaceted scenarios. European Journal of International Management, 11(5), 515-536.

Bos-Nehles, A. C., Bondarouk, T., \& Nijenhuis, K. (2017). Innovative work behaviour in knowledge-intensive public sector organizations: the case of supervisors in the Netherlands fire services. The International Journal of Human Resource Management, 28(2), 379-398.

Bos-Nehles, A. C., \& Meijerink, J. (2018). HRM implementation by multiple HRM actors: a social exchange perspective. The International Journal of Human Resource Management, $x(\mathrm{x}), 1-25$.

Bos-Nehles, A. C., Van Riemsdijk, M. J., \& Looise, J. K. (2013). Employee perceptions of line management performance: Applying the AMO theory to explain the effectiveness of line managers' HRM implementation. Human Resource Management, 52(6), 861-877.

Bourdieu, P. (1977). Outline of a Theory of Practice (Vol. 16). Cambridge university press. Bourdieu, P. (1990). The logic of practice. Stanford University Press. 
Bowen, D. E., \& Ostroff, C. (2004). Understanding HRM-firm performance linkages: The role of the "strength" of the HRM system. Academy of Management Review, 29(2), $203-221$.

Boxall, P. (1996). The strategic HRM debate and the resource-based view of the firm. Human Resource Management Journal, 6(3), 59-75.

Boxall, P., Hutchison, A., \& Wassenaar, B. (2015). How do high-involvement work processes influence employee outcomes? An examination of the mediating roles of skill utilisation and intrinsic motivation. The International Journal of Human Resource Management, 26(13), 1737-1752.

Bradbury Huang, H. (2010). What is good action research. Action Research, 8(1), 93-109.

Brannick, T., \& Coghlan, D. (2007). In Defense of Being "Native": The Case for Insider Academic Research. Organizational Research Methods, 10(1), 59-74.

Brewster, C., Gollan, P. J., \& Wright, P. M. (2013). Guest editors' note: Human Resource Management and the Line. Human Resource Management, 52(6), 829-838.

Budjanovcanin, A. (2018). Actions speak louder than words: how employees mind the implementation gap. The International Journal of Human Resource Management, $1-20$.

Burrell, G., \& Morgan, G. (1979). Sociological paradigms and organisational analysis (Vol. 248). london: Heinemann.

Busco, C. (2009). Giddens' structuration theory and its implications for management accounting research. Journal of Management \& Governance, 13(3), 249-260.

Cascio, W. (2015). Strategic HRM: too important for an insular approach. Human Resource Management, 54(3), 423-426. 
Cetina, K. K., Schatzki, T. R., \& Von Savigny, E. (2005). The practice turn in contemporary theory. Routledge.

Chiu, L. F. (2007). Health promotion and participatory action research: The significance of participatory praxis in developing participatory health intervention. Handbook of Action Research: Participative Inquiry and Practice, 534-549.

Chow, I. H.-S. (2012). The roles of implementation and organizational culture in the HRperformance link. The International Journal of Human Resource Management, 23(15), 3114-3132.

Coad, A. F., \& Herbert, I. P. (2009). Back to the future: new potential for structuration theory in management accounting research? Management Accounting Research, 20(3), 177-192.

Coghlan, D. (2011). Action research: Exploring perspectives on a philosophy of practical knowing. The Academy of Management Annals, 5(1), 53-87.

Cohendet, P. S., \& Simon, L. O. (2016). Always playable: Recombining routines for creative efficiency at Ubisoft Montreal's video game studio. Organization Science, 27(3), $614-632$.

Coleman, J. S. (1990). Foundations of social theory. Cambridge, MA: The Belknap Press of Harvard University Press.

Cooke, B., Macau, F., \& Wood Jr, T. (2013). Brazilian management gurus as reflexive softHRM practitioners: an empirical study. The International Journal of Human Resource Management, 24(1), 110-129. 
Cooke, F. L., \& Xiao, Y. (2014). Gender roles and organizational HR practices: The case of women's careers in accountancy and consultancy firms in China. Human Resource Management, 53(1), 23-44.

Coughlan, P., \& Coghlan, D. (2002). Action research for operations management. International Journal of Operations \& Production Management, 22(2), 220-240.

D'Adderio, L. (2008). The performativity of routines: Theorising the influence of artefacts and distributed agencies on routines dynamics. Research Policy, 37(5), 769-789.

D’Adderio, L. (2014). The replication dilemma unravelled: How organizations enact multiple goals in routine transfer. Organization Science, 25(5), 1325-1350.

Danner-Schröder, A., \& Geiger, D. (2016). Unravelling the motor of patterning work: Toward an understanding of the microlevel dynamics of standardization and flexibility. Organization Science, 27(3), 633-658.

Davis, A. J., Parkes, C., \& Budhwar, P. (2013). Bridging difference-national and organisational adaptation for responsible performance. The International Journal of Human Resource Management, 24(12), 2273-2277.

Davis, G. F. (2010). Do theories of organizations progress? Organizational Research Methods, 13(4), 690-709.

De Cieri, H., Fenwick, M., \& Hutchings, K. (2005). The challenge of international human resource management: balancing the duality of strategy and practice. The International Journal of Human Resource Management, 16(4), 584-598.

Deken, F., Carlile, P. R., Berends, H., \& Lauche, K. (2016). Generating novelty through interdependent routines: A process model of routine work. Organization Science, 27(3), 659-677. 
Delery, J. E., \& Doty, D. H. (1996). Modes of theorizing in strategic human resource management: Tests of universalistic, contingency, and configurational performance predictions. Academy of Management Journal, 39(4), 802-835.

Delmotte, J., De Winne, S., \& Sels, L. (2012). Toward an assessment of perceived HRM system strength: scale development and validation. The International Journal of Human Resource Management, 23(7), 1481-1506.

Den Hartog, D. N., Boon, C., Verburg, R. M., \& Croon, M. A. (2013). HRM, communication, satisfaction, and perceived performance: A cross-level test. Journal of Management, 39(6), 1637-1665.

DeSanctis, G., \& Poole, M. S. (1994). Capturing the complexity in advanced technology use: Adaptive structuration theory. Organization Science, 5(2), 121-147.

Dickens, L., \& Watkins, K. (1999). Action research: rethinking Lewin. Management Learning, $30(2), 127-140$.

Doh, J. P. (2015). From the Editor: Why we need phenomenon-based research in international business. Journal of World Business, 50(4), 609-611.

Doherty, N. T., \& Dickmann, M. (2012). Measuring the return on investment in international assignments: an action research approach. The International Journal of Human Resource Management, 23(16), 3434-3454.

Dönmez, D., Grote, G., \& Brusoni, S. (2016). Routine interdependencies as a source of stability and flexibility. A study of agile software development teams. Information and Organization, 26(3), 63-83.

Dutch Federal Government. Bruggen slaan: Regeerakkoord VVD - PvdA (2012). 
Dymek, C. (2008). IT and action sensemaking: Making sense of new technology. The Sage Handbook of Action Research. Participative Inquiry and Practice. London: Sage.

Eden, C., \& Huxham, C. (1996). Action research for management research. British Journal of Management, 7(1), 75-86.

Eisenhardt, K. M., \& Graebner, M. E. (2007). Theory building from cases: Opportunities and challenges. The Academy of Management Journal, 50(1), 25-32.

Farndale, E., \& Kelliher, C. (2013). Implementing performance appraisal: Exploring the employee experience. Human Resource Management, 52(6), 879-897.

Feldman, M. S. (2000). Organizational routines as a source of continuous change. Organization Science, 11(6), 611-629.

Feldman, M. S. (2015). Theory of routine dynamics and connections to strategy as practice. In D. Golsorkhi, L. Rouleau, D. Seidl, \& E. Vaara (Eds.), Cambridge Handbook of Strategy as Practice (pp. 317-330). Cambridge, United Kingdom: Cambridge University Press.

Feldman, M. S., \& Orlikowski, W. J. (2011). Theorizing practice and practicing theory. Organization Science, 22(5), 1240-1253.

Feldman, M. S., \& Pentland, B. T. (2003). Reconceptualizing organizational routines as a source of flexibility and change. Administrative Science Quarterly, 48(1), 94-118.

Feldman, M. S., Pentland, B. T., D'Adderio, L., \& Lazaric, N. (2016). Beyond Routines as Things: Introduction to the Special Issue on Routine Dynamics. Organization Science, 27(3), 505-513. 
Festing, M., \& Maletzky, M. (2011). Cross-cultural leadership adjustment-A multilevel framework based on the theory of structuration. Human Resource Management Review, 21(3), 186-200.

Fletcher, L., Bailey, C., \& Gilman, M. W. (2017). Fluctuating levels of personal role engagement within the working day: A multilevel study. Human Resource Management Journal.

Fletcher, M., \& Plakoyiannaki, E. (2011). Case selection in international business: key issues and common misconceptions. In R. Piekkari \& C. Welch (Eds.), Rethinking the case study in international business and management research (Vol. 171, pp. 171-191). Cheltenham, United Kingdom: Edward Elgar Publishing.

Flick, U. (2009). An introduction to qualitative research. London, United Kingdom: Sage.

Flyvbjerg, B. (2011). Case study. In N. K. Denzin \& Y. S. Lincoln (Eds.), The Sage handbook of qualitative research (4th ed., pp. 301-316). Thousand Oaks, CA: Sage.

Fombrun, C. J., Tichy, N. M., \& Devanna, M. A. (1984). Strategic Human Resource Management. Wiley.

Fox, S., \& Cowan, R. L. (2015). Revision of the workplace bullying checklist: the importance of human resource management's role in defining and addressing workplace bullying. Human Resource Management Journal, 25(1), 116-130.

Franco, L. A., \& Rouwette, E. A. (2011). Decision development in facilitated modelling workshops. European Journal of Operational Research, 212(1), 164-178. 
Geare, A., Edgar, F., \& Deng, M. (2006). Implementation and consumption of HRM: Stakeholder differences. Research and Practice in Human Resource Management, 14(2), 34-48.

Gersick, C. J., \& Hackman, J. R. (1990). Habitual routines in task-performing groups. Organizational Behavior and Human Decision Processes, 47(1), 65-97.

Gherardi, S. (2009). Organizational knowledge: The texture of workplace learning. John Wiley \& Sons.

Giddens, A. (1979). Central problems in social theory: Action, structure, and contradiction in social analysis. Berkeley, CA: University of California Press.

Giddens, A. (1984). The constitution of society: Outline of the theory of structuration. United Kingdom, Cambridge: Polity Press.

Giddens, A. (1989). A reply to my critics. In D. Held \& J. B. Thompson (Eds.), Social theory of modern societies: Anthony Giddens and his critics. Cambridge, United Kingdom: Press Syndicate of the University of Cambridge.

Giddens, A. (1991). Modernity and self-identity: Self and society in the late modern age. Stanford university press.

Gilbert, C., De Winne, S., \& Sels, L. (2011). The influence of line managers and HR department on employees' affective commitment. The International Journal of Human Resource Management, 22(8), 1618-1637.

Glaser, B. G., \& Strauss, A. L. (2017). Discovery of grounded theory: Strategies for qualitative research. Routledge.

Goldkuhl, G. (2012). Pragmatism vs interpretivism in qualitative information systems research. European Journal of Information Systems, 21(2), 135-146. 
Gratton, L., \& Truss, C. (2003). The three-dimensional people strategy: Putting human resources policies into action. The Academy of Management Executive, 17(3), 7486.

Groen, B. A., Wilderom, C. P., \& Wouters, M. J. (2017). High Job Performance Through CoDeveloping Performance Measures With Employees. Human Resource Management, 56(1), 111-132.

Grössler, A., \& Zock, A. (2010). Supporting long-term workforce planning with a dynamic aging chain model: A case study from the service industry. Human Resource Management, 49(5), 829-848.

Guerrero, S. (2008). Changes in employees' attitudes at work following an acquisition: a comparative study by acquisition type. Human Resource Management Journal, 18(3), 216-236.

Guest, D. (1987). Human resource management and industrial relations. Journal of Management Studies, 24(5), 503-521.

Guest, D., \& Bos-Nehles, A. C. (2013). Human resource management and performance: the role of effective implementation. In J. Paauwe \& P. Wright (Eds.), HRM and performance: Achievements and challenges (pp. 79-96). Chichester, United Kingdom: Wiley-Blackwell.

Guest, D., \& Conway, N. (2011). The impact of HR practices, HR effectiveness and a 'strong HR system' on organisational outcomes: a stakeholder perspective. The International Journal of Human Resource Management, 22(8), 1686-1702. 
Halperin, R., \& Backhouse, J. (2007). Using structuration theory in IS research: Operationalizing key constructs. ICIS 2007 Proceedings, 127.

Haslberger, A. (2005). The complexities of expatriate adaptation. Human Resource Management Review, 15(2), 160-180.

Hayton, J. C. (2015). Editor-in-Chief's Note. Human Resource Management, 54(3), 385-388. Held, D., \& Thompson, J. B. (1989). Social theory of modern societies: Anthony Giddens and his critics. Cambridge University Press.

Hodges, J., \& Martin, G. (2012). Can leadership branding work in theory and practice to resolve the integration-responsiveness problems facing multinational enterprises? The International Journal of Human Resource Management, 23(18), 3794-3812.

Howard-Grenville, J. A. (2005). The persistence of flexible organizational routines: The role of agency and organizational context. Organization Science, 16(6), 618-636.

Huang, J., \& Martin-Taylor, M. (2013). Turnaround user acceptance in the context of HR selfservice technology adoption: an action research approach. The International Journal of Human Resource Management, 24(3), 621-642.

Huselid, M. A. (1995). The impact of human resource management practices on turnover, productivity, and corporate financial performance. Academy of Management Journal, 38(3), 635-672.

Jarzabkowski, P. (2008). Shaping strategy as a structuration process. Academy of Management Journal, 51(4), 621-650.

Jarzabkowski, P., Lê, J. K., \& Feldman, M. S. (2012). Toward a theory of coordinating: Creating coordinating mechanisms in practice. Organization Science, 23(4), 907927. 
Jiang, K., Lepak, D. P., Hu, J., \& Baer, J. C. (2012). How does human resource management influence organizational outcomes? A meta-analytic investigation of mediating mechanisms. Academy of Management Journal, 55(6), 1264-1294.

Jones, M. R., \& Karsten, H. (2008). Giddens's structuration theory and information systems research. Mis Quarterly, 32(1), 127-157.

Jørgensen, F., \& Becker, K. (2015). Balancing organizational and professional commitments in professional service firms: the HR practices that matter. The International Journal of Human Resource Management, 26(1), 23-41.

Jung, J., \& Kim, Y. (2012). Causes of newspaper firm employee burnout in Korea and its impact on organizational commitment and turnover intention. The International Journal of Human Resource Management, 23(17), 3636-3651.

Kaila, H. L. (2011). Organizational cases on behaviour-based safety (BBS) in India. The International Journal of Human Resource Management, 22(10), 2135-2146.

Kaufman, B. E. (2012). Strategic Human Resource Management Research in the United States: A Failing Grade After 30 Years? Academy of Management Perspectives, $26(2), 12-36$.

Kets de Vries, M. F., Vrignaud, P., Agrawal, A., \& Florent-Treacy, E. (2010). Development and application of the leadership archetype questionnaire. The International Journal of Human Resource Management, 21(15), 2848-2863.

Kets de Vries, M. F., Vrignaud, P., \& Florent-Treacy, E. (2004). The Global Leadership Life Inventory: development and psychometric properties of a 360-degree feedback 
instrument. The International Journal of Human Resource Management, 15(3), 475-492.

Khilji, S. E., Tarique, I., \& Schuler, R. S. (2015). Incorporating the macro view in global talent management. Human Resource Management Review, 25(3), 236-248.

Khilji, S. E., \& Wang, X. (2006). 'Intended' and 'implemented' HRM: the missing linchpin in strategic human resource management research. The International Journal of Human Resource Management, 17(7), 1171-1189.

Klaas, B. S., McClendon, J., \& Gainey, T. W. (1999). HR outsourcing and its impact: The role of transaction costs. Personnel Psychology, 52(1), 113-136.

Klein, K. J., \& Sorra, J. S. (1996). The challenge of innovation implementation. Academy of Management Review, 21(4), 1055-1080.

Klijnsma, J. Beantwoording schriftelijke vragen één-meting, Ministerie van Sociale Zaken en Werkgelegenheid $\S(2016)$.

Kroon, B., \& Paauwe, J. (2014). Structuration of precarious employment in economically constrained firms: the case of Dutch agriculture: Structuration of precarious employment. Human Resource Management Journal, 24(1), 19-37.

Lammers, J. C., \& Barbour, J. B. (2006). An Institutional Theory of Organizational Communication. Communication Theory, 16(3), 356-377.

Langley, A. (1999). Strategies for theorizing from process data. Academy of Management Review, 24(4), 691-710.

Lazaric, N., \& Denis, B. (2005). Routinization and memorization of tasks in a workshop: the case of the introduction of ISO norms. Industrial and Corporate Change, 14(5), 873-896. 
Lepak, D. P., \& Snell, S. A. (2002). Examining the human resource architecture: The relationships among human capital, employment, and human resource configurations. Journal of Management, 28(4), 517-543.

Levenson, A. (2017). Using workforce analytics to improve strategy execution. Human Resource Management.

Lewin, K. (1946). Action research and minority problems. Journal of Social Issues, 2(4), 3446.

Lewis, S., Gambles, R., \& Rapoport, R. (2007). The constraints of a 'work-life balance' approach: an international perspective. The International Journal of Human Resource Management, 18(3), 360-373.

Li, X., Frenkel, S. J., \& Sanders, K. (2011). Strategic HRM as process: How HR system and organizational climate strength influence Chinese employee attitudes. The International Journal of Human Resource Management, 22(9), 1825-1842.

Maatman, M., Bondarouk, T., \& Looise, J. K. (2010). Conceptualising the capabilities and value creation of HRM shared service models. Human Resource Management Review, 20(4), 327-339.

Macintosh, N. B., \& Scapens, R. W. (1990). Structuration theory in management accounting. Accounting, Organizations and Society, 15(5), 455-477.

Makhecha, U. P., Srinivasan, V., Prabhu, G. N., \& Mukherji, S. (2016). Multi-level gaps: a study of intended, actual and experienced human resource practices in a hypermarket chain in India. The International Journal of Human Resource Management, 1-39. 
Marchington, M. (2015). Human resource management (HRM): Too busy looking up to see where it is going longer term? Human Resource Management Review, 25(2), 176187.

Markóczy, L. (2004). Multiple motives behind single acts of co-operation. The International Journal of Human Resource Management, 15(6), 1018-1039.

Meijerink, J. (2014). Practicing Social Innovation: Enactment of the Employee-Organization Relationship by Employees. In T. Bondarouk \& M. R. Olivas-Luján (Eds.), Human Resource Management, Social Innovation and Technology (pp. 135-153). Emerald Group Publishing Limited.

Meijerink, J., Bondarouk, T., \& Kees Looise, J. (2012). Value creation through HR shared services: towards a conceptual framework. Personnel Review, 42(1), 83-104.

Meijerink, J., Bondarouk, T., \& Lepak, D. P. (2016). Employees as active consumers of HRM: Linking employees' HRM competences with their perceptions of HRM service value. Human Resource Management, 55(2), 219-240.

Ministerie van Binnenlandse Zaken en Koninkrijksrelaties. (2017, November 21). Meerjarige aanpak realisatie banenafspraak sector Rijk.

Ministerie van Sociale Zaken en Werkgelegenheid. Wet banenafspraak en quotum arbeidsbeperkten (2016).

Mirfakhar, A. S., Trullen, J., \& Valverde, M. (2018). Easier said than done: A review of antecedents influencing effective HR implementation. The International Journal of Human Resource Management. 
Molineux, J. (2013). Enabling organizational cultural change using systemic strategic human resource management-a longitudinal case study. The International Journal of Human Resource Management, 24(8), 1588-1612.

Morgan, G., \& Smircich, L. (1980). The Case for Qualitative Research. The Academy of Management Review, 5(4), 491. https://doi.org/10.2307/257453

Moynihan, D. P., \& Landuyt, N. (2009). How do public organizations learn? Bridging cultural and structural perspectives. Public Administration Review, 69(6), 1097-1105.

Nehles, A. C., Van Riemsdijk, M., Kok, I., \& Looise, J. K. (2006). Implementing human resource management successfully: A first-line management challenge. Management Revue, 17(3), 256-273.

Nishii, L. H., Lepak, D. P., \& Schneider, B. (2008). Employee attributions of the "why" of HR practices: Their effects on employee attitudes and behaviors, and customer satisfaction. Personnel Psychology, 61(3), 503-545.

Ogbonnaya, C., \& Valizade, D. (2016). High performance work practices, employee outcomes and organizational performance: A 2-1-2 multilevel mediation analysis. The International Journal of Human Resource Management, 1-21.

Op de Beeck, S., Wynen, J., \& Hondeghem, A. (2016). HRM implementation by line managers: explaining the discrepancy in HR-line perceptions of HR devolution. The International Journal of Human Resource Management, 27(17), 1901-1919.

Orlikowski, W. J. (1992). The duality of technology: Rethinking the concept of technology in organizations. Organization Science, 3(3), 398-427. 
Orlikowski, W. J. (2000). Using technology and constituting structures: A practice lens for studying technology in organizations. Organization Science, 11(4), 404-428.

Ostroff, C., \& Bowen, D. E. (2016). Reflections on the 2014 decade award: Is there strength in the construct of HR system strength? Academy of Management Review, 41(2), 196-214.

Pentland, B. T., \& Feldman, M. S. (2005). Organizational routines as a unit of analysis. Industrial and Corporate Change, 14(5), 793-815.

Pentland, B. T., \& Feldman, M. S. (2008). Designing routines: On the folly of designing artifacts, while hoping for patterns of action. Information and Organization, 18(4), $235-250$.

Pichault, F. (2007). HRM-based reforms in public organisations: problems and perspectives. Human Resource Management Journal, 17(3), 265-282.

Piening, E. P., Baluch, A. M., \& Ridder, H.-G. (2014). Mind the intended-implemented gap: Understanding employees' perceptions of HRM. Human Resource Management, 53(4), 545-567.

Pinnington, A. (2005). Learning in a competitive field: MBA students' improvised case studies of IHRM. The International Journal of Human Resource Management, 16(4), $615-631$.

Pullin, A. S., Knight, T. M., Stone, D. A., \& Charman, K. (2004). Do conservation managers use scientific evidence to support their decision-making? Biological Conservation, $119(2), 245-252$. 
Purcell, J., \& Hutchinson, S. (2007). Front-line managers as agents in the HRM-performance causal chain: theory, analysis and evidence. Human Resource Management Journal, 17(1), 3-20.

Racko, G., Oborn, E., \& Barrett, M. (2017). Developing collaborative professionalism: an investigation of status differentiation in academic organizations in knowledge transfer partnerships. The International Journal of Human Resource Management, 1-22.

Reason, P., \& Bradbury, H. (2001). Handbook of action research: Participative inquiry and practice. Sage.

Renkema, M., Meijerink, J., \& Bondarouk, T. (2017). Advancing multilevel thinking in human resource management research: Applications and guidelines. Human Resource Management Review, 27(3), 397-415.

Rerup, C., \& Feldman, M. S. (2011). Routines as a source of change in organizational schemata: The role of trial-and-error learning. Academy of Management Journal, 54(3), 577-610.

Rousseau, D. M. (2005). I-deals, idiosyncratic deals employees bargain for themselves. ME Sharpe.

Runhaar, P., \& Sanders, K. (2013). Implementing Human Resources Management (HRM) within Dutch VET institutions: examining the fostering and hindering factors. Journal of Vocational Education \& Training, 65(2), 236-255. 
Rynes, S. L., Colbert, A. E., \& Brown, K. G. (2002). HR professionals' beliefs about effective human resource practices: Correspondence between research and practice. Human Resource Management, 41(2), 149-174.

Rynes, S. L., Giluk, T. L., \& Brown, K. G. (2007). The very separate worlds of academic and practitioner periodicals in human resource management: Implications for evidence-based management. Academy of Management Journal, 50(5), 987-1008.

Salvato, C., \& Rerup, C. (2017). Routine regulation: Balancing conflicting goals in organizational routines. Administrative Science Quarterly, 0001839217707738.

Sanders, K., Dorenbosch, L., \& de Reuver, R. (2008). The impact of individual and shared employee perceptions of HRM on affective commitment: Considering climate strength. Personnel Review, 37(4), 412-425.

Sanders, K., Shipton, H., \& Gomes, J. F. (2014). Guest editors' introduction: Is the HRM process important? Past, current, and future challenges. Human Resource Management, 53(4), 489-503.

Sanders, K., \& Yang, H. (2016). The HRM Process Approach: The Influence of Employees' Attribution to Explain the HRM-Performance Relationship. Human Resource Management, 55(2), 201-217.

Scotland, J. (2012). Exploring the Philosophical Underpinnings of Research: Relating Ontology and Epistemology to the Methodology and Methods of the Scientific, Interpretive, and Critical Research Paradigms. English Language Teaching, 5(9).

Scott, W. R. (2005). Institutional theory: Contributing to a theoretical research program. Great Minds in Management: The Process of Theory Development, 37, 460-484. 
Scott, W. R., \& Davis, G. F. (2007). Organizations and organizing: Rational, natural, and open system perspectives. Prentice Hall.

Servon, L. J., \& Visser, M. A. (2011). Progress hindered: The retention and advancement of women in science, engineering and technology careers. Human Resource Management Journal, 21(3), 272-284.

Sheldon, P., \& Sanders, K. (2016). Contextualizing HRM in China: differences within the country. The International Journal of Human Resource Management, 27(18), 20172033.

Sheldon, P., Sun, J. J. M., \& Sanders, K. (2014). Special issue on HRM in China: differences within the country: International Journal of Human Resource Management. The International Journal of Human Resource Management, 25(15), 2213-2217.

Simón, C., \& Ferreiro, E. (2017). Workforce analytics: A case study of scholar-practitioner collaboration. Human Resource Management.

Sonenshein, S. (2016). Routines and creativity: From dualism to duality. Organization Science, 27(3), 739-758.

Stake, R. E. (2005). Qualitative case studies. In N. K. Denzin \& Y. S. Lincoln (Eds.), The Sage handbook of qualitative research (3rd ed., pp. 443-466). Thousand Oaks, CA: Sage.

Strohmeier, S. (2007). Research in e-HRM: Review and implications. Human Resource Management Review, 17(1), 19-37.

Tatli, A., Ozturk, M. B., \& Woo, H. S. (2017). Individualization and marketization of responsibility for gender equality: the case of female managers in China. Human Resource Management, 56(3), 407-430. 
Taylor, J. R., Groleau, C., Heaton, L., \& Van Every, E. J. (2001). The Computerization of Work: A Communication Perspective. Thousand Oaks, CA: SAGE Publications.

Team Inclusief. (2015, August). Instroom en behoud van medewerkers met een arbeidsbeperking.

Ter Horst, G. Brief van de minister van Binnenlandse Zaken en Koninkrijksrelaties, Pub. L. No. 31701, 10 (2009).

Theodorakopoulos, N., Ram, M., \& Beckinsale, M. (2013). Human resource development for inclusive procurement by intermediation: a situated learning theory application. The International Journal of Human Resource Management, 24(12), 2321-2338.

Thornhill, A., Lewis, P., Millmore, M., \& Saunders, M. (2000). Managing Change: A Human Resource Strategy Approach (1st ed.). Essex, United Kingdom: Pearson Education.

Top, M., \& Gider, O. (2013). Interaction of organizational commitment and job satisfaction of nurses and medical secretaries in Turkey. The International Journal of Human Resource Management, 24(3), 667-683.

Trullen, J., Stirpe, L., Bonache, J., \& Valverde, M. (2016). The HR department's contribution to line managers' effective implementation of HR practices. Human Resource Management Journal, 26(4), 449-470.

Turner, J. H. (1986). The Theory of Structuration. American Journal of Sociology, 91(4), 969977.

Turner, S. F., \& Rindova, V. (2012). A balancing act: How organizations pursue consistency in routine functioning in the face of ongoing change. Organization Science, 23(1), 24-46. 
Valverde, M., Ryan, G., \& Soler, C. (2006). Distributing HRM responsibilities: a classification of organisations. Personnel Review, 35(6), 618-636.

van der Steen, M. (2011). The emergence and change of management accounting routines. Accounting, Auditing \& Accountability Journal, 24(4), 502-547.

Van Leeuwen, H. (2015). Charter Diversiteit.

Van Mierlo, J., \& Bondarouk, T. (2015). Revisiting HRM Systems Strength: Conceptualising the dynamic nature of HRM implementations. In 9th Biennial International Conference of the Dutch HRM Network. Utrecht, the Netherlands.

van Mierlo, J., \& Bondarouk, T. (2017). The struggle towards maturity: the evolution of HRM practices in the Dutch federal government. Presented at the 10th Biennial International Conference of the Dutch HRM Network, Nijmegen, the Netherlands.

Van Mierlo, J., \& Bondarouk, T. (2018). The Process of Implementing HRM Practices: a Case Study in the Dutch Federal Government. Presented at the Academy of Management Conference, Chicago.

Van Mierlo, J., Bondarouk, T., \& Sanders, K. (2018). The dynamic nature of HRM implementation: a structuration perspective. The International Journal of Human Resource Management, $\quad x(\mathrm{xx}), \quad$ 1-30. https://doi.org/10.1080/09585192.2018.1443957

Vashdi, D. R., Bamberger, P. A., Erez, M., \& Weiss-Meilik, A. (2007). Briefing-debriefing: using a reflexive organizational learning model from the military to enhance the performance of surgical teams. Human Resource Management, 46(1), 115-142. 
Vermeeren, B. (2014). Variability in HRM implementation among line managers and its effect on performance: a 2-1-2 mediational multilevel approach. The International Journal of Human Resource Management, 25(22), 3039-3059.

Vosburgh, R. M. (2017). Closing the academic-practitioner gap: Research must answer the "SO WHAT" question. Human Resource Management Review.

Wallace, M. (1987). A historical review of action research: some implications for the education of teachers in their managerial role. Journal of Education for Teaching, 13(2), 97-115.

Walsham, G. (1995). The emergence of interpretivism in IS research. Information Systems Research, 6(4), 376-394.

Walsham, G., \& Han, C. K. (1990). Structuration theory and information systems research. Presented at the ICIS 1990 Proceedings.

Weick, K. E., Sutcliffe, K. M., \& Obstfeld, D. (2005). Organizing and the Process of Sensemaking. Organization Science, 16(4), 409-421. https://doi.org/10.1287/orsc.1050.0133

Weiss, H. M., \& Ilgen, D. R. (1985). Routinized behavior in organizations. Journal of Behavioral Economics, 14(1), 57-67.

Whittington, R. (2006). Completing the practice turn in strategy research. Organization Studies, 27(5), 613-634.

Woodrow, C., \& Guest, D. (2014). When good HR gets bad results: exploring the challenge of HR implementation in the case of workplace bullying. Human Resource Management Journal, 24(1), 38-56. 
Wright, P. M., McMahan, G. C., \& McWilliams, A. (1994). Human resources and sustained competitive advantage: a resource-based perspective. International Journal of Human Resource Management, 5(2), 301-326.

Wright, P. M., \& Nishii, L. H. (2013). Strategic HRM and organizational behavior: integrating multiple levels of analysis. In D. Guest \& J. Paauwe (Eds.), HRM and performance: Achievements and challenges (pp. 97-110). Chichester, United Kingdom: WileyBlackwell.

Wrzesniewski, A., \& Dutton, J. E. (2001). Crafting a job: Revisioning employees as active crafters of their work. Academy of Management Review, 26(2), 179-201.

Yin, R. K. (2018). Case Study Research: Design and Methods (Vol. 6). Thousand Oaks, CA: Sage.

Yin, Y., Wang, Y., \& Lu, Y. (2018). Why firms adopt empowerment practices and how such practices affect firm performance? A transaction cost-exchange perspective. Human Resource Management Review.

Zhang, W., Levenson, A., \& Crossley, C. (2015). Move Your Research From The Ivy Tower To The Board Room: A Primer On Action Research For Academics, Consultants, And Business Executives. Human Resource Management, 54(1), 151-174. 



\section{Appendices}

This section contains the following appendices:

Appendix A - Interview protocol The Ministry

Appendix $B$ - Description of the constructs

Appendix C - Interview protocol Dutch Cleaners

Appendix D - Action patterns identified at Dutch Cleaners

Appendix E - Overview of "action research" papers in HRM journals 


\section{Appendix A (Chapter 3) - Interview protocol The Ministry (latest version)}

\section{Introduction respondent}

1. Own role and objectives

2. Responsibilities regarding Job Agreement

3. Evaluated on number of hired impaired workers? $\rightarrow$ Opinion on this

4. Daily tasks and responsibilities

5. When gotten involved? $\rightarrow$ First thought?

Vision on Job Agreement (goals, design, added value)

1. What do you understand with Job Agreement?

2. Do you still have unclear aspects?

3. What would you change of its design?

4. Coping with whether impaired workers count or not for the portion

5. Resistance (experience and coping with it)

6. Displacement (positive discrimination)

7. People who just not fall within the rules of being 'impaired'

\section{Design process (describe)}

1. Facilities (tools, information, budget)

2. Enforcing

3. Decision makers (formal and in practice)

4. Contributing own ideas / vision

5. Do you see different phases / stages?

6. Co-operation with other departments / ministries / organisations / people

\section{Vision other civil servant on Job Agreement}

1. Reaction colleagues to new (impaired) employees

2. Reaction supervisors to new tasks and responsibilities

\section{Rest}

1. There is a vacancy, how do you fill it with an impaired worker?

2. Why do some ministries fall behind, where others do meet their portion?

3. With whom should I talk next? Key role?

4. Own topic / comment? Add something? 
O⿱
$\frac{7}{y}$
$\frac{0}{0}$
$\frac{0}{d}$
$\frac{0}{2}$
$\frac{0}{2}$

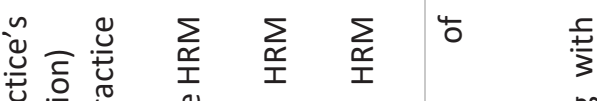

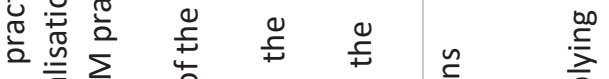

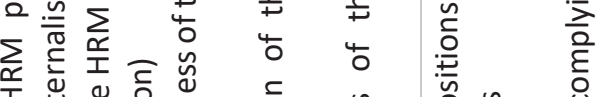

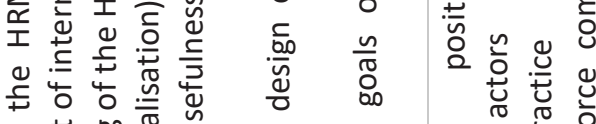

ডั

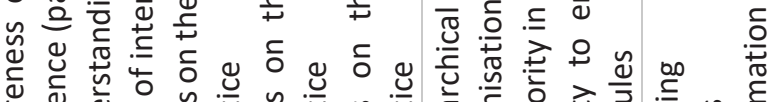

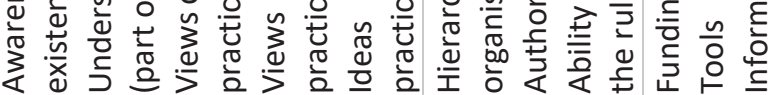

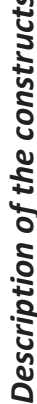

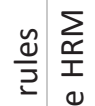

$\stackrel{n}{3}$

$\stackrel{n}{\pi}^{\pi}$

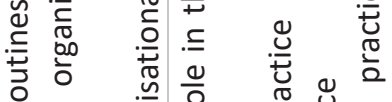

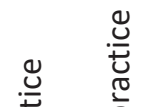

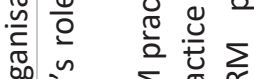

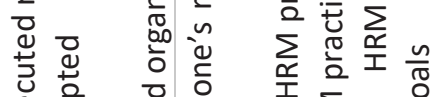

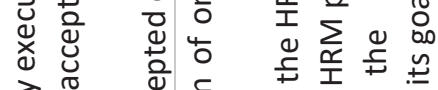

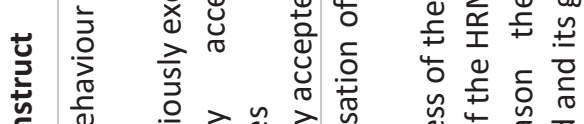

ஸे

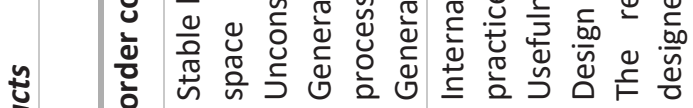
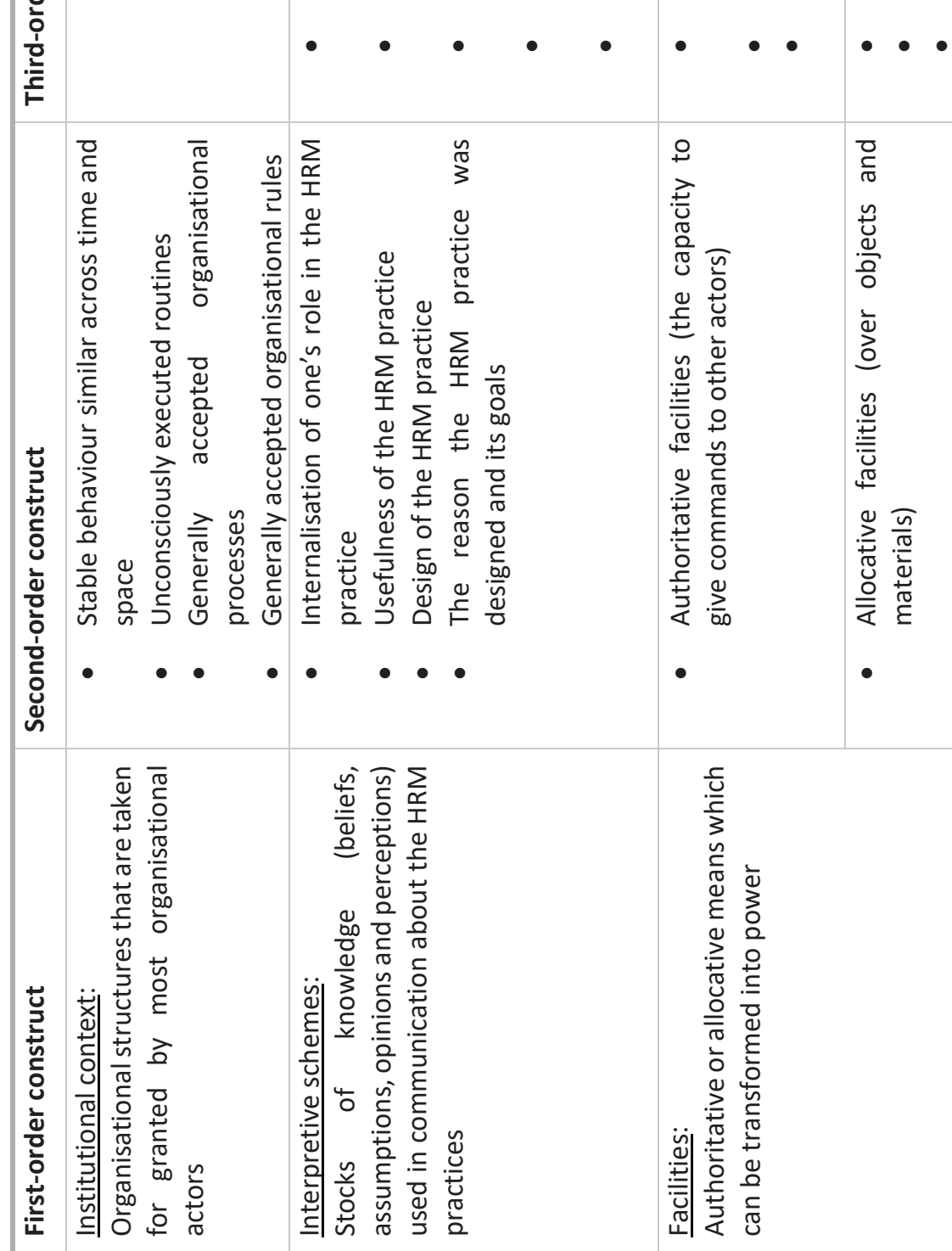

$\frac{1}{m}$

ऐัँ

2.

ป 4

象

: $\frac{x}{2}$

๕ั ญे

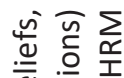

气 을

บㄴ

응

잉 응

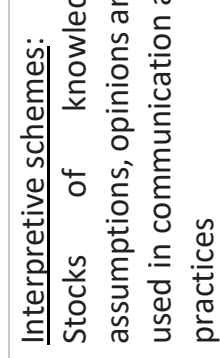

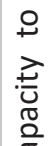

ํํำ

$\stackrel{0}{ \pm}$

Е ए

옴

은

$\leftarrow$ 은

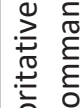

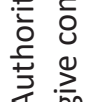

둥

$\frac{\dddot{U}}{\stackrel{0}{0}}$

ปั

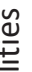




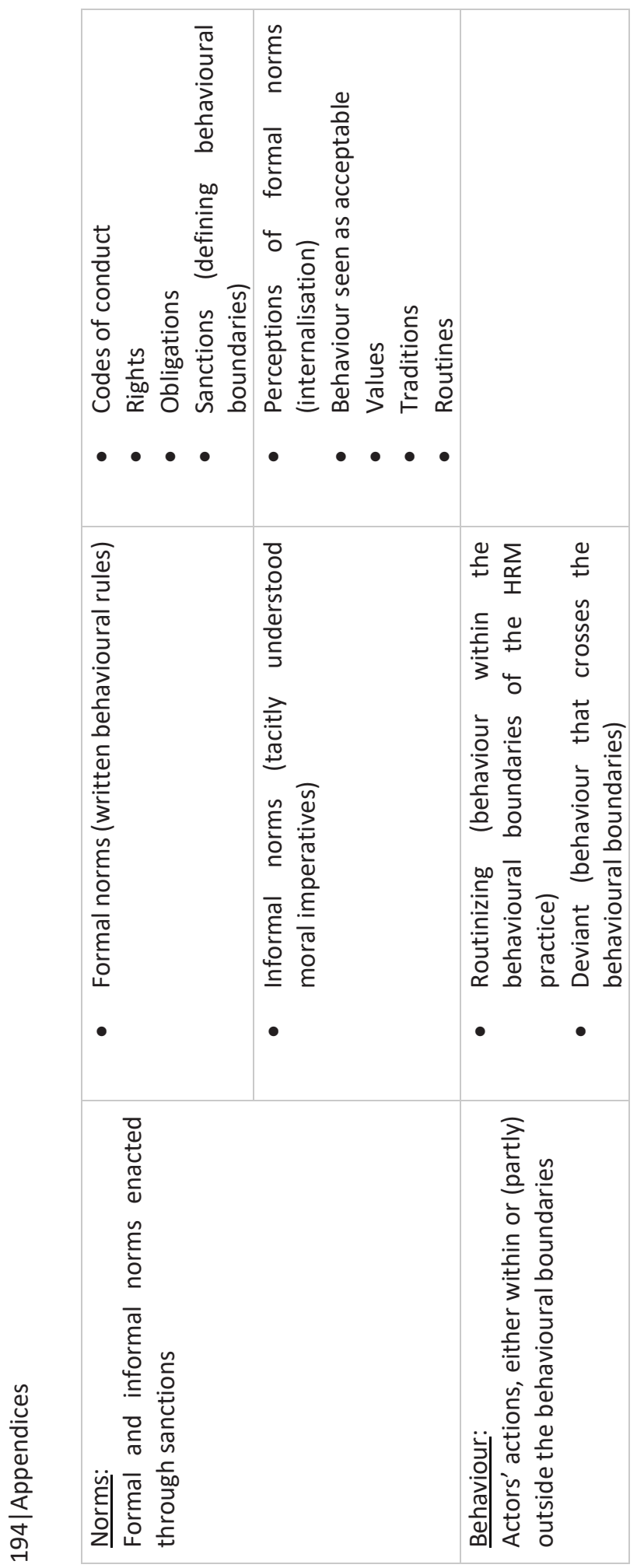




\section{Appendix C (Chapter 4) - Interview protocol Dutch Cleaners (latest version)}

\section{Introduction respondent}

1. Own role and objectives

2. Responsibilities regarding inclusivity

3. Evaluated on number of hired disadvantaged workers? $\rightarrow$ Opinion on this

4. Daily tasks and responsibilities

5. When gotten involved? $\rightarrow$ First thought?

\section{Vision on Job Agreement (goals, design, added value)}

1. What do you understand with inclusivity?

2. Do you still have unclear aspects?

3. What would you change of its design?

4. Coping with whether impaired workers count or not for the portion

5. Resistance (experience and coping with it)

6. Displacement (positive discrimination)

7. People who just not fall within the rules of being 'impaired'

\section{Design process (describe)}

1. Process of recruitment and selection

2. Facilities (tools, information, budget)

3. Enforcing

4. Decision makers (formal and in practice)

5. Contributing own ideas / vision

6. Do you see different phases / stages?

7. Co-operation with other locations/actors/HRM/senior managers/line managers

\section{Vision colleagues on inclusivity}

1. Reaction colleagues to new (disadvantaged) employees

2. Reaction supervisors to new tasks and responsibilities

\section{Rest}

1. There is a vacancy, how do you fill it with an disadvantaged worker?

2. Why do some locations and regions fall behind, where others meet their objective?

3. With whom should I talk next? Key role?

4. Own topic / comment? Add something? 

$\hat{\sigma}$
$\frac{1}{y}$
$\frac{0}{0}$
$\frac{0}{0}$
$\frac{0}{2}$
$\frac{0}{2}$

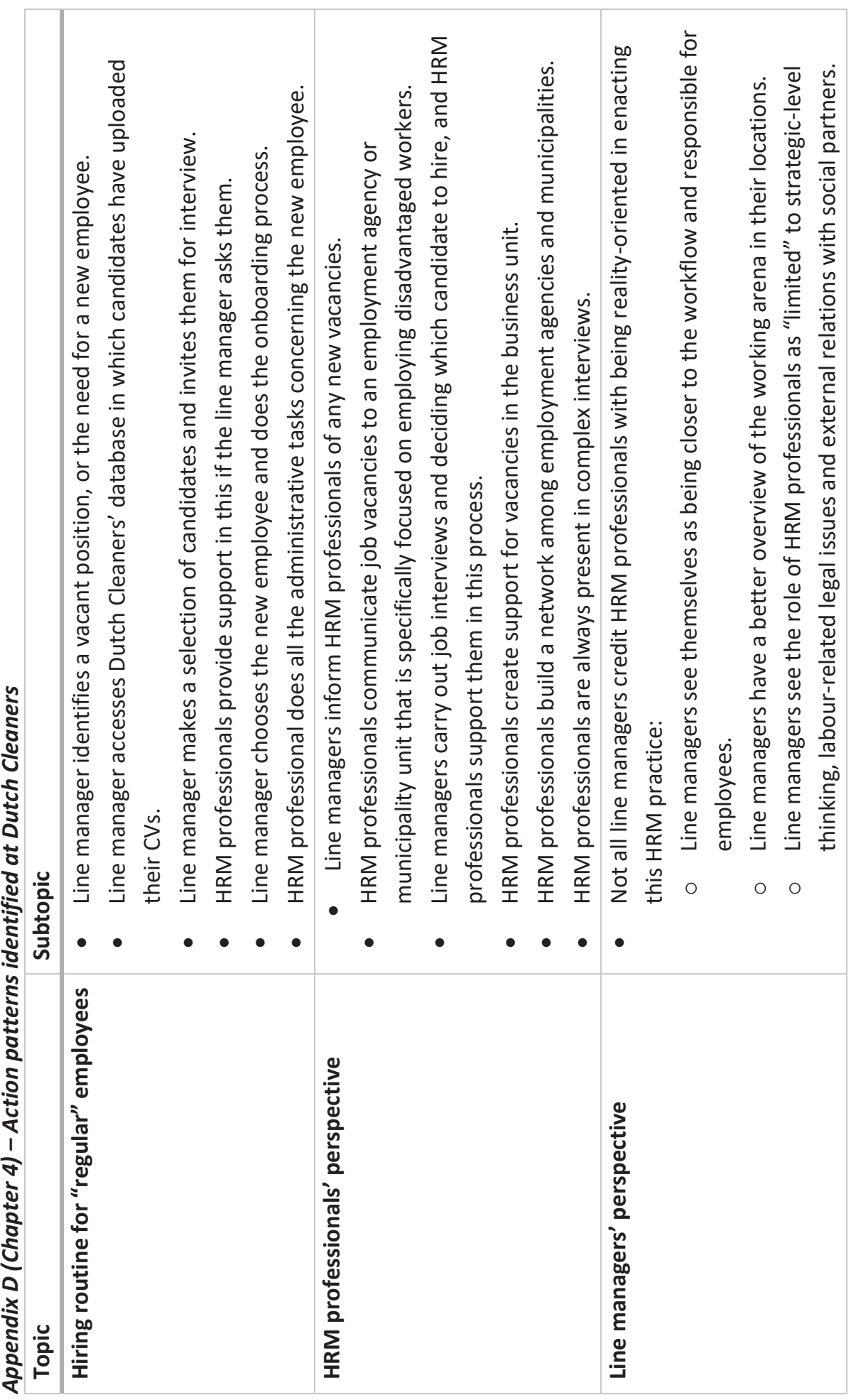




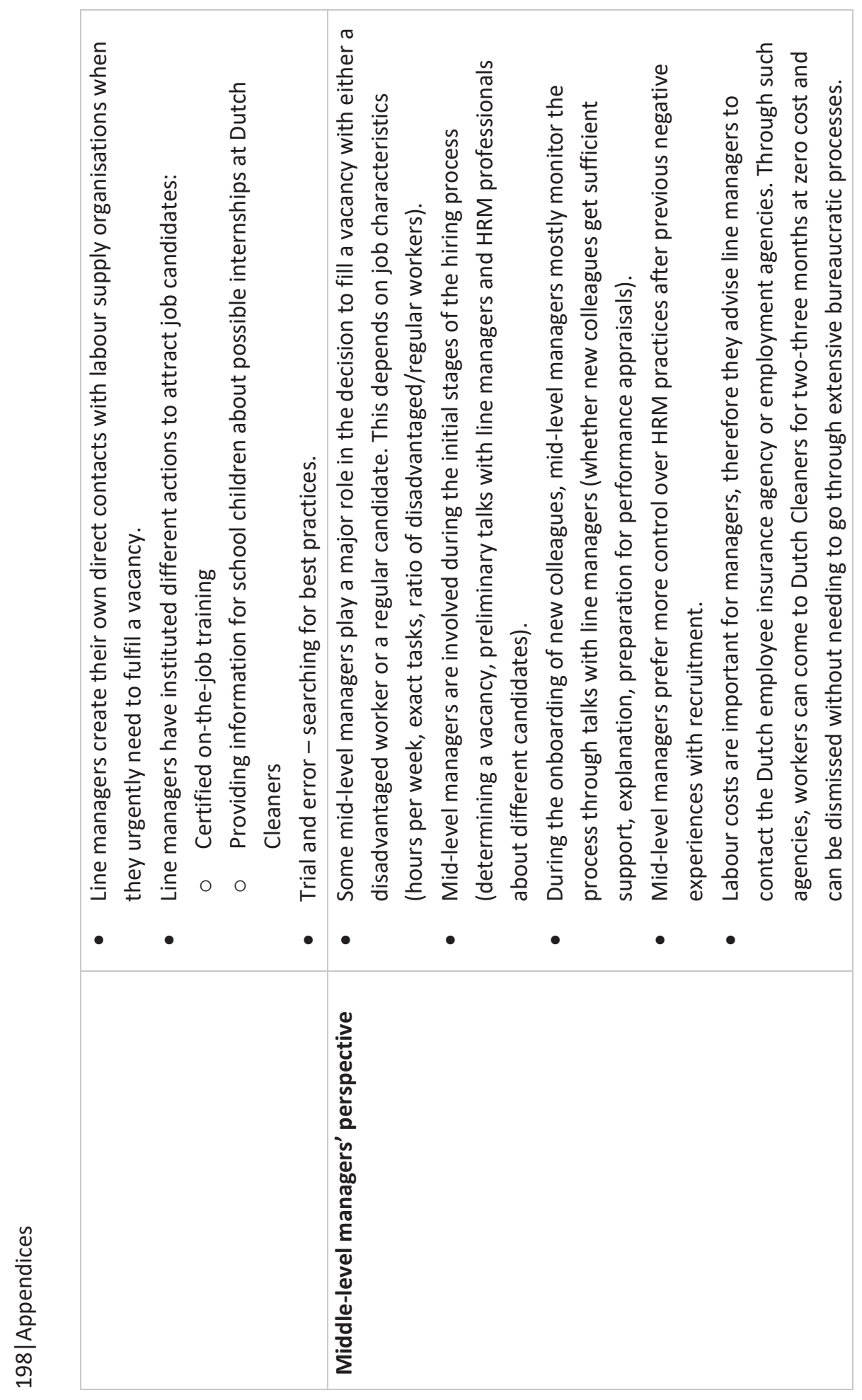


Appendix E (Chapter 5) - Overview of "action research" papers in HRM journals

\begin{tabular}{|c|c|c|c|}
\hline Journal $^{4}$ & Authors & Year & HRM-Action research? \\
\hline HRM & Beer \& Cannon & 2004 & As possible future study \\
\hline IJHRM & Markóczy & 2004 & No \\
\hline IJHRM & Kets de Vries, Vrignaud \& Florent-Treacy & 2004 & No \\
\hline HRMR & Haslberger & 2005 & To set an agenda \\
\hline IJHRM & De Cieri, Fenwick \& Hutchings & 2005 & As possible future study \\
\hline IJHRM & Pinnington & 2005 & No \\
\hline IJHRM & Lewis, Gambles \& Rapoport & 2007 & As possible future study \\
\hline HRMJ & Pichault & 2007 & No \\
\hline HRM & Vashdi, Bamberger, Erez \& Weiss-Meilik & 2007 & Partially \\
\hline HRMR & Strohmeier & 2007 & To set an agenda \\
\hline HRMJ & Guerrero & 2008 & As possible future study \\
\hline IJHRM & Akdere & 2009 & No \\
\hline IJHRM & $\begin{array}{l}\text { Kets de Vries, Vrignaud, Agrawal \& } \\
\text { Florent-Treacy }\end{array}$ & 2010 & No \\
\hline IJHRM & Kaila & 2011 & No \\
\hline IJHRM & Jung \& Kim & 2012 & As possible future study \\
\hline IJHRM & Doherty \& Dickmann & 2012 & Yes \\
\hline IJHRM & Hodges \& Martin & 2012 & Yes \\
\hline IJHRM & Huang \& Martin-Taylor & 2013 & Yes \\
\hline IJHRM & Molineux & 2013 & Yes \\
\hline IJHRM & Top \& Gider & 2013 & As possible future study \\
\hline IJHRM & Cooke, Macau \& Wood Jr. & 2013 & As a contribution \\
\hline IJHRM & Theodorakopoulos, Ram \& Beckinsale & 2013 & Not HRM \\
\hline IJHRM & Davis, Parkes \& Budhwar & 2013 & No \\
\hline HRM & Cooke \& Xiao & 2014 & As possible future study \\
\hline IJHRM & Sheldon, Sun \& Sanders & 2014 & No \\
\hline HRMR & Khilji, Tarique \& Schuler & 2015 & As possible future study \\
\hline IJHRM & Jørgensen \& Becker & 2015 & As possible future study \\
\hline HRM & Zhang, Levenson \& Crossley & 2015 & To set an agenda \\
\hline HRM & Hayton & 2015 & To set an agenda \\
\hline
\end{tabular}

${ }^{4}$ HRM: Human Resource Management; HRMR: Human Resource Management Review; IJHRM: The International Journal of Human Resource Management; HRMJ: Human Resource Management Journal 


\begin{tabular}{l|l|l|l}
\hline HRM & Beer, Boselie \& Brewster & 2015 & To set an agenda \\
\hline HRM & Beer & 2015 & To set an agenda \\
\hline HRM & Cascio & 2015 & To set an agenda \\
\hline HRMR & Bailey & 2016 & No \\
\hline IJHRM & Sheldon \& Sanders & 2016 & As possible future study \\
\hline IJHRM & Bondarouk \& Brewster & 2016 & As possible future study \\
\hline HRM & Tatli, Ozturk \& Woo & 2017 & As possible future study \\
\hline HRM & Groen, Wilderom \& Wouters & 2017 & As possible future study \\
\hline IJHRM & Racko, Oborn \& Barrett & 2017 & No \\
\hline HRMJ & Fletcher, Bailey \& Gilman & 2017 & As possible future study \\
\hline HRM & Simón \& Ferreiro & 2017 & Yes \\
\hline HRM & Levenson & 2017 & To set an agenda \\
\hline HRM & Athanasopoulou, Moss-Cowan, Smets \& & 2017 & As possible future study \\
\hline HRMR & Vosburgh & 2017 & No \\
\hline HRMR & Beer & 2017 & To set an agenda \\
\hline
\end{tabular}




\section{About the author}

Jorrit grew up around Arnhem. And even though he is very dedicated to both his home town and a lifelong supporter of the city's football club, Vitesse, he has spent almost half of his life far away from it.

His educational background is rather broad. After traveling through Central America in 2004, he started studying International Tourism Management and Consultancy at the NHTV in Breda. At the time, he wanted to become a 'professional tourist'. His thesis, titled Mexico City: a paradise under a layer of smog, obliged him to do fieldwork in Mexico City. However, it was just an excuse to spend another half-year on the other side of the globe. Not surprisingly, after graduating in 2008, he moved to Mexico City where he engaged in jobs such as convincing Mexicans that they needed to go on holiday and serving their drinks in a hotspot restaurant.

In 2011 Jorrit returned to the Netherlands to study at the Erasmus University Rotterdam, from which he graduated in 2014 with a Master's degree in Sociology. During his thesis he focused on the pharmaceutical company Organon. He studied how the company managed to grow considerably in the period 1945-1990, while being highly innovative at the same time. Particularly, he focused on Organon's organisational structures and the consequences they had for its innovation capacity. His fieldwork brought him into contact with former employees, retired a long time ago. The remarkably long interviews, which always took place in houses looking just like his grandmother's and included a lot of home-made cookies and tea, often brought unexpected insights. One of those insights was the phenomenon of grey research, with which the interviewees referred to experiments that researchers at Organon's laboratory performed in between their actual assignments. Some of these experiments later evolved into successful products for the company.

After graduating Jorrit, again, moved to Mexico. However, later in 2014, the concept of grey research inspired him to apply at the HRM Department of the University of Twente. In September 2014 he started as a PhD Candidate in the NWO-sponsored research project 'Innovating Human Resource Management for Employee-Driven Innovation'.

And now, towards a new adventure! 




\section{Unravelling the dynamics of HRM implementation}

A process perspective

During the HRM implementation process, HRM practices evolve from an idea or goal into a working instrument, often aimed at enhancing the contribution of organisational actors to their organisation. Even though efficient HRM implementation is seen as a vital step for making HRM practices contribute to performance, little research has been done into the dynamics that occur during their implementation. Therefore, in this dissertation, a process perspective is used to study the dynamics that take place during the HRM implementation process, as well as the roles that organisational actors play in this process.

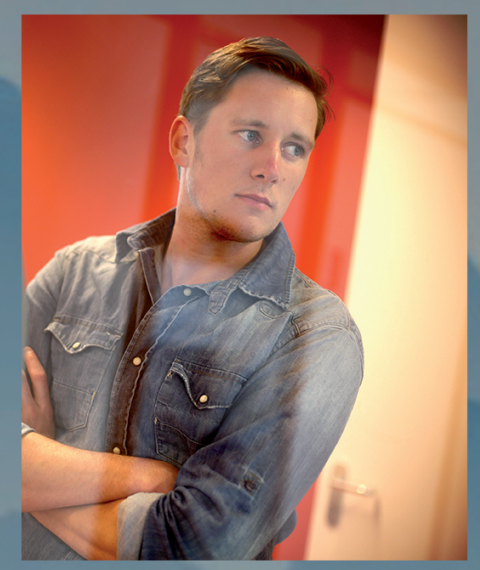

The theoretical insights and empirical findings which are discussed in this dissertation demonstrate that during their implementation process, HRM practices continue to develop. At the moment of taking the decision to adopt a new HRM practice, it is rather an anticipated one, instead of an end product. During the dynamic HRM implementation process, HRM practices evolve into an orchestrated version which is in line with the ideas, interests and routines of organisational stakeholders. Rather than seeing this process as an unwanted effect of the involvement of a large number of stakeholders in HRM implementation, I argue it is a necessary element which can contribute to the creation of a supported, fitting and sustainable HRM practice.

ISBN: 978-94-028-1209-1 